\title{
Exploring career satisfaction, burnout, and compassion fatigue as indicators of the quality of career engagement of public school educators
}

\author{
Beth Colleen Robinson \\ West Virginia University
}

Follow this and additional works at: https://researchrepository.wvu.edu/etd

\footnotetext{
Recommended Citation

Robinson, Beth Colleen, "Exploring career satisfaction, burnout, and compassion fatigue as indicators of the quality of career engagement of public school educators" (2005). Graduate Theses, Dissertations, and Problem Reports. 2264.

https://researchrepository.wvu.edu/etd/2264

This Dissertation is protected by copyright and/or related rights. It has been brought to you by the The Research Repository @ WVU with permission from the rights-holder(s). You are free to use this Dissertation in any way that is permitted by the copyright and related rights legislation that applies to your use. For other uses you must obtain permission from the rights-holder(s) directly, unless additional rights are indicated by a Creative Commons license in the record and/ or on the work itself. This Dissertation has been accepted for inclusion in WVU Graduate Theses, Dissertations, and Problem Reports collection by an authorized administrator of The Research Repository @ WVU. For more information, please contact researchrepository@mail.wvu.edu.
} 


\title{
Exploring Career Satisfaction, Burnout, and Compassion Fatigue as Indicators of the Quality of Career Engagement of Public School Educators
}

\author{
Beth Colleen Robinson \\ Dissertation submitted to the \\ College of Human Resources and Education \\ at West Virginia University \\ in partial fulfillment of the requirements \\ for the degree of
}

\author{
Doctor of Philosophy \\ in \\ Counseling Psychology
}

\author{
L. Sherilyn Cormier, Ph.D. \\ Margaret K. Glenn, Ed.D., Chairperson \\ Robert P. Marinelli, Ed.D. \\ Jan Melcher, Ph.D. \\ Richard T. Walls, Ph.D.
}

Department of Counseling, Rehabilitation Counseling, and Counseling Psychology

Morgantown, West Virginia 2005

Keywords: career engagement, career satisfaction, compassion fatigue, burnout 


\begin{abstract}
Exploring Career Satisfaction, Burnout, and Compassion Fatigue as Indicators of the Quality of Career Engagement of Public School Educators
\end{abstract}

Beth Colleen Robinson

This study explored the experiences of career satisfaction, burnout, and compassion fatigue in public school educators working with students in Primary/Kindergarten through grade 12 in schools in Nova Scotia and West Virginia. The research participants included 184 teachers, counselors, and administrators employed by the Annapolis Valley Regional School Board in Nova Scotia and Monongalia County Board of Education in West Virginia. Participants completed a questionnaire assessing the constructs of compassion satisfaction, burnout, and compassion fatigue that have been conceptualized in this study as indicators of healthy career engagement, career disengagement, and career overengagement, respectively. Participants also responded to a demographic survey and to questionnaires exploring history and residual effects of direct and indirect traumatic experiences. Measures included the Professional Quality of Life: Compassion Satisfaction and Fatigue Subscales - Revision III (ProQOL-CSF-R III), History of Traumatic Experiences (HTE), and Impact of Events Scale - Revised (IES-R) for direct and indirect trauma. Previous career engagement studies with educators focused on career satisfaction and burnout. Very few addressed educator trauma or compassion fatigue. In the current study, evidence of career satisfaction, burnout, and compassion fatigue was found across all educator subgroups. Burnout and compassion fatigue were significantly related with current traumatization status deriving from a history of direct and indirect trauma. Multiple regression analyses provided limited support to the hypothesis that elementary educators would exhibit higher rates of compassion fatigue than middle and high school educators. The hypothesis that classroom teachers at all grade levels would report higher levels of compassion fatigue than counselors and administrators was not supported. Nor was support obtained for the hypothesis that educators with fewer years of experience would be more vulnerable to compassion fatigue than those with lengthier career paths. The inability of demographic characteristics to differentially predict the $26.09 \%$ of the sample who scored in the upper quartile for risk for burnout, and $33.15 \%$ who scored in the upper quartile for risk for compassion fatigue, suggests that prevention and intervention programs should target all educators across demographic subgroups. 


\section{Acknowledgments}

I would like to acknowledge the invaluable contributions of several individuals and groups who have directly or indirectly influenced the content and direction of this dissertation. First I would like to thank my colleagues in the public school system in Nova Scotia, who over the years shared the trials and tribulations of caring deeply about the students and families with whom they worked. These dedicated educators communicated the joys and pain associated with being invited to step into the lives of their young charges. Well beyond focusing on the academic components of their job descriptions, these educators were committed to addressing the needs of the whole child, and quite often, his or her family. They also described acute compassion for their colleagues, who at times were faced with their own crises and traumatic life events.

This study would not be possible were it not for the thousands of students and their immediate and extended family members, who passed through the doors of the schools in which I had the honor of working. The challenges and complications of their lives sometimes led to them reaching out to the school as a symbol of stability in chaotic times, or conversely, to school staffs anticipating need and offering assistance in the manner of guidance and advice, caring support, financial assistance, food, clothing, and more. Over the past two decades, the relationship between home and school has become, I believe, much more complex and intimate. This has been manifested in closer relationships between educators and their students and students' families.

It goes without saying that this study could not have been conducted without the gracious cooperation of those educators in Nova Scotia and West Virginia who took the 
time to complete surveys and questionnaires. These busy educators willingly engaged in self-reflection in the interests of furthering our collective understanding of the nature of educator career engagement, and the corresponding effects of primary and secondary traumatic experiences.

I would like to extend my appreciation to those who have enriched both the doctoral and dissertation experience. Dan Hursh offered thoughtful and timely recommendations as the proposed study unfolded. The synergistic contributions of my committee members created the conditions for a most rewarding and fulfilling dissertation experience. Margaret Glenn, as Chair of my dissertation committee, helped to keep the process in perspective with her calm manner, sensitive pacing, and healthy infusion of humor. Sherry Cormier, initially assigned the role of advisor as I entered the program, became so much more to me than the role would imply at first glance. She is a warm, generous, and supportive mentor who promoted my actualization on both personal and professional levels throughout the program of study. Dick Walls shared his extensive statistical expertise, systematic organization, and attention to detail in a contagiously enthusiastic manner that enriched the outcome. Jan Melcher offered her experience with school systems and research in her own inimitable caring and empowering manner. Bob Marinelli has been a steady and encouraging supporter at the coursework, comprehensive exam, and dissertation levels. I am extremely grateful that Michael Vetere, in his demanding role as Superintendent of Schools for the Monongalia County Board of Education could find the time and energy to contribute his expertise to this project. 
The past and present students in the West Virginia University's Counseling Psychology program have been a wonderful source of support and friendship. Those who were one or two steps ahead offered sage advice based on wisdom accrued on their journey through the program. In particular, I am indebted to my two cohort classmates, Liz Cassidy and Phil Cromer. Our little class of three established a bond that allowed us to 'pace' each other through the dissertation process, and cemented us as friends for life.

Finally, I want to express my love and gratitude to my 'behind the scenes' supporters. My mother, Leta, has always offered steadfast support and belief in my ability to achieve academic goals. Both she and my stepfather, Hugh, have done everything in their power to ensure that this longstanding dream of pursuing a doctoral degree could be realized. Twenty years ago, my then new partner, Peter, communicated his commitment to helping me achieve the goal of doctoral study. He has more than lived up to his word despite the sacrifices entailed in leaving his career and moving 1400 miles to assist me in pursuing my professional goals. His nurturing nature and unflagging encouragement have made this doctoral experience a wonderful life adventure. Our five children Paula, Scott, Jennifer, Allison, and Rachel, have been the best cheerleading squad a mother could ask for. I am forever indebted to my family and treasure each of you more than you may know. 
Table of Contents

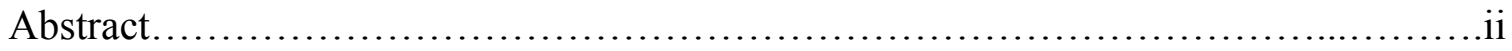

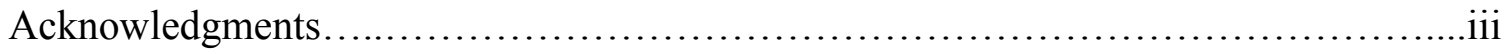

Table of Contents.............................................................

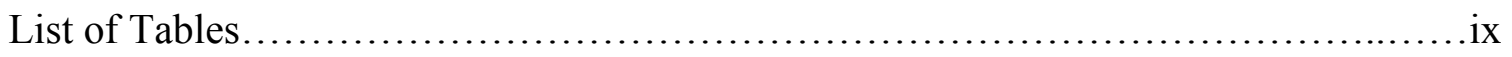

List of Figures..............................................................

Chapter 1: Introduction...................................................

Quality of Career Engagement in Helping Professionals........................2

Quality of Career Engagement in Educators...............................4

Statement of the Problem..............................................

Career Engagement Continuum........................................11

Purpose of the Study ................................................ 12

Definition of Terms................................................... 12

Chapter 2: Literature Review.............................................. 30

Career Satisfaction.................................................. 30

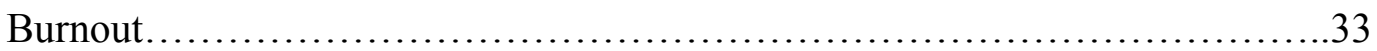

Compassion Fatigue................................................42

Impact of Trauma in the School Setting.................................46

Summary of Literature Review.......................................53

Research Questions....................................................55

Operational Definitions..............................................58 
Chapter 3: Method..............................................................6

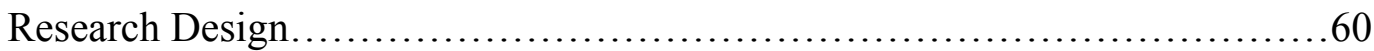

Participant Recruitment...............................................6 60

Procedure for Data Collection..............................................61

Independent and Dependent Variables.....................................66

Research Instrumentation...............................................68

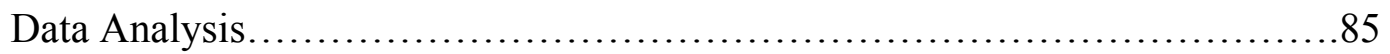

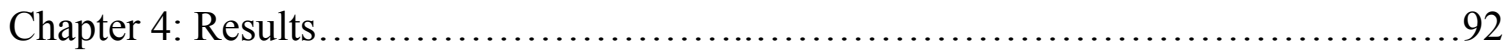

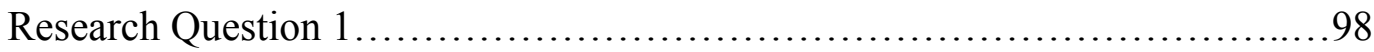

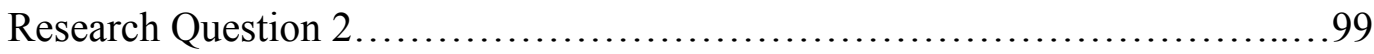

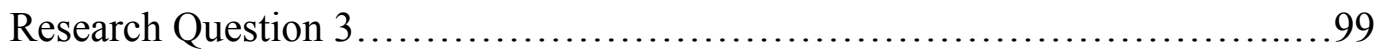

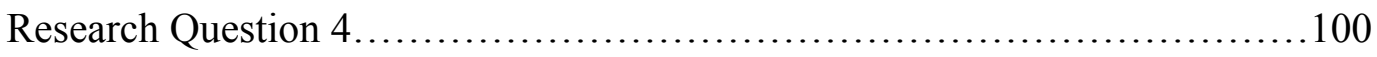

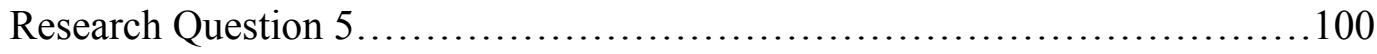

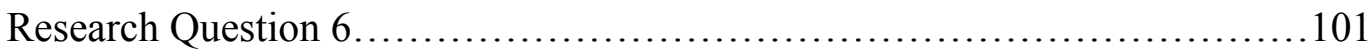

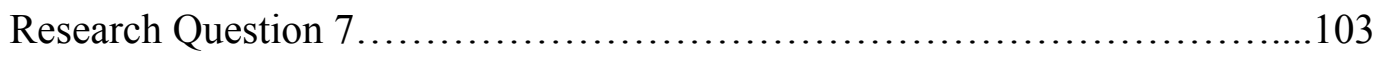

Supplemental Analyses................................................. 108

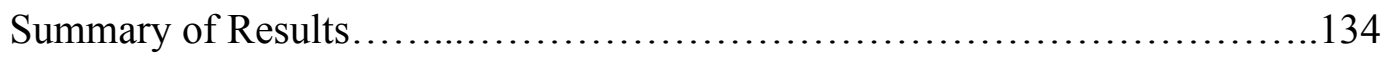

Chapter 5: Discussion...................................................... 140

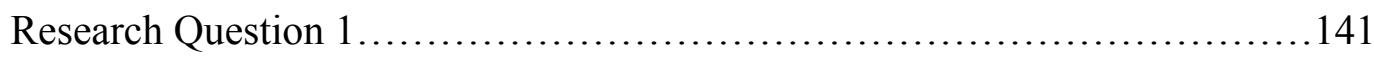

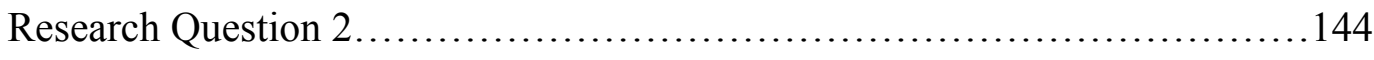

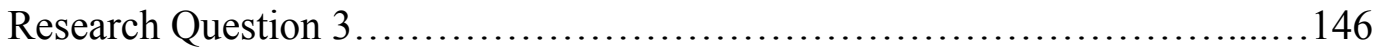

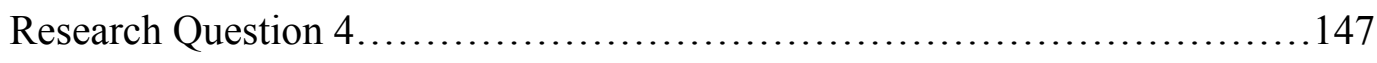

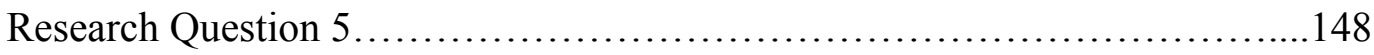




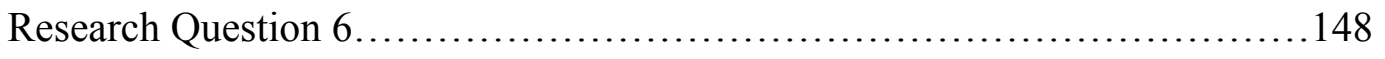

Research Question 7.....................................................151

Supplemental Analyses.................................................. 153

Summary and Implications............................................. 156

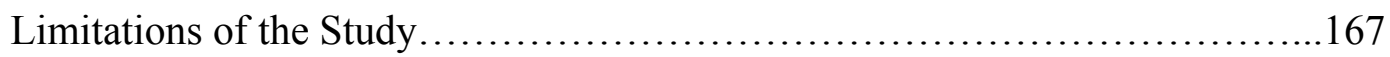

Future Directions................................................... 171

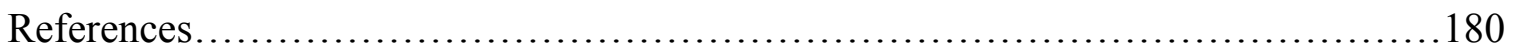

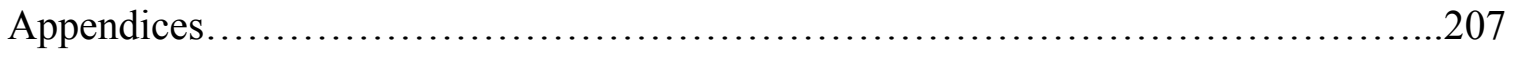

Appendix A: Diagnostic Criteria for Posttraumatic Stress Disorder.............208

Appendix B: Diagnostic Criteria for Acute Stress Disorder....................210

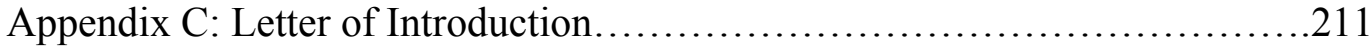

Appendix D: Rationale for Proposed Study ................................215

Appendix E: Staff Room Poster.........................................2 216

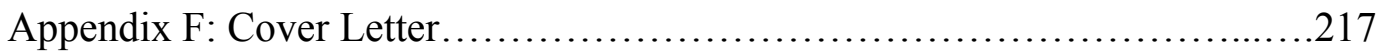

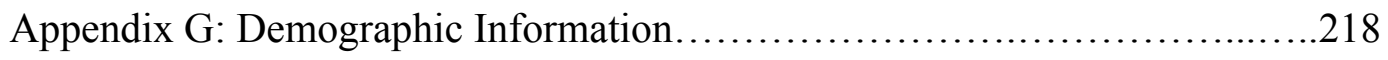

Appendix H: History of Traumatic Experiences...............................219

Appendix I: Impact of Event Scale - Revised (Direct Trauma Focus)............220

Appendix J: Impact of Event Scale - Revised (Indirect Trauma Focus).........221

Appendix K: Professional Quality of Life: Compassion Satisfaction and Fatigue Subscales - Revision III .......................................222

Appendix L: Stress Management Strategies Checklist..........................223

Appendix M: Counseling Referral Resources...............................226

Appendix N: Reminder Postcard........................................227

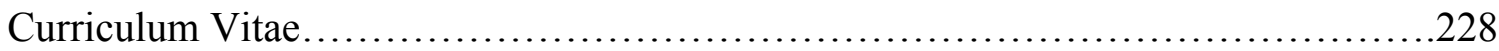




\section{List of Tables}

Table 1. Assessing the Independent Variables of Demographics, Trauma History, and Traumatization Status.

Table 2. Measuring the Three Levels of the Dependent Variable of Quality of Career Engagement.................................................. 68

Table 3. ProQOL-CSF-R III Cut Scores and Career Engagement Categories......82

Table 4. Frequency and Percent of Educators' Demographic Responses ...........112

Table 5. Means and Standard Deviations of Educators' Demographic Responses

Table 6. $\quad$ Frequency and Percent of Direct and Indirect Trauma History in Personal and Work Life

Table 7. Frequency and Percent of Direct and Indirect Trauma History by Trauma Category.

Table 8. Frequency and Percent of Direct Trauma in Personal and Work Life

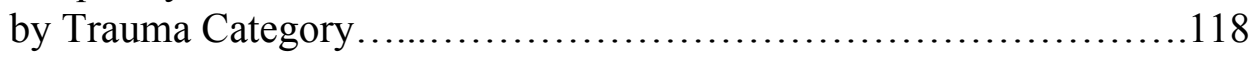

Table 9. Frequency and Percent of Indirect Trauma in Personal and Work Life

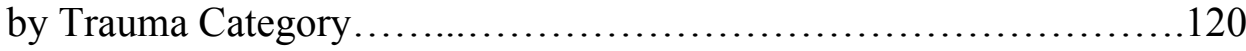

Table 10. Range, Means, and Standard Deviations of Impact of Event Scale Revised

Table 11. Range, Means, and Standard Deviations of ProQOL-CSF-R III Subscales.

Table 12. Frequency and Percent of Cut Scores Surpassed on the ProQOL-CSF-R

III Subscales.

Table 13. Correlations Between the Subscales of the ProQOL-CSF-R III and IES - R Total Score for Direct or Primary Trauma......................125

Table 14. Correlations Between the Subscales of the ProQOL-CSF-R III and IES - R Total Score for Indirect or Secondary Trauma

Table 15. Means and Standard Deviations of ProQOL-CSF-R III Subscales by Demographic Level. 
Table 16. Correlation Matrix Crossing Demographics with ProQOL-CSF-R III Subscales........................................................ 130

Table 17. Correlations Between ProQOL-CSF-R III Subscales......................131

Table 18. Model Summaries of Stepwise Multiple Regression Analyses for the Dependent Variables of Compassion Satisfaction, Burnout, and Compassion Fatigue....

Table 19. Frequency and Percent of Combinations of Cut-Scores Surpassed on the ProQOL-CSF-R III Subscales.....................................133

Table 20. Unified Language and Construct Restructuring........................164

\section{List of Figures}

Figure 1. Career Engagement Continuum....................................11 


\section{CHAPTER I}

Introduction

Career satisfaction, burnout, and more recently, compassion fatigue, have been identified in the research literature as issues influencing the cognitive, affective, social, spiritual, physical, and behavioral experiences of helping professionals. If satisfaction, burnout, and compassion fatigue are postulated to be indicators of the quality of career engagement, representing healthy engagement, disengagement, and overengagement, respectively, then it behooves those in the helping professions to develop a better understanding of how each of these manifests. Enhanced awareness fosters greater sensitivity to risk factors and early signs of these psychological states. This is crucial given that burnout and compassion fatigue serve to detract from full enjoyment of the rewards of working in the helping fields. These constellations of symptoms may also impede attainment of optimal levels of professional functioning. Taken to the extreme, burnout and compassion fatigue may result in a degree of helper impairment that endangers the well-being of the helpee.

In this chapter, the concept of a career engagement continuum will be more fully explored, first in the context of the helping professions in general, and then more specifically in the context of public education. A rationale for the study will identify the need for research focusing on the quality of career engagement of public school educators as a special subgroup of helping professionals. In particular, the paucity of research addressing the construct of compassion fatigue in this group will be highlighted. The latter section of the chapter will be devoted to definitions of terms related to the study, including: educator, helping professional, healthy career engagement, career satisfaction, 
career disengagement, burnout, traumatic stress, primary traumatization, secondary traumatization, vicarious traumatization, post-traumatic stress disorder, career overengagement, and compassion fatigue.

\section{Quality of Career Engagement in Helping Professionals}

A fairly extensive body of research literature exists that explores issues of quality of career engagement in helping professionals. This literature is to be found under many interrelated headings, including career satisfaction, burnout, primary traumatization, secondary traumatization, vicarious traumatization, and compassion fatigue.

Career satisfaction and its antithesis, burnout, would appear to have the longest histories and broadest spans of exploration. These constructs have been researched across helping professions and other occupational spheres (Brown \& O’Brien, 1998; Collins \& Long, 2003; Illiffe, 2000; Isaacson, 1985; James \& Gilliland, 2001; Maslach, 1982, 1999; Quick, Murphy \& Hurrell, 1997; Salston \& Figley, 2003; Skovholt, 2001; Super, 1990). Conversely, the concepts of primary (direct) and secondary (indirect) traumatization have been explored much more recently with respect to their impact on the quality of career engagement in the helping professional. The secondary trauma category encompasses vicarious traumatization and compassion fatigue.

The introduction of the diagnostic category of Posttraumatic Stress Disorder (PTSD) in the third edition of the Diagnostic and Statistical Manual (APA, 1980) heralded a new era in the study of post-traumatic sequelae in those who had been victims of primary traumatization. Gradually, recognition dawned that there were deleterious effects of trauma on those assisting the victims in their recovery (Conrad \& Perry, 2000; Morrissette, 2001; Thompson, 2003a; Thompson, 2004; Visionary Productions, 1994). 
Consequently, by the 1990s a proliferation of studies and writings on secondary traumatic stress, vicarious traumatization, and compassion fatigue were observed (Ballon, 2001; Black \& Weinrich, 2000; Brown \& O’Brien, 1998; Catherall, 2002; Charney \& Pearlman, 1998; Chrestman, 1999; Cornille \& Meyers, 1999; Courtois, 1993; Dane, 2000; Etherington, 2000; Figley, 1995; Figley, 1999; Figley, 2003; Gabriel, 2001; Herbert \& Wetmore, 1999; Janik, 1995; Johnson, 1998; Lapp, 2002; Monahon, 1993; Nelson, 2002; Pearlman \& MacIan, 1995; Rainer, 2000; Robb, 1999; Ruzek, 1993; Saakvitne \& Pearlman, 1996; Salston \& Figley, 2003; Stamm, 1999; Steed \& Downing, 1998; Stone, 1998; White, 2001). Forerunners in this field of secondary trauma study included Beth Hudnall Stamm, Charles Figley, Linda McCann, Laurie Anne Pearlman, and Karen Saakvitne (Struwig, 2002; Zimering et al, 2003).

Despite the auspicious launch of this subfield of traumatology, Zimerling and colleagues (2003) maintained that secondary trauma is in dire need of a much more extensive research base. They lamented the paucity of peer-reviewed literature, noting that of the 17 articles located in a recent literature search, only 12 presented data. Statistically sound research findings would help to fend off the controversy that surrounds the notion of secondary traumatization. Debate has arisen out of concerns that helpers' responses to indirect trauma are being pathologized by diagnosing them as a form of secondary post-traumatic stress disorder (Zimerling et al., 2003).

These secondarily or vicariously wounded helpers included front-line workers such as firefighters, police officers, paramedics and other emergency management technicians, search-and-rescue workers, disaster workers, and hospital staff. Nonemergency personnel who were similarly impacted during subsequent involvement with 
the victims included psychologists, psychiatrists, counselors, social workers, crisis-line volunteers, child protection workers, clergy, judges and lawyers (PTSD Alliance, 2000; Kinzel, 2000; Stamm, 1999; Thompson, 2003b). Occasionally, the traumatology literature acknowledged that teachers are among those who are susceptible to the psychological fallout of working with trauma victims (Conrad \& Perry, 2000; Kees \& Lashwood, 1996; Thompson, 2003a).

Quality of Career Engagement in Educators

Those working in the field of education today are faced with multiple demands, arguably more than ever before in the history of public education. Concerns about class sizes, adequate staffing, access to teaching and learning resources, funding committed to education, and environmental safety of facilities abound. Societal changes have conspired to present families with challenges in the areas of employment security, life partnership stability, and philosophies of child-rearing, the effects of which are evident in the school setting (Krueger, 1997). Child physical and sexual abuse, domestic violence, and violence in schools have become well-documented issues (Cohen \& Cox, 1995; Cornille \& Meyers, 1999; Cuffe \& Shugart, 2001; Dayton, 2000; Evans \& Rey, 2001; Giggans \& Levy, 1997; James \& Gilliland, 2001; Kass et al., 1995; Morrell \& Rubin, 2001; Parnell, 1997; Porterfield, 1996; Thompson, 2004).

All of these factors have served to augment an already formidable task set before educators who are charged with fostering the cognitive, emotional, social, and physical development of students in preparation for their future roles as caring, contributing, and fulfilled citizens in a global community. We are reminded of the relevance of Maslow's hierarchy of needs (Coon, 1998; Tamparo \& Lindh, 2000) when we become aware of 
students who are coming to school inadequately fed and clothed due to poverty, money management difficulties, or parents whose personal needs get in the way of their children's needs (Krueger, 1997). Educators are cognizant of the fact that anger, sadness, fear, and depression are no strangers to students who may be dealing with trauma and grief-inducing incidents in their lives (Alexander, 1999; Armsworth \& Holaday, 1993; Bienfeld, 1995; Bramblett, 1991; Brooks \& Siegel, 1996; Cornille \& Meyers, 1999; Cuffe \& Shugart, 2001; Cytryn \& McKnew, 1996; DiGiulio \& Kranz, 1995; Evans \& Rey, 2001; Falasca \& Caulfield, 1999; Fisher, 1999; Fitzgerald, 1992; Freyd, 1996; Giggans \& Levy, 1997; Grollman, 1995; Hallowell, 1996; Hamilton, 1999; Health Canada, 2000; Horton \& Cruise, 2001; Ingersoll \& Goldstein, 1995; James \& Gilliland, 2001; Johnson, 1998; Johnson, 1999; Levine, 1997; Lowenstein, 1995; Maloney \& Kranz, 1991; Marcus, 1996; Monahon, 1993; Neuman, 1998; Newman, 1993; Nunes \& Simmie, 2002; Pfefferbaum et al., 2000; Porterfield, 1996; Richards \& Bates, 2000; Schaefer \& Lyons, 1993; Son \& Kirchner, 2000; Stevenson \& Black, 1996; StronachBuschel, 1990; Terr, 1991; Thompson, 2004; Tinker \& Wilson, 1999; Trozzi, 1999; Wolfelt, 1991). Maslow's theory suggests that until basic safety and nurturance needs are met, students are unlikely to excel in academic endeavors (Coon, 1998; Tamparo \& Lindh, 2000).

In this author's perception, the daunting task of promoting achievement of full potential in students is rendered all the more arduous because of numerous other requirements of educators such as planning, assessing, reporting, communicating with parents, committee work, fundraising, and remaining abreast of current developments in the broad field of education (curriculum changes, learning theory, assessment, child 
development, management and discipline, policy and procedures, education law, etc.). Johnson (1998) suggested that the profession of teaching is perceived to be one of the most stressful occupations due to the conflicting demands and competing needs inherent in its multifaceted work. Classroom teachers find themselves at the middle level of a hierarchy that includes school board superintendents, school board members, central office staff, principals, assistant principals or vice-principals, other teachers, students, and students' families.

Given the complexity of the role of educator and the challenges inherent in executing the associated duties, it would appear worthwhile to engage educators in reflection on the degree to which their career brings them a sense of fulfillment, and to explore whether they may be at risk for developing burnout or compassion fatigue. Burnout is manifested as a pervasive sense of discontent and dissatisfaction with regard to one's career that may develop due to being overwhelmed with the demands of the job or because stagnation has set in (Figley, 1995; Figley, 1999; James \& Gilliland, 2001; Stamm, 1999; Truch, 1980; Williams \& Davis, 2002). Compassion fatigue is a relatively new concept describing a condition that may develop in those who are responsible for ensuring the well-being of others (Figley, 1995; Figley, 1999; Figley, 2002b; Thompson, 2003a; Thompson 2003b; Thompson 2004; Visionary Productions, 1994; Zimering et al., 2003). Caring is an essential component of effective teaching, but the cost of caring becomes evident when we begin to share or take on the burden of suffering of those in our school community. Compassion fatigue is the negative physical, emotional, and cognitive impact on our lives that results from the accumulation of concerns about our students, their parents, and our co-workers, borne of our caring and compassionate 
involvement (Figley, 1995; Figley, 1999; Figley, 2002a; Figley, 2002b; Herbert \&

Wetmore, 1999; Johnson; 1998; Rainer, 2000; Saakvitne and Pearlman, 1996; Stamm, 1999; Thompson, 2003b; Thompson 2004; Visionary Productions, 1994). Beaton and Murphy (1995) referred to the absorption of traumatic stress as the catalyst for the onset of compassion fatigue.

\section{Statement of the Problem}

Public school educators spend the second greatest amount of time in the life of a child next to the child's primary caregivers. In some cases, educators' daily contact may exceed that of the caregiver. Yet, studies exploring the effects of primary and secondary traumatization on this group who become quite intimate with their students, and often with their families, are conspicuously absent in the current body of research literature. While burnout has been studied quite extensively in educators, researchers have not examined the nature, extent, or potential impact of primary and secondary trauma in the lives of school personnel.

Schlozman (2001) identified public school educators as ideally situated to address the traumatic aftermath of global events such as the terrorist attacks of September 11, 2001. However, the intervention focus rested solely on students, and the psychological needs of teachers appear to have been overlooked. Krueger referred to an epidemic of "needy, heartbreaking kids" (1997, p. 44), who may have been neglected, physically abused, raped, or traumatized prior to immigrating from war-torn countries. Krueger (1997) observed that attempting to meet the needs of such troubled students fostered burnout in some educators. The question of potential secondary traumatization of these teachers was not raised. 
Iliffe wondered if domestic violence counselors might be "hidden victims" of secondary traumatization (2000, p.393). Her qualitative research with 18 domestic violence counselors concluded that vicarious traumatization and burnout were evident in this sample. Given the current rate of exposure of educators to students' and colleagues' myriad incidents of similar domestic violence trauma, the relevance of compassion fatigue, in addition to or instead of burnout, is brought into question.

Figley (2003) recommended that future research ponder the question of vulnerability to compassion fatigue with respect to work setting and conditions. To date, however, it does not appear that such research has targeted the population of public school educators.

It is conceivable that the paucity of empirical literature exploring compassion fatigue in educators, and the relative abundance of literature on burnout, may reflect a confounding of the two concepts. In the extant literature on compassion fatigue, the term at times is used synonymously with the concept of burnout (PTSD Alliance, 2000; Follette, Polusny, \& Milbeck, 1994; Wright, 2004) and at other times is differentiated from burnout (Collins \& Long, 2003; Conrad \& Perry, 2000; Dane, 2000; Figley, 1995; Figley, 2002b; James \& Gilliland, 2001; Kassam-Adams, 1999; Kinzel, 2000; McBratney, 2000; O’Grady, 2004; Stamm, 1999; Stamm, 2002; White, 2001). Still other researchers and authors attempt to identify the unique nature of compassion fatigue and then ultimately categorize it as a form of burnout (Catherall, 2002; Figley, 1998; Figley, 2000a; Figley, 2003; Thompson, 2003a).

Kochevar (2002) listed burnout as one of the possible symptoms of compassion fatigue. In a similar vein, Jenkins and Baird's (2002) formula for compassion fatigue 
comprised PTSD symptomatology plus burnout. Steed and Bicknell (2001) observed that burnout has been identified in the literature both as a predictor of compassion fatigue and an indicator of unresolved compassion fatigue. Collins and Long (2003) posited that burnout might represent a risk factor or harbinger of compassion fatigue. Gentry, Baranowsky, and Dunning (2002) suggested that a state of burnout predisposes a caregiver to compassion fatigue due to lowered resiliency. Later, on the same page, they identified burnout and secondary traumatization as the two components of compassion fatigue (2002, p. 125), thus engendering the question of whether burnout is discrete from compassion fatigue or integral to it. In contrast to Gentry and his colleagues, James and Gilliland (2001) posited that the experience of vicarious trauma and compassion fatigue predispose an individual to burnout. Thompson (2003a) postulated that untreated compassion fatigue could lead to burnout and depression. These latter two conceptualizations are congruent with the model of career engagement being presented in this study.

The literature evinces disagreement as to whether onset of compassion fatigue is sudden and acute (Collins \& Long, 2003; Figley, 1995; Figley 2002a; Figley, 2002b; Jenkins \& Baird, 2002; Salston \& Figley, 2003; Stamm, 1999) or gradual and insidious (James \& Gilliland, 2001; O’Grady, 2004; Struwig, 2002; Thompson, 2003a;Thompson 2003b; Thompson, 2004; Wright, 2004). Collins and Long (2003) commented on the plethora of terms that have been disseminated to describe the effects on helpers of engaging empathically with traumatized clients. Of these terms, Salston and Figley (2003) categorized burnout, compassion fatigue, vicarious traumatization, and traumatic countertransference as synonyms or near synonyms of secondary traumatic stress. 
They then noted that secondary traumatic stress and burnout refer to processes rather than events. This line of reasoning would imply that compassion fatigue is best conceptualized as a process rather than as an acute-onset condition.

Figley's (1995) description of compassion fatigue as the cost of caring is congruent with Thompson's depiction of compassion fatigue as "the professional consequences of caring too much" (2004, p. 275). Blurring of the parameters of the construct ensues, however, when we are reminded that Maslach's (1982) treatise on burnout was entitled Burnout: The Cost of Caring. Additionally, the term professional burnout has been used to describe the outcome of "confronting human suffering through trauma work" (Wilson et al., 2001, p. 6). Likewise, Figley (1998, 2003) identified family burnout as the interpersonal equivalent of compassion fatigue. The shared language in definitions of the constructs of compassion fatigue and burnout has contributed to difficulty in establishing clear semantic parameters.

The one constant in the various approaches to defining compassion fatigue is the requirement that the sufferer be engaged in a professional caregiving role. However, given the lack of consistency and precision in defining compassion fatigue, it may be that conditions of presumed disengagement or burnout previously were inappropriately labeled in educators. In fact, the quality of career engagement might have been identified more accurately as career overengagement manifesting in compassion fatigue.

Thus, confusion exists as to the exact definitions of compassion fatigue and burnout, which leads in turn to uncertain or incorrect diagnoses. It is important that burnout and compassion fatigue be recognized and identified accurately in public school educators, so that suitable interventions may be implemented. Self-care strategies may be 
prescribed or collaboratively determined which will help re-establish career engagement equilibrium. The ultimate goal is healthy engagement in one's work in the field of education. Both disengagement in the form of burnout, and overengagement as manifested in compassion fatigue, detract from a rewarding and productive career experience and contribute to deterioration in professional functioning.

\section{Career Engagement Continuum}

Figure 1

\section{HEALTHY CAREER ENGAGEMENT}

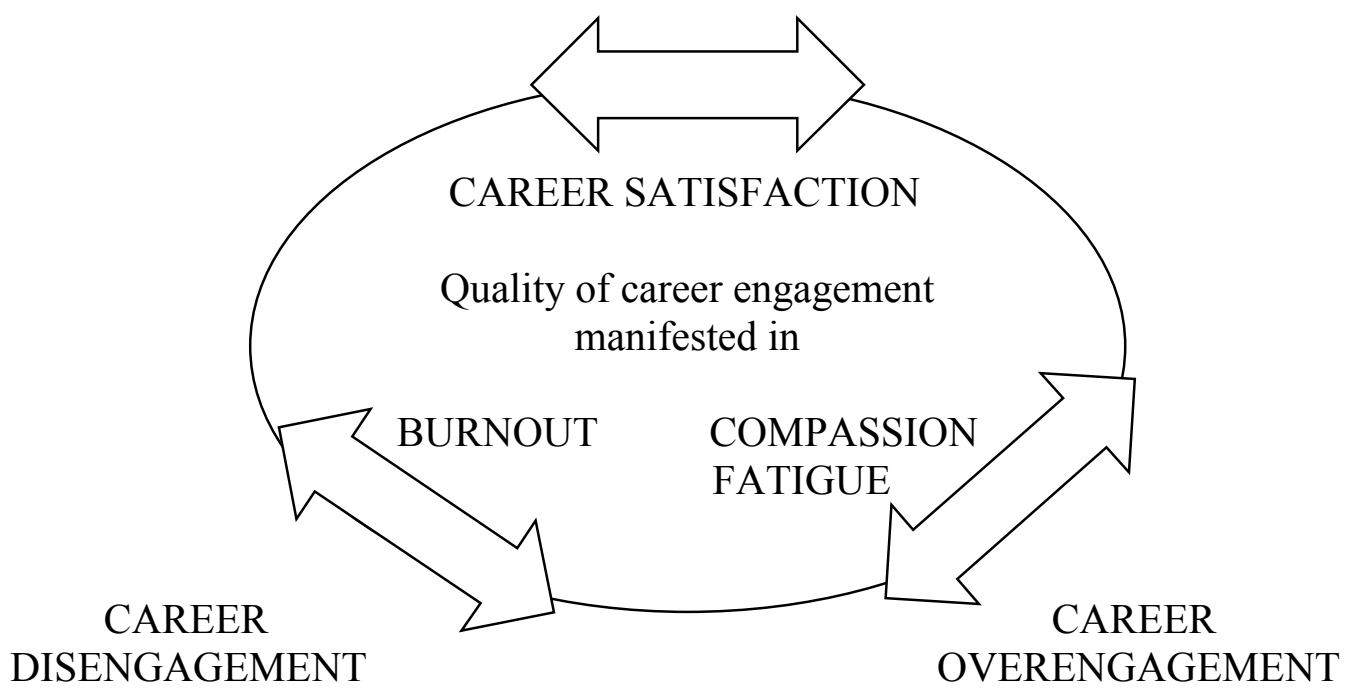

As illustrated in Figure 1, the proposed career engagement continuum is delineated by a nonlinear, nonstatic model. This suggests that educators may find themselves at various points on the continuum over the course of their career. In contrast to a dichotomous scale which either assigns a certain label or does not, a continuum allows for more flexible assessment of quality of engagement. Educators may indeed demonstrate rather 'pure' presentations of one of the three constructs of career satisfaction, burnout, or compassion fatigue. Alternatively, they may manifest a hybrid quality of engagement such that indicators of both career satisfaction and compassion 
fatigue, compassion fatigue and burnout, or career satisfaction and burnout are noted. Conceivably, educators might exhibit a certain degree of all three constructs, although this study anticipated that a dominant quality of engagement would be displayed.

Purpose of the Study

As families continue to be besieged by financial, mental and physical health issues, and intrapersonal and interpersonal difficulties, their levels of distress and dysfunction will continue to spill over into the school system. Educators will be challenged to maintain a healthy degree of engagement with their students, the students' families, and their colleagues in the school system. This study was undertaken to explore the components of career satisfaction, burnout, and compassion fatigue as indicators of healthy engagement, disengagement, and overengagement. The study sought to determine where educators tend to be located on the continuum of career engagement, and whether relationships exist between the nature of career engagement and demographic characteristics, traumatization history, and current trauma status.

\section{Definition of Terms}

\section{Educator}

This group is comprised of classroom, subject, and other (specialist areas including resource and special education) teachers, as well as guidance counselors and administrators (assistant principals or vice-principals, and principals) working in the public school system with students in Primary or Kindergarten through Grade 12. Helping Professional

The conventional category of helping professionals consists of those whose mandate it is to help individuals and families re-establish a sense of life equilibrium 
through counseling, therapy, and similar interventions. Such professionals would include counselors, psychologists, psychiatrists, social workers, and members of the clergy. Broader definitions have also included other professionals such as physicians, nurses, physical therapists, physiotherapists, occupational therapists, judges, and lawyers. Due to the significantly evolved and expanded role of public school educators over the past few decades, their inclusion as a subgroup of helping professionals seems appropriate.

\section{Healthy Career Engagement}

Healthy career engagement is evidenced when educators interact in a consistently caring and compassionate manner with students, students' families, and colleagues, and they are not drained or depleted by these interactions. Healthily-engaged educators achieve balance in the degree of cognitive and emotional involvement in their work. While the work may be perceived as demanding and challenging, educators are able to regroup through activities in their personal lives. Attention to self-care allows energy reserves to be replenished so that educators feel that they have more to give and can sustain the professional pace required over the long-term. Particularly when working with those who have experienced trauma, Grinspoon (1991) recommended avoiding both overcommitment and detachment, which appear to align with overengagement and disengagement, respectively.

\section{Career Satisfaction/Fulfillment}

When educators demonstrate healthy career engagement, they are able to express a sense of satisfaction with their career choice and a commitment to remaining in the field of education. The work is perceived as rewarding despite its degree of challenge. Educators describe a sense of personal agency and efficacy. In the helping professions, 
career satisfaction may be represented by the construct of compassion satisfaction, which is an indicator of the degree to which the helping professional derives fulfillment from engaging in helping interchanges with others.

\section{Career Disengagement}

Career disengagement refers to educators detaching themselves in their career involvement to the point of exerting a deleterious effect on the helping relationships that exist between them and their students, students' families, and colleagues. As educators distance themselves professionally, they become less accessible cognitively, affectively, interpersonally, and behaviorally. It becomes apparent that a decreasing amount of energy is available to, and invested in their career.

\section{Burnout}

Educators whose career involvement is characterized by disengagement quite often are suffering from burnout, assuming that there was a good match initially between the professional and career choice. Burnout is manifested as a pervasive sense of discontent and dissatisfaction with regard to career that may develop because educators are overwhelmed with the demands of the job or because stagnation has set in.

The majority of models of burnout appear to focus on systemic and/or interpersonal stressors. Girdin, Everly, and Dusek (1996) conceptualized burnout as a state of mental and/or physical exhaustion resulting from extended periods of stress overload. Blair and Ramones (1996) depicted burnout as a psychological response to frequent interaction with individuals in need. Pines and Aronson (1988) defined burnout as a multifaceted state of exhaustion emanating from emotionally demanding professional interactions. According to Cedoline (1982), the condition of burnout derived from the 
employee's perception of discrepancy between the demands of the job and the resources available to fulfill those demands.

Factors that may contribute to burnout include: high job stress, unrealistic job demands, constant pressure to produce or perform, a predominance of unrewarding tasks, excessive interference and interruptions, lack of acknowledgement of effort and contributions, absence of collegial support, and imbalance between personal and work life spheres (Gibson \& Mitchell, 1999). A discrepancy between employee values and system priorities can be a precursor to burnout (Center for Mental Health in Schools at UCLA, 2004; Salston \& Figley, 2003). Burnout may be precipitated by lack of participatory decision-making, limited communication and feedback, excessive workload, tedium, frequent and stressful interactions, role conflict, role ambiguity, and insufficient job training (Cedoline, 1982).

Maslach (1982) identified the three component strands of burnout as emotional exhaustion, depersonalization, and reduced sense of accomplishment. Figley based his model of burnout on Kahill's (1988) five categories of physical, behavioural, emotional, interpersonal, and work-related symptoms. Jenkins and Baird (2002) suggested that these general symptom classifications would be viewed by Maslach as repercussions, rather than components of burnout. Kinzel (2000) noted that the third stage in the Cherniss burnout model comprising stress, strain, and defensive coping was characterized by detachment from the client. This is consistent with the disengagement sector of the model of career engagement proposed in this study.

Edelwich and Brodsky (1982) depicted four phases of unhealthy career engagement leading to burnout: enthusiasm accompanied by unrealistic expectations of 
self and system, stagnation resulting from unmet needs, frustration due to increased perception of occupational obstacles, and apathy which is highly resistant to intervention. The Center for Mental Health in Schools at UCLA (2004) outlined a three-phase model comprising stress arousal, energy conservation, and exhaustion. This model is similar to Hans Selye's General Adaptation Syndrome that depicts the human stress response over three stages of alarm, resistance, and exhaustion (Bisbey \& Bisbey, 1999; Everly \& Lating, 2002; James \& Gilliland, 2001; Kass et al., 1995; Scaer, 2001; Tamparo \& Lindh, 2000; Wilson et al., 2001).

Burnout is evidenced by withdrawal, increased absenteeism, apathy, cynicism, exhaustion, and decreased productivity (Gibson \& Mitchell, 1999; Tamparo \& Lindh, 2000). Those in the helping professions feel that they have nothing more to offer or do not want to invest any more energy in career-related activities. The thought of remaining on the current career path over the long-term becomes distasteful or even intolerable (Figley, 1995; Stamm, 1999; Truch, 1980).

In contrast to compassion fatigue, which is viewed as inherent and unavoidable in trauma work, burnout is considered preventable (McBratney, 2000). Education and training emphases thus differ; self-awareness and coping strategies are utilized preventatively to fend off burnout, as opposed to responsive interventions that are implemented when changes in frame of reference and onset of PTSD symptoms herald the onset of compassion fatigue. Schauben and Frazier (1995) contrasted vicarious trauma and burnout, noting that the former requires interaction with traumatized clientele whereas burnout can result from any difficult client work.

While the literature appears to have proclaimed Pines and Maslach as trailblazers 
in the field of burnout (Berg, 1994; Black \& Weinreich, 2000; Brown \& O’Brien, 1998; Burke, Greenglass, \& Schwarzer, 1996; Collins \& Long, 2003; Maslach, 1982; Maslach, 1999; Maslach \& Leiter, 1999; Maslach, Shaufeli, \& Leiter, 2001; Pines, 2002; Pines \& Aronson, 1988; Pines, Aronson, \& Kafry, 1981; Quick, Murphy, \& Hurrell, 1992), numerous models, phases, stages, and components of burnout have been seeded by other researchers and practitioners. As is also the case with the constructs of secondary traumatic stress, traumatic countertransference, vicarious trauma, and compassion fatigue, burnout does not enjoy a clear, unencumbered definition. Edwards and colleagues (2000) highlighted the absence of a consensus in this regard. Agreement does appear to exist, however, that distancing is a hallmark of burnout (Center for Mental Health in Schools at UCLA, 2004; Collins \& Long, 2003). Distancing behavior is consistent with the concept of disengagement, which likewise is associated with burnout in the career engagement model proposed in this study. Maslach, Schaufeli, and Leiter (2001) supported this conceptualization when they described (healthy) engagement as the antithesis of burnout.

\section{Traumatic Stress}

The term traumatic stress has been used interchangeably with post-trauma stress, post-traumatic stress, traumatic incident stress, and critical incident stress, although it bears noting that traumatic stress technically can be experienced prior to the completion of a traumatic event (Parkinson, 1993).

Traumatic stress is engendered when individuals are exposed to a sudden and unexpected stimulus that overwhelms their normal coping mechanisms. Traumatic stress is defined as a normal reaction to an event that does not usually fall within the realm of 
normal experience, nor is anticipated by the individual (National Defence, 1994; Parkinson, 1993). In addition to manmade and natural disasters, violent crime, and accidents, traumatic stress may be engendered as a result of unexpected divorce or bereavement, medical procedures, miscarriage, or job loss. Although it may be argued that these latter incidents do not meet the criterion of atypical human experience, individuals often describe intense psychological responses congruent with traumatic experiencing (Herbert \& Wetmore, 1999). Bisbey and Bisbey (1998) espoused a broad and inclusive definition of trauma that encompasses any event outside a particular individual's normal range of experience that violates previously-held beliefs about how the world works or how people interact with each other.

Exposure to a traumatic event may be direct, resulting in primary traumatization, or indirect, leading to secondary traumatic stress (Catherall, 2002). Figley's (1995; 2002a; 2002b) definition of secondary traumatic stress suggests that exposure to the recounting of another's trauma, and possible triggering of memories of one's own traumatic experiences, can lead to secondary traumatic stress. He proposed also the category of Secondary Traumatic Stress Disorder (STSD) that would meet all criteria for PTSD save for a Criterion A event. In the case of STSD, the individual would not have to experience a traumatic incident directly, but instead would have been traumatized via bearing witness to the traumatic suffering of another (Cornille \& Meyers, 1999). Salston and Figley (2003) proposed that the term compassion stress could encapsulate the experience of secondary traumatic stress, while compassion fatigue could be used interchangeably with STSD. 
Traumatic stressors are inherently subjective in valence; an event that generates traumatic stress for one individual may leave another psychologically unscathed (Giller, 1999; Parkinson, 1993; Scaer, 2001). It is the subjective rather than the objective experience that determines whether an incident will be perceived as traumatic (Giller, 1999). Factors contributing to the degree of traumatic stress experienced, include: the individual's personality and degree of sensitivity (Deskin \& Steckler, 1997), the nature of the event, the context of the event, prior traumatic history which may serve either to predispose or inoculate the victim, and current coping strategies and support network (Keane, 1998). Scaer (2001) postulated that prior trauma history, especially during childhood, might prime an individual to experience traumatic stress following an incident that others might describe as relatively minor. On the whole, those with a history of primary trauma appear vulnerable to secondary traumatic stress, including vicarious trauma and compassion fatigue, although it is unclear whether this risk is significantly higher than in those who do not report a trauma history (Collins \& Long, 2003; Cornille \& Meyers, 1999; Pearlman \& Saakvitne, 1995; Williams \& Sommer, 1999).

Levine (1997) asserted that the core of a traumatic reaction includes four components of hyperarousal, physical and perpceptual constriction, dissociation, and freezing associated with the feeling of helplessness. These four elements occur to varying degrees during and after the traumatic incident.

\section{Primary or Direct Traumatization}

Primary traumatization occurs when individuals directly experience or witness an event that involves a sense of horror and helplessness. A serious threat to the well-being of self or another is perceived. Individuals' worldviews are altered as a result of the 
shattering of previously held assumptions related to a sense of trust, safety, control, self- and other-esteem, and self- and other-intimacy (Rosenbloom \& Williams, 1999). The intrusive, avoidant, and arousal symptoms associated with a primary trauma can be triggered when individuals are exposed to reminders of the original event, or experience another traumatic event either directly or indirectly. In this manner, individuals may find themselves re-experiencing or reliving the trauma long after it occurred (APA, 2000; Matsakis, 1996; Meichenbaum, 1994; Shapiro \& Forrest, 1997; Smyth, 1999).

Carlson and Furby (1997) reported that the characteristics of a primary traumatic incident include suddenness of the event, lack of controllability, and the perception of the event as negative. They described a biphasic model of reliving and denial that mirrors the core responses of re-experiencing and avoidance. In adults, re-experiencing may be manifested in anxiety, arousal, sleeplessness, somatization, and violent aggression. Aggression directed toward oneself may be enacted in the form of substance abuse. Avoidance may be displayed in the cognitive realm as dissociation. Additionally, according to Carlson and Furby (1997), adults with a history of trauma display higher rates of antisocial practices including delinquency, general adult criminality, and violent criminal activity. Depression occurs at much higher rate in abused versus nonabused populations (Carlson \& Furby, 1997).

Carlson and Furby (1997) identified factors that influence the degree of impact of trauma such as abuse. These factors include the individual's biological predisposition and accompanying neurological changes, developmental level at the time of the event, severity of the stressor, social support system, and prior and subsequent events. 


\section{Secondary or Indirect Traumatization}

Secondary traumatization may transpire when individuals learn about a traumatic event from another person, hear about it on the radio, read about it in a newspaper article, or watch the event on television. Just as with primary traumatization, individuals' worldviews may be altered as a result of the shattering of previously held assumptions related to a sense of trust, safety, and control. Individuals may also experience the full symptomatology triad of intrusion, avoidance, and hyperarousal in the same manner as did the primary victim(s) of the trauma (Catherall, 2002; Chrestman, 1999; Cornille \& Meyers, 1999; Figley, 1995; Figley, 2000a; Figley, 2000b; Figley, 2003; Iliffe, 2000; Jenkins \& Baird, 2002; Stamm, 1999).

\section{Vicarious Traumatization}

According to Charney and Pearlman (1998), the term vicarious traumatization was introduced by McCann and Pearlman, and the construct was subsequently expanded by Pearlman and Saakvitne. The concept derives from constructivist self development theory and refers to the transformation of the inner world of helpers due to empathic connection with trauma survivors (Ballon, 2001; Cornille \& Meyers, 1999; Courtois, 1993; Dane, 2000; Gabriel, 2001; Nelson, 2002; Ruzek, 1993). Exposure to stories of horror and tragedy leads to changes in personal and professional identity, worldview, and spirituality of helping professionals (Jenkins \& Baird, 2002; Kadambi \& Truscott, 2004). Previously-held core beliefs about a just and orderly world must be rewritten into a revised personal narrative.

Altruism and arousal are two elements of work with trauma victims that predispose helpers to vicarious traumatization. Highly committed and dedicated helpers 
seek to ameliorate the post-trauma context for the individuals with whom they work, and find that the energy, arousal, and "ecstasy" elicited in this type of intimate helping relationship can "lead to overactivity and overinvolvement culminating in the responder working beyond his or her capacity" (Charney \& Pearlman, 1998, p. 421). A sense of professional calling, coupled with a rescuer mentality, can foster overidentification and enmeshment with trauma victims. This is congruent with the overengagement component of the career engagement continuum proposed in the current study. James and Gilliland (2001) further suggested that subsequent changes in the helpers' inner worlds due to disruptions in their belief system are precursors to compassion fatigue.

Compassion fatigue and vicarious traumatization are commonly held to be components of secondary traumatization (Friedman, 2001; Herbert \& Wetmore, 1999; Johnson, 1998; Saakvitne \& Pearlman, 1996). Some authors employ the terms interchangeably (James \& Gilliland, 2001). McBratney (2000) asserted that vicarious trauma is a more current term than compassion fatigue, but this contention does not appear to have been supported by other authors. Both compassion fatigue and vicarious traumatization are viewed as normal and inevitable occupational hazards associated with working with traumatized people (Charney \& Pearlman, 1998; Figley, 1995; Figley, 2002b; Iliffe, 2000; Kochevar, 2002; PTSD Alliance, 2000; Schauben \& Frazier, 1995). At particular risk are those who work with traumatized children (Conrad \& Perry, 2000; Cornille \& Meyers, 1999; Iliffe, 2000; Kochevar, 2002).

Helping professionals may begin to demonstrate symptoms of traumatic stress even though they did not directly experience or witness the traumatic event that has elicited these responses. Traumatic contagion occurs when self-other boundaries become 
blurred, as might be the case in the overengaged helper. The heightened arousal transmitted from the primary trauma victim to the helper may result in loss of perspective such that the helper overestimates the potential for danger in the world (Catherall, 2002; Janik, 1995). The helper manifests suspicion, distrust, and guardedness, and concomitant overprotectiveness of loved ones.

Some authors use the term vicarious traumatization more specifically to refer to the systemic traumatization that occurs when a family member or other loved one has been the victim of a primary traumatic event (Conrad \& Perry, 2000; Monahon, 1993). Vicarious traumatization is thus differentiated from more general secondary traumatization by the individual's ongoing intimate relationship with the victim of the primary trauma. It bears noting that such a relationship might be depicted between educators and students in that a sense of closeness is often reported due to the extended periods of time spent together (Schaefer \& Lyons, 1993).

Post-traumatic Stress Disorder

The diagnosis of Posttraumatic Stress Disorder (PTSD) was first entered into the third edition of the Diagnostic and Statistical Manual of Mental Disorders (DSM-III) in 1980 (APA, 1980; Horowitz, 2001; Schiraldi, 2000; Yehuda et al., 1998). Currently, the diagnosis requires exposure to a Criterion A event during which the individual experienced severe horror, fear, or helplessness. This is followed by a cluster of reexperiencing, avoidance, and arousal symptoms that have persisted for more than one month, causing significant distress or dysfunction in daily functioning (APA, 2000). A summary of DSM-IV-TR criteria for PTSD is presented in Appendix A. 
A Criterion A event involves experiencing, witnessing, or otherwise confronting a traumatic event that involved actual or threatened death, serious injury, or other threat to the physical integrity of oneself or others. The magnitude of the event is such that it renders individuals unable to cope and function in their daily lives (Hales \& Hales, 1995; PTSD Alliance, 2000; Schiraldi, 2000). Such events include natural disasters, accidents, serious illness and medical procedures, exposure to war or civil violence, and betrayal or violent crimes including abuse, rape, abduction, assault, and robbery (Barnhill \& Rosen, 1999; Dayton, 2000; Friedman, 2001; Parnell, 1997; Thompson, 2003b).

It is noted that up to 70 percent of adults in the United States have experienced a traumatic event at least once over the course of their lifetime (Keane, 1998). Various studies uncovered general trauma exposure rates of $69 \%$ in four samples of urban adults, criminal victimization rates of $69 \%$ in women, and undergraduate student trauma rates of 84\% (Foa et al., 2000). An estimated 20-25 percent of those who experience a traumatic event go on to develop PTSD (Matsakis, 1996; PTSD Alliance, 2000). At any one time, approximately 5 percent, or more than 13 million people in the United States, demonstrate clinical levels of PTSD symptomatology (PTSD Alliance, 2000). Lifetime prevalence estimates for PTSD range from 1-14 percent (Hales \& Hales, 1995; Yehuda et al., 1998). Giller (1999) asserted that 15 million American children are at risk for PTSD due to physical abuse.

Although men report more extensive exposure to traumatic incidents (Keane, 1998), women are twice as likely to develop PTSD, perhaps due to a higher exposure rate to sexual assault and domestic violence (Foa et al., 2000). In a sample of 4,000 women, one in eight had been raped, and one-third of those were under the age of 11 at the time 
of the first sexual assault (Giller, 1999). These intentional, human-perpetrated acts have been determined to predispose victims to developing PTSD and related disorders (Friedman, 2001; PTSD Alliance, 2000). Giller (1999) reported that at least $40 \%$ of psychiatric inpatients were sexually abused as children.

Other risk factors for the development of PTSD are a high level of distress related to a traumatic incident, and dissociation around the time of the incident (Foa et al., 2000; Schiraldi, 2000). Everly and Lating (2002) postulated that two factors would predispose an individual to PTSD. The first is neurological sensitivity, leading to autonomic arousal at the time of an event. The second is psychological sensitivity, resulting from the violation of a core worldview due to a traumatic event. Janoff-Bulman referred to the shattering of assumptions about the predictability and fairness of the world and its inhabitants (Charney \& Pearlman, 1998; Janoff-Bulman, 1992). This, in turn, tends to become reflected in a loss of sense of trust, safety, control, self- and other-esteem, and self- and other-intimacy (Rosenbloom \& Williams, 1999). Schiraldi (2000) offered three categories of vulnerability to PTSD: individual differences, family characteristics, and recent life stressors. Individual differences include prior trauma history, lack of coping strategies, reactive autonomic nervous system, and characterological traits of introversion and pessimism. Predisposing family dynamics include: nurturing of insecurity, enmeshment, shame, guilt, secrecy, distrust, isolation, externalized blame, and repressed emotionality. Prior life stressors that remain unresolved serve to diminish resiliency in the face of a traumatic event.

PTSD is manifested in emotional, psychological, and physiological changes that are assigned to one of three categories of intrusive, avoidant, and hyperarousal 
symptomatology. Intrusive symptoms include reliving or reexperiencing the incident through nightmares, flashbacks, intrusive images and thoughts, and physical reactions. Avoidant symptoms include psychic numbing, restricted range of affect, loss of interest in previously enjoyed activities, withdrawal from friends, family, and co-workers, avoiding reminders of the event, and sense of foreshortened future. Victims may even avoid awareness of the traumatic event through denial, or experience psychogenic amnesia for trauma-related memories. Hyperarousal symptoms include irritability, sudden angry outbursts, sleep difficulties, difficulties with concentration, exaggerated startle response, and a sense of being on guard. The world is experienced as a dangerous place (Friedman, 2001; PTSD Alliance, 2000: Schiraldi, 2000; Schlozman, 2001).

The etiology of PTSD can be traced to any life event that overwhelms individuals' capacities to cope. Incidents may derive from human aggression and violence and include domestic violence, child abuse, rape, sexual assault, physical assault and random violent acts. Life-threatening illness, invasive medical procedures, or the sudden tragic death of a family member or friend may result in PTSD. Vehicular accidents, house fires, and plane crashes qualify as Criterion A events. Likewise, natural disasters such as floods, earthquakes, hurricanes, and tornados tend to engender horror and helplessness. Manmade catastrophes such as terrorism or war, as well as disasters resulting from human error such as industrial accidents may lead to PTSD.

Various classifications of post-traumatic stress disorders have been proposed, including Lenore Terr's (1991) model focusing on etiology due to isolated versus repeated traumata. Terr's Type I trauma designation refers to post-trauma symptoms generated by a single traumatic incident whereas Type II trauma results from chronic 
incidents such as sexual abuse or domestic violence (Cuffe \& Shugart, 2001; James \& Gilliland, 2001; Matsakis, 1996; Morrissette, 2001; Terr, 1991; Volpe, 2003). A history of Type I trauma tends to be accompanied by vivid, deeply-etched sensory memories for the event, whereas a Type II trauma history is often accompanied by self-preservation coping strategies such as denial, psychic numbing, and dissociation (James \& Gilliland, 1998). Individuals who have suffered a single, discrete trauma are more likely to clearly meet criteria for PTSD. Those individuals who have endured multiple traumatic events, particularly of a deliberate, human-perpetrated nature, may present with more ambiguous symptoms suggestive of characterological disorders (Hodges, 2003).

Post-traumatic symptomatology lasting less than a month may qualify for the diagnosis of Acute Stress Disorder (APA, 2000). Criteria for this disorder are presented in Appendix B. If symptoms persist for longer than 3 months, a specifier of chronic PTSD is applied. The condition is diagnosed as delayed-onset PTSD if there is an interim period of at least 6 months after the traumatic incident before symptoms arise (Foa et al., 2000; Horowitz, 2001; Yehuda et al., 1998).

\section{Career Overengagement}

Career overengagement refers to a lack of, or the crossing of professional boundaries. The boundaries between self and others become blurred as educators become enmeshed with the lives of their students, students' families, and colleagues. When educators demonstrate career overinvolvement, it may be accompanied by detrimental effects to their mental health, and possibly, physical health. They feel it is not possible to care or do enough in the line of professional duty and thus continue to invest more and more energy and time in pursuit of exacting self-imposed standards of performance. 
Overengagement is represented by continuing to 'move toward', in contrast to disengagement where there is a 'moving away'. Johnson (1998) noted that professionals such as educators who work with children are predisposed to significant stress due to their high motivation to ameliorate life conditions for their clients. Thus, in the most challenging and compelling scenarios, these professionals set an even higher standard of performance for themselves, and immerse in rather than disengage from the situation.

\section{Compassion Fatigue}

First identified in nurses by Carla Joinson (1992), compassion fatigue has since been reported in front-line emergency responders and in helping professionals who assist traumatized victims in re-establishing a sense of normalcy. Compassion fatigue is the negative physical, emotional, social, spiritual, and cognitive toll on professionals' functioning that is borne of caring and compassionate involvement with another human being's traumata. Similar to PTSD, compassion fatigue is manifested in a triad of posttraumatic sequelae including intrusive, avoidant, and hyperarousal symptomatology (Thompson, 2003b; Thompson, 2004). The helper experiences symptoms similar to those of the helpee, engendered by the cognitions, emotions, and images elicited in the process of stepping into and sharing the other's traumatized world (Kochevar, 2002).

Charles Figley, a world-renowned traumatologist and pioneer in the area of secondary trauma, defined compassion fatigue as "a state of tension and preoccupation with the individual or cumulative trauma of clients" (2002b, p. 125). Affected helpers will report re-experiencing of clients' traumatic events, avoidance of reminders or numbing when confronted with reminders, and persistent arousal. In Figley's view, susceptibility to compassion fatigue may be fostered by burnout due to pre-existing 
cumulative stress (2002a). Unlike burnout, compassion fatigue may have a sudden onset, although it also may be the result of cumulative events reaching a critical threshold. Compassion fatigue is due to primary and secondary trauma responses being triggered in the context of a helping relationship. Helpers may experience secondary trauma related to the trauma reported by helpees, and/or may find their own history of primary trauma triggered through exposure to clients' traumatic experiences (Campbell, 2000; Figley, 1995; O’Grady, 2004; Stamm, 1999). Career overengagement increases individual's vulnerability to this condition, because emotional distancing as a coping strategy is not practiced (Holaday \& Smith, 1995). Due to overinvolvement, helping professionals suffer angst and guilt over a sense of personal responsibility for a client's outcome; this rescuer orientation is a hallmark of compassion fatigue (Kinzel, 2000). 


\section{CHAPTER 2}

Literature Review

This chapter will present the salient findings in the professional literature with respect to the quality of career engagement in public educators. A review of the psychological constructs of career satisfaction, burnout, and compassion fatigue will be followed by a summary of the literature on the impact of trauma in the school setting. A reminder of the increasing prevalence of traumatic events in school communities will provide a backdrop for educators' exposure to secondary trauma, and clarify the need to revisit the construct of burnout. Previous determinations of burnout actually may be mislabelled, warranting a more accurate diagnosis of compassion fatigue. The chapter will close with an overview of the research questions that were explored in the current study, and operational definitions of the variables under study.

\section{Career Satisfaction}

Educator career satisfaction is presented as a multifaceted construct (Shann, 1998). Overall satisfaction with one's teaching career can mitigate the effects of jobrelated stress. This is important given that stress appears to be an inherent aspect of working in the field of education. Nearly three quarters of the participants in a 1995 MetLife survey of teachers reported experiencing job-related stress at least once or twice per week (Latham, 1998). Despite the frequency of stress reported, however, teachers participating in the MetLife survey also indicated that they derived more satisfaction from teaching in 1995 than was the case a decade previously. The percentage of those rating themselves as very satisfied with their careers increased to $54 \%$ in 1995 from $44 \%$ in 1985. The benefits of promoting teacher career satisfaction include reduced educator 
attrition, enhanced educator functioning, a positive school climate of collegiality, and improved student performance (Woods \& Weasmer, 2002).

According to Danielson (2002) and Surpuriya and Jordan (1997), it appears that the majority of teachers who exit the teaching profession may do so within their first three years of teaching, and half of those may leave before completing a full year. Furthermore, as many as $50 \%$ of new teachers may leave the profession within five years of commencing a career in education (Danielson, 2002; Woods \& Weasmer, 2002). This leaves little time for administrators and co-workers to identify and address their new colleagues' distress or dissatisfaction with teaching. However, a lack of consensus on when teacher defection is at its highest was discussed by Rosenholtz and Simpson (1990) who noted that some researchers reported a peak at the earliest stage of teaching careers while others depicted a curvilinear relationship. Thus, debate continues as to whether the highest rates of exiting are at the beginning and end of careers, or at the mid-career point. Latham (1998) suggested that career satisfaction does not appear related to such extrinsic factors as school level (elementary, middle, high) or location (urban, rural, suburban). Likewise, Baughman (1996) noted no significant correlations between satisfaction and age, level of education, gender, salary, or years of experience. This challenged Ma and MacMillan's (1999) findings that female teachers report more job satisfaction than males, and that length of time in the teaching profession is inversely related to satisfaction attained.

Highly satisfied teachers are depicted as being spontaneous and creative, dedicated, less inhibited, and able to enjoy solitude as well as the company of others. They describe a sense of control over their work, healthy self-respect, and psychological 
integration reflected in a low degree of self-conflict (Truch, 1980). Teachers who report fulfillment enjoy working with students and derive satisfaction from seeing them grow and develop (Brunetti, 2001; Latham, 1998; Stanford, 2001). They demonstrate a passion for teaching, and value both autonomy and collegiality (Brunetti, 2001).

A high degree of communication and collaboration promotes career satisfaction (Latham, 1998), as does a sense of being part of a team (Stanford, 2001). Similarly, highly satisfied educators endorse and call upon a support network of family, friends, colleagues, and church community members (Stanford, 2001). Isolation is perceived as a threat to satisfaction (Danielson, 2002).

Brunetti (2001) acknowledged that satisfied educators are disappointed when students do not achieve success, but do not assume personal responsibility for their students' performance. This approach is consistent with the concept of healthy career engagement. Shann (1998) reported that positive teacher-pupil relationships contribute most to satisfaction and negative parent-teacher relationships elicit the most concern.

Workplace conditions are identified as a factor in the degree of teacher satisfaction and include control and competence at the administrative level, teacher excellence, and a positive school climate (Ma \& MacMillan, 1999). Cheng (1996) referred to this as a climate of professionalism in which teachers demonstrate higher esprit, more positive attitudes toward their careers, and less disengagement. Baughman (1996) described such an environment as one characterized by engagement, high morale, supportive staff, trust, and friendship. In a healthy work atmosphere, teachers are involved in decision-making (Shann, 1998), intrinsic rewards are valued more than 
extrinsic rewards (Latham, 1998), and mentoring is viewed as an avenue to increased teacher satisfaction (Danielson, 2002; Surpuriya \& Jordan, 1997).

Friedman and Farber (1992) conducted a study with Israeli teachers and found support for the idea that it is possible for teachers to experience significant work-related stress and yet report career satisfaction and fulfillment. The authors noted that professional satisfaction carried the most weight in conferring immunity to burnout and that satisfaction derived from positive professional self-concept. They observed also that professional self-concept tended to reflect teacher self-perceptions and student perceptions of their competence and job satisfaction, rather than perceptions of administrators and parents. These finding are congruent with Stamm's (1999) hypothesis that compassion satisfaction (reflecting satisfaction with one's role as a helper) confers protection from compassion fatigue.

\section{Burnout}

The construct of burnout was first researched in human services workers in the 1970s (Vandenberghe \& Huberman, 1999). Freudenberger coined the term in 1974 to describe the conditions of physical and emotional exhaustion witnessed in employees of alternative health care institutions (Berg, 1994; Wearne, 1991; James \& Gilliland, 2001; Salston \& Figley, 2003; Williams \& Davis, 2002 ). Similar to the risk factors for compassion fatigue, Freudenburger postulated that overcommittment and overdedication would predispose helping professionals to burnout (Dane, 2000). Figley and Salston (2003) credited Maslach with the comprehensive exploration and development of the construct of burnout from the mid-1970s on. Maslach and colleagues became renowned pioneers in this field of research as they surveyed thousands of employees and 
interviewed hundreds more in their quest to understand better the nature of burnout and its causes (Maslach and Leiter, 1999). Kottler and Hazler (1997) subsequently proposed that the term rustout might be more fitting since the condition refers to a gradual erosion of commitment and depletion of energy. Burnout in teachers became a steady research focus during this period of time and continued into the 1990s (Brissie et al., 1988; Friedman \& Farber, 1992; Lunenburg \& Cadavid, 1992). The stress management movement of the 1980s and 1990s was a preventative response to concerns about burnout in the workplace (Gibson \& Mitchell, 1999).

Friedman (1995) acknowledged that while burnout and stress are distinct phenomena, it is difficult to clearly distinguish between the two. He opined that stressful conditions have the potential to lead to burnout in teachers if not ameliorated. Thus, burnout is perceived to be a process rather than a discrete event. Kottler referred to burnout as an "insidious and progressive condition" (1999, p. 131). Burnout results from multiple, cumulative stressors and is relatively predictable in its course (Figley, 1995; James \& Gilliland, 2001). Figley (1995) contrasted this with compassion fatigue that may have a sudden and unexpected onset after exposure to another's traumata.

Burnout continues to present a serious challenge to the education system (Center for Mental Health in Schools at UCLA, 2004; Gold \& Rothman, 1992). After reviewing the literature on burnout, Farber (as cited in Schaufeli \& Daamen, 1994) concluded that the incidence of burnout in American teachers ranges between 5 and 20\%. A study of 1,017 teachers in Israeli schools found that one-quarter of the participants were contemplating leaving the profession, and one-half reported emotional exhaustion due 
to teaching (Friedman \& Farber, 1992). In the Netherlands, $60 \%$ of teachers receiving disability pensions reported stress-related disorders in their claims. This rate is twice that found in other occupations (Schaufeli \& Daamen, 1994). Corrigan (1994) identified teacher burnout as the most pressing problem faced by schools. He also predicted a teacher shortage, given the high rate of departing teachers and declining enrolment in teacher education programs.

Burnout is defined as changes in the attitude, behavior, and physical health of individuals that gradually erodes their ability to perform to potential. This deterioration of spirit is most commonly observed in those in the helping or people-oriented professions (Center for Mental Health in Schools at UCLA, 2004; Friedman, 1995; Truch, 1980). Often, the strain arising from stressors associated with teaching leads to the development of maladaptive coping strategies (Lunenburg \& Cadavid, 1992). However, burnout is not perceived as due to a lack of ability or desire to succeed (Brock \& Grady, 2000).

Farber (2000) described three types of burnout. The first was depicted as a wearing out of the professional who becomes overwhelmed, is unable to manage jobrelated stress, and gives up. This would be consistent with the concept of disengagement in the career engagement model proposed in this dissertation. The second type of burnout was referred to as classic burnout in which the individual works increasingly harder in the face of stress. This subtype is congruent with the overengagement concept of career engagement. The third form of burnout was one in which the individual disengages due to understimulation, monotony, and stagnation. While this latter subtype could also align with the disengagement section of the career engagement continuum, it is less likely to be 
encountered in the field of education where frequent stressors, changes, and demands for new learning and adaptation generally preclude stagnation.

The characteristics of burnout include a loss of interest in teaching, becoming cynical, and withdrawing from co-workers. Educators describe feeling exhausted and overwhelmed (Brock \& Grady, 2000) Physical, emotional, and attitudinal exhaustion lead to chronic tiredness, sleep difficulties, guilt, depression, and frequent minor illnesses (Friedman, 1991). Educators display discontentment, detachment, dehumanization or robot-like behavior, negativity, anger, rigidity, and suspiciousness. Absenteeism alternates with behavior and attitudes that suggest they are just putting in time (Truch, 1980). Educators are no longer able to derive happiness and fulfillment from their work (Vann, 1995). This may be due in part due to negative professional self-evaluation (Friedman, 1993). Burnout may be so extreme that educators wake up each morning dreading the day that awaits (Stern \& Cox, 1993). According to Friedman, this level of distress may lead ultimately to a "nervous breakdown" (1991, p. 325).

The outcome of burnout is educators who either may leave the profession prematurely or continue to go through the motions with decreased effectiveness and productivity (Brissie et al., 1988; Brock \& Grady, 2000; Friedman, 1993; Truch, 1980). In a sample of teachers described by Truch (1980), one-third said they would not select teaching if they were to choose again, and only $60 \%$ planned to teach until retirement. Ninety percent of the sample reported stress, with $20 \%$ describing teaching as very stressful or extremely stressful. A full $95 \%$ identified the need for stress management training. Truch (1980) noted that an increased number of younger teachers were leaving within their first five years of practice and more senior teachers were retiring earlier. 
Another outcome of teacher burnout is the detrimental effect on the learning of the students involved. They become casualties of educators' decreased motivation and enthusiasm (Stern \& Cox, 1993). Apathy becomes contagious when educators disengage by remaining seated behind their desks to avoid contact with students and the subject matter. Friedman and Farber (1992) went even further to suggest that the contagion effect of teacher burnout and stress impacts the lives of teachers, administrators, students and their respective families, and filters through to affect all of society.

Truch (1980) contended that being responsible for people rather than things, is one of the causes of burnout due to the increased stress associated with interpersonal responsibility. In addition, he attributed a greater risk for burnout to being identified as a Type "A" personality because of the perfectionist, rigid, and exacting standards set by such individuals. An inability to say no or to delegate also may be a precursor to burnout when educators overextend themselves as they continue to assume new duties and responsibilities and to take on new projects (Stern \& Cox, 1993; Vann, 1995).

A psychodynamic existential etiology of burnout was postulated by Pines (2002), who suggested that teachers seek existential meaning through their work, and select teaching for psychodynamic reasons. This purported existential aspect of burnout was supported by a comparative study of teachers in Israel and the United States. A lower level of burnout in Israeli teachers was noted despite the higher levels of stress recorded. It was presumed that the meaningfulness attached to their work by the Israeli teachers conferred a certain degree of immunity to the effects of stress (Pines, 2002).

Lunenburg and Cadavid's (1992) study of burnout in teachers concluded that there is a greater risk of burnout in those who exhibit an external locus of control and 
who adopt a custodial orientation toward student behavior management and discipline. An external locus of control was found to be associated with depersonalization in teaching interactions and a decreased sense of personal accomplishment. Due to their external locus of control, these teachers tended to see student-related problems as insurmountable rather than within their ability to overcome. Additionally, frustrations encountered in dealing with student control issues in a rigid and authoritarian manner engendered learned helplessness in teachers espousing a custodial orientation.

Brissie and colleagues (1988) noted that teacher burnout could be attributed to both individual variables such as total years taught, years taught in the current school, and degree level attained, as well as to variables related to the school environment such as organizational rigidity, peer support, and administrative support. Higher correlations were found for the systemic variables as compared to individual status variables. Friedman (1991) supported this notion of dual causality, attributing burnout to teacher background and demographic variables of age, sex, level of education, and experience, as well as to environmental variables of pedagogical environment (educational goals and teacher qualifications), administrative environment (hierarchy, roles, participation in decisionmaking, and in-service training), and physical environment (cleanliness and multipurpose spaces). The results of Friedman's (1991) study of 1,597 elementary teachers who engaged in an interview and completed a modified version of the Maslach Burnout Inventory indicated that teachers in high-burnout schools tended to be older, male, with lower levels of education, and lengthier experience. High-burnout schools tended to be highly structured with an emphasis on hierarchy, formality, cleanliness and orderliness, low noise level, and rigid focus on academic achievement. 
Bryne (1998) emphasized the influence of uncaring administrators and students to the development of teacher burnout, and acknowledged that the personal problems of students may present barriers to teaching and learning success. Wearne (1991) identified contributing organizational factors related to perceived control of the work environment, access to and use of social supports and feedback, and leadership and management style of administrators. In examining burnout across occupations, Maslach and Leiter (1999) emphasized organizational as opposed to individual factors in burnout. Their research supported a six-factor model of burnout etiology; minimization of the risk for burnout requires a reasonable workload, opportunity to exercise personal control, extrinsic as well as intrinsic rewards, the perception of a work community, a sense of fairness, and common values.

Some authors suggested that there may be a gender factor associated with the rates and nature of burnout. In a study in which 362 educators completed the Maslach Burnout Inventory that explores three facets of burnout, males scored higher than females on the depersonalization and emotional exhaustion subscales (Burke at al., 1996). Additionally, teachers indicated higher levels of burnout than administrators on these two subscales. In contrast, administrators received higher scores in the area of personal accomplishment burnout, indicating that they were dissatisfied with their sense of accomplishment. It bears noting that a higher percentage of administrators in this study were male, and a higher percentage of teachers were female, possibly confounding apparent gender differences. The primary factor contributing to burnout in administrators was the red tape associated with the bureaucratic nature of the education system, while 
behaviorally challenging students represented the primary factor for teachers (Burke et al., 1996).

As was the case in the exploration of career satisfaction, disagreement exists as to whether the highest rates of burnout occur at the beginning of an educator's career or at mid-career (Rosenholtz \& Simpson, 1990). Supporting a curvilinear proposition, Friedman (1991) suggested that the rate of teacher burnout is positively correlated with increasing age until it reaches a peak at age 41-45, after which the incidence declines. Despite the lack of consensus about a burnout timeline, however, what is agreed upon is the reality that teachers are now confronted with greater demands on their time and energy, fewer resources, and fewer extrinsic and intrinsic rewards than in previous decades (Center for Mental Health in Schools at UCLA, 2004; Corrigan, 1994; Schaufeli \& Daamen, 1994).

Surpuriya and Jordan (1997) observed that as a group, teachers in the United States are older, better educated, and more experienced than has ever been the case before. Approximately two-thirds are over the age of 40, more than one-half hold a Master's degree or have attended university for at least six years, and the average number of years taught is 16 . However, the increase in maturity and preparedness for teaching has been accompanied by an increase in demands not addressed in teacher training. Teachers are being confronted with challenges that would previously have been the domain of parents, physicians, clergy, law enforcement officers, and mental health practitioners. Educators can no longer rely on support from students' homes due to parents' own issues including difficulties with drugs and alcohol. Community issues intrude as violence is 
carried in from the neighborhood to the school in the form of assaults and gunshots

(Giggans \& Levy, 1997; James \& Gilliland, 2001).

Wearne (1991) postulated that employment within the field of education predisposes individuals to burnout due to their ongoing interactions with others who are experiencing stress. Such an observation also might be interpreted as indicative of a risk for compassion fatigue depending on whether the individual's response pattern is one of moving along with, toward, or away from the students, students' families, and colleagues who are stressed. These three options, which represent slight variations to the approaches to handling anxiety depicted by Horney (1950), coincide with the three main segments of the career engagement continuum. Moving along with, or accompanying others during their stressful times might be viewed as maintaining healthy career engagement. Conversely, moving away could be indicative of career disengagement possibly leading to burnout, while moving toward might be conceptualized as career overengagement possibly leading to compassion fatigue due to the dissolution of boundaries between self and other.

Wearne also noted the systemic effects of burnout resulting from environmental contamination. "Due to the very nature of educational settings, students and faculty alike bear the burden of another's health issues due to the ripple effect" (1991, p. 16). Again, the outcome alluded to here could be compassion fatigue rather than burnout. Emotional contagion is more suggestive of psychological connection than disconnection with another's woes. If the helping relationship is characterized by caring and compassion, the educator may be more inclined to overengage than disengage in his/her interactions with the individual in need. 
In their study conducted with Dutch teachers in the Netherlands, Schaufeli and Daamen (1994) found that compared to workers in other occupations, teachers reported higher levels of emotional exhaustion, fewer indicators of depersonalization, and a greater sense of personal accomplishment, as measured by the Maslach Burnout Inventory. Teachers also experienced greater psychological strain (anxiety, depression, irritability) and somatic distress. Given that the teachers' presentation did not involve a withdrawing from their pupils, nor a reduced sense of accomplishment, one might question whether this profile is more indicative of compassion fatigue than of burnout.

\section{Compassion Fatigue}

Compassion fatigue is a relatively new construct in the field of psychotraumatology. The term was introduced by Joinson (1992) to describe the experiences of those in the nursing profession who were overwhelmed and exhausted not only from the stress and demands of the occupation, but also from the investment of energy in caring and compassionate relationships with their patients. Since then, the phenomenon of compassion fatigue in other helping professions has been explored by a number of researchers (Edwards, 1995; Figley, 1995; Gentry, Baranowsky, \& Dunning, 1997; Janik, 1995; Jenkins \& Baird, 2002; Stamm, 1999).

Figley first applied the concept of secondary traumatic stress (which he later referred to as compassion fatigue) to PTSD-like symptoms in 1991 (Stamm, 1997). At times, the term compassion fatigue has been used synonymously with those of burnout, vicarious traumatization, and/or secondary traumatic stress, although debate continues about the nuances of these related descriptors (James \& Gilliland, 2001; Sexton, 1999). 
Stamm (1997) observed that in contrast to compassion fatigue, exposure to traumatic stories and events is not a prerequisite for developing burnout.

As the construct of compassion fatigue evolves, it appears to be encapsulating a condition whereby the helping professional experiences the triad of traumatic sequelae of intrusive, avoidant, and arousal symptomatology due to indirect exposure to another's trauma and possible restimulation of one's own traumatic memories. It may be conceived of as the cost of caring as helping professionals share in the aftermath of traumatic events in their clients' lives. Morrissette (2001) offered the following definition of compassion fatigue: "Compassion fatigue has been defined as a state of tension and preoccupation with individual or cumulative trauma of clients as manifested in one or more ways, including (a) reexperiencing the traumatic event, (b) avoidance or numbing of reminders of the event, and (c) persistent arousal" (p. 140).

Rudolph, Stamm, and Stamm (1997) described compassion fatigue as the presence of PTSD symptoms that generally are related to the client's Criterion A traumatic event and blended with the helper's life experiences. Although a cumulative component is often associated with compassion fatigue, the onset can be rapid. The good news is that recovery from compassion fatigue is held to be faster than recuperation from burnout if appropriate interventions are implemented (Sexton, 1999).

Working with victims of trauma can change helpers' worldviews due to assumptions about the predictability of an orderly world, invulnerability, fairness, and personal efficacy being shattered (Janoff-Bulman, 1992; Matsakis, 1996). As is the case with primary victims of trauma, professionals dealing with compassion fatigue experience alterations in their sense of safety, trust, control, esteem, and intimacy. It is 
difficult, if not impossible, to find meaning in the trauma suffered by others (Rosenbloom \& Williams, 1999). Bearing witness to the pain of clients transforms helping professionals (Charney \& Pearlman, 1998; McSwain, Robinson, \& Panteluk, 1998). Pearlman and MacIan described "the transformation that occurs with the therapist (or other trauma worker) as a result of empathic engagement with clients' trauma experiences and their sequelae" (1995, p. 558).

Edwards (1995) and Pfifferling and Gilley (2000) acknowledged the emotionally draining experience of working with traumatized clients and the difficulty in trying to maintain the optimum degree of engagement with respect to a balance between empathy and objectivity. To be effective, professionals must not overly distance themselves as a self-protective measure, nor become caught up in reliving the client's trauma. Strategies for preventing the development of compassion fatigue include leading a balanced life, maintaining boundaries between one's professional and personal worlds, and seeking therapy and supervision.

Figley (1995) noted that helping professionals can become obsessed with, and consequently incapacitated by, the traumata of their clients. Figley suggested that mental health professionals are at particular risk for compassion fatigue not only because of their encounters with victims of trauma, but also due to their caring and empathic natures. $\mathrm{He}$ expressed concern that helping professions stand to lose highly dedicated professionals due to unidentified or untreated compassion fatigue.

Gentry, Baranowsky, and Dunning (1997) identified the provision of aid to others as a risk factor for compassion fatigue and suggested that emergency services personnel, medical and mental health providers, lawyers, police, and shelter workers are possible 
candidates for the diagnosis. Research exploring work-related secondary trauma also examined exposure in Holocaust Memorial Museum workers, jurors, clergy, and media eyewitnesses to executions (Stamm, 1997).

Janik (1995) became alerted to the risk of compassion fatigue in correctional officers after reflecting on his early professional experiences. His secondary traumatization manifested in heightened safety concerns for his family and increased protectiveness toward his daughter, after a psychiatric inpatient inmate shared traumatic tales both from the perspective of victim and perpetrator. Janik's metaphor of sin-eater depicted the role that corrections officers play in carrying the "toxic and corrosive ideas, images, memories and experiences of the offenders they work with" (1995, p. 163).

Surprisingly, the issue of compassion fatigue in educators appears to have been neglected. Conspicuously absent in the lists of occupations at risk are educators at any level, despite the caring and compassion that characterizes their relationships with students who present with a plethora of critical incidents and crises. In the literature reviewed, only Conrad and Perry (2000), Kees and Lashwood (1996), and Thompson (2003a), warned of the risk of secondary trauma and compassion fatigue in teachers. Kees and Lashwood (1996) lamented the paucity of research and literature on the phenomenon of compassion fatigue in educators. They noted that studies of compassion fatigue and secondary traumatic stress to date have focused on front line emergency workers, and mental health professionals and family members who help victims in the aftermath of traumatic events. However, the authors contended that educators serve both as front line workers and as those who guide the subsequent healing process. Educators are subject to both primary and secondary traumatization as their own prior traumata are 
restimulated or triggered in the context of assisting traumatized students. Thus, educators who are confronted with their students' critical incidents or crises are at risk for developing compassion fatigue. The symptoms of compassion fatigue mirror the traumatic response of primary survivors but are focused on the student's traumatic experience (Kees \& Lashwood, 1996).

Nias (1999) depicted burnout as a possible outcome of the moral value of caring for students that is espoused by many teachers. Nias noted that if teachers failed to observe the resultant symptoms of stress and to engage in self-care, a full-fledged condition of burnout might ensue. It is the aim of this study to foster closer inspection when a stress response transpires, for refined assessment may reveal that the educator is manifesting signs of compassion fatigue in addition to, or rather than, burnout.

\section{Impact of Trauma in the School Setting}

Historically, there has been a limited number of psychiatrists actively involved in addressing the impact of childhood traumatic stress (Cohen \& Mannarino, 1998). This is believed due to a lack of emphasis during training and residency. Falasca and Caulfield (1999) noted the recent interest in the impact of trauma on children, a group traditionally overlooked due to the mistaken belief that children did not possess the requisite cognitive ability to truly comprehend and therefore suffer from the horror of traumatic incidents.

Falasca and Caulfield (1999) noted the difficulty in operationally defining a traumatic incident, owing to factors such as: children's stage of development, ability to adapt and cope, support system, role as victim or witness, the nature of the event, and whether the event was an isolated event or is ongoing. However, it is generally agreed that certain circumstances almost inevitably lead to a perception of trauma. These include 
natural disaster, loss of a significant other through sudden death or illness, sudden or prolonged threat to the child's life, acts of violence, and sexual abuse (Alexander, 1999; Brooks \& Siegel, 1996; Deskin \& Steckler, 1997; Falasca \& Caulfield, 1999; Freyd, 1996; Horton \& Cruise, 2001; Porterfield, 1996; Schaefer \& Lyons, 1993; Tinker \& Wilson, 1999). Richards and Bates (2000) extended the risk for traumatization beyond a child's directly experiencing or witnessing an event, to the indirect learning of famine, sexual or physical assault, murder, brutality, and natural disaster.

Despite difficulties in clearly delineating traumatic experiences, Everly and Lating (2002) reported a childhood trauma prevalence rate of approximately $40 \%$. For example, Faraone (2003) found that $60 \%$ of children who had sustained moderate injuries due to a biking or car accident, demonstrated signs of PTSD more than one month later. Six months later, $40 \%$ of this sample continued to experience PTSD symptomatology. Among those children who witnessed a school shooting, 75\% met criteria for PTSD. (Faraone, 2003).

Falasca and Caulfield (1999) divided trauma symptoms into three categories of memories, affect, and behaviors. Richards and Bates (2000) similarly categorized symptoms under the headings of cognitive, affective, and behavioral, and added somaticphysiological. Children may respond to traumatic events in a hyperresponsive manner, with anxiety and hyperactivity, or in a hyporesponsive manner, manifested in social and emotional withdrawal. The child responding in the former manner will more typically demonstrate increased affectivity in the form of irritability, anger, and rage, whereas the latter is associated with decreased affectivity and emotional constriction (Falasca \& Caulfield, 1999). 
Stronach-Buschel (1990) identified the shattered assumptions that result from children's experience of trauma. Traumatized children lose faith in the existence of a safe place to reside inside or outside of the self. Order and continuity in life are no longer taken as givens. Children may attempt to ward off the full impact of the trauma through the use of defense mechanisms such as denial, denial in fantasy, dissociation, isolation, regression, projection, and splitting (Brooks \& Siegel, 1996; Fitzgerald, 1992; Freyd, 1996; Johnson, 1999; Schaefer \& Lyons, 1993; Stronach-Buschel, 1990; Tinker \& Wilson, 1999; Wolfelt, 1991). Paradoxically, as children seek to avoid re-experiencing the trauma, they may become compulsively engaged in repetitive play and re-enactment (Cuffe \& Shugart, 2001; James \& Gilliland, 2001; Levine, 1997; Porterfield, 1996).

A marked decrease in the ability to use symbols and mental images is noted in traumatized children. Consequently, such children rely on motoric rather than reflective verbal responses, and act out anger, fears, and guilt rather than talking or writing about them. Impulse inhibition is observed when children identify with the aggressor or harbor revenge fantasies. In the event of parents as perpetrators, children may displace the malevolent image onto another or onto the self, in order to preserve the dependent relationship (Freyd, 1996; Stronach-Buschel, 1990).

Professionals working with children who have been traumatized by exposure to domestic violence need to be cognizant of the potential for developmental disruption to occur as a result of the trauma. Short-term effects of such trauma may include withdrawal, depression, abnormal fears, regression, decline in academic achievement, absenteeism, truancy, bullying or increased victimization, interpersonal difficulties, impulsivity, denial of the incident, or rumination and preoccupation (Fisher, 1999). 
Armsworth and Holaday (1993) noted that psychological trauma effects in children include academic and learning difficulties, lowered IQ, developmental delays, poor language and communication skills, withdrawal, depression, fatalistic outlook, belief in omens, inability to read social cues, rejection by peers, cruelty to animals, preoccupation with sexuality and sexual acting out (in the sexually abused), failure-to-thrive syndrome, pain agnosia, and biochemical alterations in the brain. Secondary and associated responses to abuse trauma include depression, aggression toward oneself and others, decreased self-esteem, disturbances in identity, difficulties in interpersonal relationships, and guilt and shame (Carlson \& Furby, 1997). Richards and Bates (2000) augmented the list of traumatic sequelae with the addition of constricted emotion, distress at reminders of the trauma, traumatic dreams, regressive behavior, re-enactments, avoidance of previously enjoyed activities, and exaggerated startle response.

The evaluation of the family and environmental context includes consideration of factors including socio-economic status, approaches to discipline, caretaker substance abuse, mental disorders and suicidality in the family, and domestic violence (Carlson \& Furby, 1997). Trauma treatment in children needs to be approached systemically, with recognition that non-offending caretakers are automatically at risk for vicarious traumatization by virtue of being in a care-giving role (Herbert \& Wetmore, 1999; Monahon, 1993; Parkinson, 1993). Unresolved issues may be triggered for parents, and a sense of isolation and feeling overwhelmed may result from uncertainty as how to lead their children on a path to healing (Falasca \& Caulfield, 1999). Conversely, when it is the parents who have been traumatized, there is a risk of transmitting the traumatic symptomatology to their children. This is referred to in the literature as multigenerational 
transmission (Harris, 1998) and has been researched extensively in children of Holocaust survivors.

Acute stress responses are those that follow in the first month after the traumatic incident (APA, 2000). If left untreated, these responses may lead to post-traumatic stress disorder, and later be associated with adolescent maladaptive conduct such as substance abuse, and aggressive or violent behavior (Harris, 1998). A high percentage of students in special programs for the emotionally and behaviorally disturbed have a history of trauma (Fisher, 1999).

Children who witness or experience domestic violence are more likely to become perpetrators as adults. Likewise, children who were involved in pornographic activity or sexual activity with other children or adults run a greater risk of becoming adult sexual offenders. The death of a family member to domestic violence is devastating to a child who may have been exposed to unimaginable horror, is now deprived of a future with a significant other, may be experiencing guilt for not having intervened, and who may lose the other parent to incarceration (Fisher, 1999). Virtually all children who observe the murder of a parent go on to develop PTSD (Faraone, 2003).

The past few decades have borne witness to increased demands upon educators to address the needs of the whole child rather than focus solely on academics. Discipline is no longer meted out in the form of corporal punishment, and with this more humane development there has been a concomitant emphasis on unearthing the underlying etiology in a child's behavior. This same dedication has been applied to determining causal factors in a child's academic underachievement or failure to form satisfying interpersonal relationships with peers. Bryne (1998) noted that students who are faced 
with unstable home lives, drug problems, and violence, may be more in need of a social worker than a teacher focused on academic accomplishment.

This more holistic approach has been one factor in educators becoming apprised of their students' life experiences beyond the walls of the classroom. Additionally, the increased societal and circumstantial stressors experienced by families have spilled over into the school setting. Parents faced with financial difficulty, unemployment, divorce or bereavement, illness and injury, and spousal or child abuse concerns, are much more inclined to reach out to those in the school system for advice and assistance. Few others know their child as intimately as the child's teacher, who is turned to as a resource in a time of need. School staffs have become accustomed to supporting families in a number of ways, including: offering a listening ear, making referrals, directing families to appropriate resources, and assisting families with financial and material needs.

The benefits of this more intimate involvement with students and their families lie in enhanced rapport with students and their parents and a stronger home and school connection. The downside of this closer relationship is the toll it takes on dedicated educators who internalize the pain and suffering of an increasing number of wounded students and families. Educators may become secondarily traumatized by virtue of sharing students' or parents' primary traumata. Care and compassion exact a cost as educators strive to meet the needs of students and families in an era of decreased human and material resources. A pattern of overengagement may predispose educators to compassion fatigue. Eventually this may lead to disengagement and burnout.

In a study of trauma workers, Arvay and Uhlemann (1996) noted that $14 \%$ of the counselors reported levels of secondary traumatic stress similar to the levels of traumatic 
stress associated with post-traumatic stress disorder. These findings are striking given that they suggest an equal or higher incidence of PTSD symptomatology to that typically manifested by primary victims of traumatic events. Additionally, $16 \%$ of these counselors indicated that they were suffering from emotional exhaustion and burnout.

While it is unlikely that educators will encounter trauma in their work to the same extent as a counselor specializing in trauma, there is no doubt that traumatic events will be experienced at some point in their career (Kees \& Lashwood, 1996). Britzman and Dippo suggest that the "parade of problems can feel more like disasters of the week, catastrophic experiences of others that have the effect of splitting the world between us and them" (2000, p. 32). Lichenstein and colleagues warned that "the astute administrator does not question whether a crisis will occur, but when it will occur, how serious it will be, and what the response should be" (1994, p. 80). The nature of the trauma will be primary in some instances as educators experience serious illness, accidents, and sudden loss of loved ones firsthand. There most definitely will be indirect experiences with the trauma of others, as students, their families, and educators' colleagues share stories of horror and helplessness.

For example, more than $10 \%$ of all assaults committed in the United States have been reported as occurring in schools or on school property (Bryne, 1998). This statistic includes assaults perpetrated against both students and teachers. Assaults represent the third highest precipitant of student injury in the school environment, surpassed only by falls and sports injuries (Giggans \& Levy, 1997). In descending order, the range of assaults encompasses: beatings, firearm discharge, pushing and shoving, stabbing, and blunt object trauma. Almost one-half of the victims of the assaults are aged 10-14, while 
nearly one-fifth are students aged 5 through 9 (Giggans \& Levy, 1997). In the American school environment, the reported presence of street gangs rose from $15-28 \%$ during the period 1989-1995, and in 1996-97 over 6,000 students were expelled for possession of a firearm on school property (Evans \& Rey, 2001). One in 25 students reportedly brought a gun to school in the United States in 1990 (Giggans \& Levy, 1997). Educators' exposure to assault and weapons offenses may lead to primary or secondary traumatization, the latter in the form of vicarious traumatization and/or compassion fatigue.

Summary of Literature Review

As the review of the literature has demonstrated, empirical research in the area of compassion fatigue in educators is not yet extant. To date, the bulk of the research conducted on quality of career engagement in this population has focused on career satisfaction and burnout. Although the effects of trauma in a variety of populations have been explored for several decades, the diagnostic category of post-traumatic stress disorder did not officially exist until its inclusion in the third edition of the DSM in 1980 (APA, 1980). Historically, trauma research focused on the experiences of direct victims. The study of the impact of secondary trauma, vicarious trauma, and compassion fatigue is still in its nascent period, having had its genesis in the 1990s.

The DSM's (APA, 1980) formal acknowledgment of the constellation of intrusive, avoidant, and hyperarousal symptomatology associated with PTSD, paved the way for studies of indirect trauma that emerged in the following decade. The original focus was on front line workers such as police officers, firefighters, rescue workers, and emergency medical technicians who met trauma victims at or near the site of the trauma. Gradually, recognition dawned that even those who were further removed geographically 
and temporally from the trauma site were being impacted as they bore witness to the primary victims' tales of horror and helplessness. Counselors, psychologists, psychiatrists, clergy, social workers, nurses, physicians, and even lawyers were beginning to manifest signs of post-traumatic stress as the result of empathic engagement with their clients.

Over the past decade, research literature has addressed the increased rates of traumatic experiencing reported in school communities. Reports of car and bus accidents, accidental skiing deaths or drowning while students are on a school-sponsored trip, house fires, domestic violence, murders, suicides, community disasters, and school shootings are not uncommon, and no societal stratum is spared. Studies of the effects of trauma on children's cognitive, affective, social, and neurophysiological development have greatly augmented our understanding of the serious repercussions of isolated and chronic exposure to overwhelming and horrific life events.

What remains to be studied are the effects on public school educators of bearing witness to traumatic events affecting the students and colleagues with whom they spend such a large chunk of their waking hours, and with whom they develop close, caring relationships.

The void in the professional literature on compassion fatigue in teachers highlights the possibility that educators may at times have been misidentified as suffering from burnout. The current study aimed to clarify the extent to which public school educators evince signs of career satisfaction, burnout, and compassion fatigue that are posited to relate to healthy career engagement, disengagement, and overengagement, respectively, on the career engagement continuum. In particular, this exploratory study 
sought to determine the degree to which compassion fatigue may be a significant issue for educators, and whether it warrants further study and research. Specific research questions follow.

\section{Research Questions}

RQ1. To what degree are educators reporting healthy career engagement, career disengagement, and career overengagement?

RQ1a. To what degree are educators reporting healthy career engagement? With what frequency do they surpass the upper quartile cut-off score on the Compassion Satisfaction subscale of the Professional Quality of Life: Compassion Satisfaction and Fatigue Subscales - Revision III (ProQOL-CSF-R III), thus endorsing this aspect of career satisfaction? Additionally, with what frequency do educators score below the lower quartile cut-off score on the ProQOL-CSF-R III, indicating dissatisfaction?

RQ1b. To what degree are educators reporting career disengagement? With what frequency do they surpass the upper quartile cut-off score on the Burnout subscale of the ProQOL-CSF-R III?

RQ1c. To what degree are educators reporting career overengagement? With what frequency do they surpass the upper quartile cut-off score on the Compassion Fatigue subscale of the ProQOL-CSF-R III?

RQ2. What is the relationship between career fulfillment, burnout, compassion fatigue, and level of traumatic stress in those respondents with an identified history of primary trauma? Specifically, what are the correlations between each of the subscales (Compassion Satisfaction, Burnout, and Compassion Fatigue) of 
the Professional Quality of Life: Compassion Satisfaction and Fatigue Subscales Revision III (ProQOL-CSF-R III), and the Traumatic Stress Response total score of the Impact of Event Scale - Revised (IES-R) for those who have identified a history of primary (direct) trauma?

RQ3. What is the relationship between career fulfillment, burnout, compassion fatigue, and level of traumatic stress in those respondents with an identified history of secondary trauma? Specifically, what are the correlations between each of the subscales (Compassion Satisfaction, Burnout, and Compassion Fatigue) of the Professional Quality of Life: Compassion Satisfaction and Fatigue Subscales - Revision III (ProQOL-CSF-R III), and the Traumatic Stress Response total score of the Impact of Event Scale - Revised (IES-R)for those with a history of secondary (indirect) trauma?

RQ4. Are elementary educators more inclined to experience compassion fatigue than those in middle school, high school, and technical school settings?

Specifically, what does an analysis of variance (ANOVA) indicate when three categories of elementary, middle, and high/technical school educators, are utilized as the independent variable (Educator Level), and the Compassion Fatigue subscale of the Professional Quality of Life: Compassion Satisfaction and Fatigue Subscales - Revision III operates as the dependent variable?

RQ5. Are classroom teachers (including subject and specialist teachers) at all levels more inclined to experience compassion fatigue than guidance counselors and administrators? Specifically, what does an ANOVA indicate when the three categories of classroom teacher, guidance counselor, and administrator are used as 
the independent variable (Educator Category), and the Compassion Fatigue subscale of the Professional Quality of Life: Compassion Satisfaction and Fatigue Subscales - Revision III serves as the dependent variable?

RQ6. To what degree do the demographic characteristics of current position, assignment level, school population, school location, number of years in the field of education, number of years in current position, employment status, age, gender, ethnicity, current salary, and highest level of education attained, relate to measured levels of career satisfaction, burnout, and compassion fatigue? Specifically, does a correlation matrix crossing demographics with the three indicators of career engagement yield any significant correlations? Of particular interest is whether a clear relationship exists between years of experience and quality of career engagement.

RQ7. Considering the potential predictors of (1) demographic characteristics (current position, assignment level, school population, school location, number of years in the field of education, number of years in current position, employment status, age, gender, ethnicity, current salary, and highest level of education attained), (2) direct and indirect trauma history in personal and workplace life spheres, and (3) current trauma status as depicted by the Impact of Event Scale Revised (IES-R) Traumatic Stress Response total scores for direct and indirect trauma, what are the significant contributors to the criterion variables of (1) Compassion Satisfaction, (2) Burnout, and (3) Compassion Fatigue? 


\section{Operational Definitions}

For the purposes of this dissertation study, the variables have been operationally defined as follows:

1. Career Satisfaction

Evidence of high career satisfaction will be demonstrated by surpassing the upper quartile cut-off score (RS > 41) of the Compassion Satisfaction subscale of the Professional Quality of Life: Compassion Satisfaction and Fatigue Subscales Revision III (ProQOL-CSF-R III). Evidence of career dissatisfaction will be demonstrated by scoring below the lower quartile cut-off score $(\mathrm{RS}<32)$ of the of the Compassion Satisfaction subscale of the ProQOL-CSF-R III.

2. Burnout

Evidence of high risk for burnout will be demonstrated by surpassing the upper quartile cut-off score $(\mathrm{RS}>28)$ of the Burnout subscale of the ProQOL-CSF-R III.

\section{History of Trauma}

Completion of the History of Traumatic Experiences (HTE) will identify whether participants have no trauma history, a history of indirect trauma, a history of direct trauma, or a history of both indirect and direct trauma. The measure will also identify whether traumatic incidents were associated with participants' personal or work environments.

3. Primary Traumatic Stress

Participants' residual levels of primary traumatic stress will be ascertained by scores received on the Impact of Event Scale - Revised (IES-R), where the focus 
is on one or more traumatic events experienced directly. Three indices of Intrusive, Avoidant, and Hyperarousal Symptoms will be combined into a Traumatic Stress Response total. Total scores equaling or exceeding 33 will be considered indicative of significant primary or direct traumatic stress.

4. Secondary Traumatic Stress

Participants' levels of secondary traumatic stress will be measured by the IES-R, where the focus is on one or more traumatic events experienced indirectly. Scores for Intrusive, Avoidant, and Hyperarousal Symptoms will be combined into a Traumatic Stress Response total score. Total scores equaling or exceeding 33 will be considered indicative of significant secondary or indirect traumatic stress.

\section{Compassion Fatigue}

Evidence of high risk for compassion fatigue will be demonstrated by surpassing the upper quartile cut-off score (RS > 17) of the Compassion Fatigue subscale of the ProQOL-CSF-R III. 


\section{CHAPTER 3}

Method

The aim of the current study was to explore the quality of career engagement in public school educators as indicated by self-reported levels of career satisfaction, and risk for burnout and compassion fatigue. This chapter outlines the method incorporated in addressing the research questions. The content covered includes: research design, participant recruitment, procedure for data collection, independent and dependent variables, research instrumentation, and statistical analyses conducted.

\section{Research Design}

The current study involved exploratory research using a between subjects approach. A correlational design was adopted to determine the presence or absence of relationships between the three levels of the dependent or criterion variable of quality of career engagement, and the independent or predictor variables of participant demographics, trauma history, and current traumatization status.

\section{Participant Recruitment}

The participants in this study included classroom teachers, subject teachers, other (specialist) teachers, school counselors, and administrators (principals and assistant principals/vice-principals) working in public schools. One group was comprised of educators working with students attending Primary through Grade 12 in schools under the administration of the Annapolis Valley Regional School Board in Nova Scotia. The other group was comprised of educators working with students in Kindergarten through twelfth grade and technical students in the Monongalia County Board of Education schools in West Virginia. At the time of the study, there were approximately 1100 educators 
employed by the Annapolis Valley Regional School Board and 750 educators employed by the Monongalia County Board of Education.

Participation in this dissertation research was on a voluntary basis. Potential participants were informed that they were under no obligation to participate in the study or to complete the survey instruments if they chose to review a packet. In order to preserve anonymity and encourage participation, participants did not return a signed informed consent form. Informed consent was assumed if the participant chose to complete the survey instruments and forward them to the researcher. Educators were invited to participate in the research in the interests of furthering our collective understanding of the career engagement constructs of career satisfaction, burnout, and compassion fatigue. It was hoped that participants would represent the full range of spectra of demographic data including: current position, assignment level (elementary, middle, secondary, technical or alternate school), school population, school location (Nova Scotia or West Virginia), number of years in field of education, number of years in current position, employment status (full-time, part-time, substitute), age, gender, salary, and highest level of education attained. Although ethnicity was included as a demographic variable, it was not anticipated that many participants would endorse heritage other than Euro-American/Canadian due to the relative ethnic homogeneity of the geographical regions being sampled.

\section{Procedure for Data Collection}

Permission was requested in October 2002 from the superintendents of both the Annapolis Valley Regional School Board (requested in writing) and Monongalia County Board of Education (requested during an interview) to conduct a study of the quality of 
educator engagement as manifested in career satisfaction, burnout, and compassion fatigue. Superintendents Dr. James Gunn and Dr. Michael Vetere granted conditional permission for the research project to proceed within their respective school boards, subject to their advance perusal of the packets to be delivered to participants, and approval of the proposed study by the West Virginia University Institutional Review Board. Preliminary draft packages including the proposal abstract, demographic questionnaire, and the four research measures (History of Traumatic Experiences (HTE), two versions of the Impact of Event Scale - Revised (IES-R), and Professional Quality of Life: Compassion Satisfaction and Fatigue Subscales - Revision III (ProQOL-CSF-R III) were forwarded to Drs. Gunn and Vetere on January 5, 2004.

In a letter dated January 26, 2004, Dr. Gunn indicated that research could proceed with the staff of the Annapolis Valley Regional School Board once the researcher's dissertation committee had approved the research proposal. The proposal meeting took place February 16, 2004, and the dissertation committee granted permission to proceed to seek Institutional Review Board approval.

A meeting was held on February 27, 2004 with Dr. Vetere, Superintendent of Schools, and Dr. Harsh, Assistant Superintendent for Curriculum and Instruction for the Monongalia County Board of Education. At that time, an application to carry out the proposed research was submitted as per the Statement of Policy Regarding Research in Monongalia County Schools. Dr. Vetere agreed to write a letter confirming general approval for the investigator to undertake the proposed research with the faculty in the Monongalia County Board of Education Schools. However, Drs. Vetere and Harsh noted that it is district policy that principals have the option of choosing whether or not their 
individual schools participate in research. Dr. Vetere offered to present an overview of the study to the principals in his district during the April principals' meeting. At that meeting, he requested that principals agree to participate in the research if approached by the researcher, and that they encourage faculty involvement in their respective schools.

Approval of the proposed research was granted by the Institutional Review Board of West Virginia University on April 15, 2004. Between April 26 and May 25, a total of 300 participant packets were delivered to 9 of 23 schools (excluding Alternative Learning Centers) in the Monongalia County Board of Education. These included four elementary schools, three middle schools, one secondary school, and one technical school. Site selection was conducted with a view to attaining a cross-sampling of educators by distributing approximately 100 participant packets at each of elementary, middle, and secondary levels to those schools whose administrators were willing to invite their staff members to participate. Delivery of the principal's package and participant packets was done in person by the researcher. A brief verbal overview of the research was provided to the administrator or support staff member taking possession of the materials. At the request of the principal of one of the high schools, the researcher presented the research study at a staff meeting prior to distributing the participant packets.

Delivery of principal packages and participant packets to schools in the Annapolis Valley Regional School Board commenced upon the researcher's return to Nova Scotia at the beginning of June 2004. Between June 8 and 10, 2004, the researcher delivered, in person, principal packages and 400 participant packets to 15 of 42 schools in the Annapolis Valley Regional School Board. These included eight elementary schools, one elementary-middle school, two middle schools, two middle-secondary schools, and two 
secondary schools. Again, an attempt was made to ensure equitable allocation of packets at each of the elementary, middle, and high school levels. Reception at schools varied from interest and enthusiasm, to reluctance to accept packets. One high school administrator in a school of approximately 900 students felt that 10 participant packets were more than he would likely find willing participants to complete. Another high school administrator noted the school's proximity to a university and consequent inundation with research requests. This administrator placed a call to the school board's central office to ascertain the legitimacy of the current study, before allowing the researcher to leave participant packets.

Principal packages were addressed to the principal of the school and contained a letter of introduction (See Appendix C.), a rationale for the study (See Appendix D.), and two copies of a recruitment poster (See Appendix E.). The letter of introduction outlined the proposed study, provided a rationale for the study, identified the perceived need for such exploration, and indicated that the research was being conducted to fulfill the requirement of a doctoral dissertation. The letter also assured principals that confidentiality and anonymity would be maintained, noting that only collective results would be analyzed and that no individual analysis would be conducted. The letter advised principals that participation by their staff members was voluntary and the option of choosing not to complete the questionnaires was available.

Principals were asked to bring the research study to their staff's attention via one or more of the following ways:

1) reading the letter of introduction and description of the study at a staff meeting or similar gathering 
2) asking the school guidance counselor to present the research request to the staff

3) posting the enclosed $8{ }_{-}$x 11 " posters in the educator staff area and/or mail room The letter of introduction requested that principals leave the participant packages in an accessible location such as the staff room, so that educators could obtain a packet and complete it at their convenience. The letter noted that participant packets were to be returned individually in the enclosed postage-paid envelope, thus maintaining confidentiality of responses.

Each participant packet had the following materials enclosed:

A. A cover letter identifying the purpose of the study; and a description of procedures, risks and discomforts, alternatives, benefits, contact persons, confidentiality, and voluntary participation (See Appendix F.)

B. A rationale for the proposed study (See Appendix D.)

C. A demographic information questionnaire (See Appendix G.)

D. A copy of the following instruments:

1. History of Traumatic Experiences (HTE) (See Appendix H.)

2. Impact of Event Scale - Revised (IES-R) focusing on direct trauma (See Appendix I.)

3. Impact of Event Scale - Revised (IES-R) focusing on indirect trauma (See Appendix J.)

4. Professional Quality of Life Compassion Satisfaction and Fatigue Subscales - Revision III (ProQOL-CSF-R III) (See Appendix K.)

E. Copies of participant resources:

1. Stress Management Strategies Checklist (See Appendix L.) 
(This checklist presented an assortment of stress management approaches for educators' consideration, in the event that participation in the research engendered an elevation of psychological stress.

Educators were reminded that this instrument was not to be returned with the packet; it was for use at their discretion.)

\section{Counseling Referral Resources (See Appendix M.)}

(This enclosure provided a listing of possible referral sources, in the event that the educator determined that professional counseling was warranted based on reflections related to the research.)

\section{F. A self-addressed stamped envelope}

Participants were asked to complete all of the questionnaires in the participant packets (except the Stress Management Strategies Checklist which was optional and for their own use and disposition) and to return these in the enclosed self-addressed stamped envelope at their earliest convenience. The use of colored paper for the research measures to be returned served to make them stand apart from the materials the participants were to retain. Reminder postcards were sent to participating schools two weeks after the delivery of the research materials (See Appendix N.).

\section{Independent and Dependent Variables}

The three groups of independent variables in this study included demographic characteristics, trauma history, and current traumatization status. These variables were assessed by the Demographic Information questionnaire, History of Traumatic Experiences survey (HTE), and Impact of Event Scale - Revised (IES-R) for direct and

indirect trauma, respectively. Copies of these measures are located in Appendices G, H, I, 
and J. A summary of the independent variables, their manner of assessment, and the corresponding number of levels for each is presented in Table 1. The Scale of

Measurement column indicates how the specific independent variables were treated in the data analysis component of this study.

Table 1

Assessing the Independent Variables of Demographics, Trauma History, and Traumatization Status

\begin{tabular}{|c|c|c|c|}
\hline $\begin{array}{l}\text { Independent } \\
\text { Variable }\end{array}$ & $\begin{array}{l}\text { Scale of } \\
\text { Measurement }\end{array}$ & $\begin{array}{l}\text { Number of } \\
\text { Levels }\end{array}$ & $\begin{array}{l}\text { Assessment } \\
\text { Measure }\end{array}$ \\
\hline Current Position & Nominal & 6 & $\begin{array}{l}\text { Demographic } \\
\text { Questionnaire }\end{array}$ \\
\hline $\begin{array}{l}\text { Assignment } \\
\text { Level }\end{array}$ & Ordinal & 4 & $\begin{array}{l}\text { Demographic } \\
\text { Questionnaire }\end{array}$ \\
\hline $\begin{array}{l}\text { School } \\
\text { Population }\end{array}$ & Ordinal & 10 & $\begin{array}{l}\text { Demographic } \\
\text { Questionnaire }\end{array}$ \\
\hline School Location & Nominal & 2 & $\begin{array}{l}\text { Demographic } \\
\text { Questionnaire }\end{array}$ \\
\hline Years in Field & Ratio & - & $\begin{array}{l}\text { Demographic } \\
\text { Questionnaire }\end{array}$ \\
\hline $\begin{array}{l}\text { Years in Current } \\
\text { Position }\end{array}$ & Ratio & - & $\begin{array}{l}\text { Demographic } \\
\text { Questionnaire }\end{array}$ \\
\hline $\begin{array}{l}\text { Employment } \\
\text { Status }\end{array}$ & Nominal & 3 & $\begin{array}{l}\text { Demographic } \\
\text { Questionnaire }\end{array}$ \\
\hline Age & Ratio & - & $\begin{array}{l}\text { Demographic } \\
\text { Questionnaire }\end{array}$ \\
\hline Gender & Nominal & 2 & $\begin{array}{l}\text { Demographic } \\
\text { Questionnaire }\end{array}$ \\
\hline Ethnicity & Nominal & 5 & $\begin{array}{l}\text { Demographic } \\
\text { Questionnaire }\end{array}$ \\
\hline Current Salary & Ordinal & 9 & $\begin{array}{l}\text { Demographic } \\
\text { Questionnaire }\end{array}$ \\
\hline $\begin{array}{l}\text { Highest Level of } \\
\text { Education }\end{array}$ & Ordinal & 4 & $\begin{array}{l}\text { Demographic } \\
\text { Questionnaire }\end{array}$ \\
\hline Trauma History & Ordinal & 4 & $\begin{array}{l}\text { History of } \\
\text { Traumatic } \\
\text { Experiences }\end{array}$ \\
\hline $\begin{array}{l}\text { Traumatization } \\
\text { Status }\end{array}$ & Interval & - & $\begin{array}{l}\text { Impact of Event } \\
\text { Scale - Revised }\end{array}$ \\
\hline
\end{tabular}


The dependent variable in this study was the quality of career engagement in public school educators. The three levels of healthy career engagement, disengagement, and overengagement were determined by scores on the Compassion Satisfaction, Burnout, and Compassion Fatigue subscales, respectively, of the Professional Quality of Life- Compassion Satisfaction and Fatigue Subscales- Revised III (ProQOL-CSF-R III). A copy of this measure is located in Appendix K. The subscales used to measure each of the three levels of the dependent variable are presented in Table 2.

Table 2

Measuring the Three Levels of the Dependent Variable of Quality of Career Engagement

\begin{tabular}{|l|l|l|l|}
\hline Level & Measure & Subscale & Score Range \\
\hline $\begin{array}{l}\text { Healthy Career } \\
\text { Engagement }\end{array}$ & ProQOL-CSF-R III & $\begin{array}{l}\text { Compassion } \\
\text { Satisfaction }\end{array}$ & $0-50$ \\
\hline Career Disengagement & ProQOL-CSF-R III & Burnout & $0-50$ \\
\hline Career Overengagement & ProQOL-CSF-R III & $\begin{array}{l}\text { Compassion } \\
\text { Fatigue }\end{array}$ & $0-50$ \\
\hline
\end{tabular}

\section{Research Instrumentation}

The measures used to assess the independent and dependent variables in this proposed study included two research instruments in the public domain whose authors are renowned in the study of traumatology. Additionally, a trauma history checklist and demographic questionnaire were designed for the purposes of this study. Each of these will be discussed in greater detail below.

Demographic data. Participants completed a demographic questionnaire that requested information on 12 predictor variables: current position, assignment level (elementary, middle, secondary, technical or alternate school), school population, school 
location (Nova Scotia or West Virginia), number of years in field of education, number of years in current position, employment status (full-time, part-time, or substitute) age, gender, ethnicity, current salary, and highest level of education attained. Several of these demographic markers were selected on the basis of previous research conducted with the public educator population. These included: current position, assignment level, number of years in the field, number of years in current position, age, gender, ethnicity, and highest level of education. Subsequent to consultation with a group of established researchers, the following demographics were also incorporated: school population and employment status. School location was added to explore potential differences between the researcher's home province and state of residence during the period of doctoral study. Salary level was included at the recommendation of the researcher's dissertation committee since it was felt that salary might influence career satisfaction and could conceivably affect access to resources that could serve to act as a buffer against psychological stressors.

History of Traumatic Experiences. Participants were asked to complete a checklist exploring their history of primary and secondary traumatic experiences. The categories of trauma on the checklist were as follows: bullying, stalking, or swarming; robbery, burglary, mugging with theft, or identity theft; child abuse or assault; physical assault as adult; sexual assault as adult; abduction, hostage-taking, confinement, or torture; shooting, stabbing, or bombing; homicide; suicide; accident; accidental or other sudden death; serious injury; serious medical or mental illness; invasive medical procedures; disaster due to human error; natural disaster; mauling or attack by animal; unexpected loss of life to pet, livestock, or other animal; war, combat, or terrorism; unexpected 
unemployment; end of a marriage or partnership; and other. Participants were asked to indicate whether or not they had experienced any of these events by placing a $P$ (experienced in personal life environment) or a $W$ (experienced in work environment) under the headings of Experienced Directly (victim or witness) or Experienced Indirectly (learned of event affecting another) as appropriate. If the event had not touched their lives, participants were to mark an $\mathrm{X}$ under the heading Have Not Experienced. The data for this independent variable were coded in four ways:

1) 0 for no experience of the event and 1 for experience of the event, under the categories of experienced: directly in personal life, directly in workplace, indirectly in personal life, and indirectly in workplace (2-level predictor variables) (See Table 6.)

2) 0 for no experience, 1 for workplace experience, 2 for personal experience, and 3 for both workplace and personal experience of events under the Experienced Directly column (4-level predictor variable) (See Table 8.)

3) 0 for no experience, 1 for workplace experience, 2 for personal experience, and 3 for both workplace and personal experience of events under the Experienced Indirectly column (4-level predictor variable) (See Table 9.)

4) 0 for no experience, 1 for indirect experience, 2 for direct experience, and 3 for both indirect and direct experience of events whether in the participant's personal life environment or workplace environment (4-level predictor variable) (See Table 7.) 
The History of Traumatic Experiences (HTE) is an instrument constructed by this researcher for the current study to identify whether participants have experienced direct (primary) and/or indirect (secondary) traumatic incidents. Item construction for the HTE derived from traumagenic experiences identified in the literature (Barnhill \& Rosen, 1999; Bisbey \& Bisbey, 1999; Conrad \& Perry, 2000; Everly \& Lating, 2002; Foa, Keane, \& Friedman, 2000; Follette et al., 1994; Friedman, 2001; Giller, 1999; Hales \& Hales, 1995; Herbert \& Wetmore, 1999; Herman, 1997; Horowitz, 2001; James \& Gilliland, 2001; Kass et al., 1995; Kleepsies, 1998; Levine, 1992; Levine, 1997; Matsakis, 1996; Monahon, 1993; Newman, 1993; Nunes \& Simmie, 2002; Parkinson, 2000; Quick et al., 1992; Rosenbloom \& Williams, 1999; Saigh, 1992; Scaer, 2001; Schiraldi, 2000; Terr, 1994; Thompson, 2003b; Thompson, 2004; Wilson, Friedman, \& Lindy, 2001; Wolfelt, 2002) Reliability and validity have not yet been established.

The measure was reviewed for readability by two groups of graduate students in counseling and their doctoral-level supervisors at West Virginia University $(n=12)$. In addition to the content and design reviews conducted by the researcher's dissertation committee, content validity was assessed by Dr. Lou Tinnin, Medical Director of the Trauma Recovery Institute in Morgantown, and Dr. Rob Roff, psychologist at the Kennedy Correctional Institute in Morgantown. Dr. Marinelli, a dissertation committee member, suggested the inclusion of an item about the loss of a pet. This was incorporated. As per Dr. Roff's recommendation, the number of categories of trauma genesis was expanded to foster greater specificity. Dr. Tinnin lent the researcher a copy of a DSM-IV task force report on the criteria for PTSD. The report appeared to present a general consensus with the contents of the History of Traumatic Experiences checklist. 
Impact of Event Scale - Revised. The Impact of Event Scale - Revised (IES-R) was selected for this study because it has been one of the most widely used instruments for reflecting on primary and secondary trauma experiences (Brunet et al., 2003; Cornille \& Meyers, 1999; Dean et al., 2003; Everly \& Lating, 2002). The IES-R represents a 1997 revision of the original 1979 IES, which Foa and colleagues (2000) identified as the most commonly-used PTSD assessment measure prior to the development of the IES-R. The IES-R has since been translated into French, German, and Chinese so as to afford a wider user base (Brunet et al., 2003).

The IES-R is a brief, self-administered measure that identifies the degree to which individuals are experiencing post-traumatic sequelae paralleling symptoms of PTSD. It taps the DSM's Criteria B, C, and D PTSD symptoms, including intrusive or reexperiencing symptoms, avoidance and psychic numbing symptoms, and hyperarousal (Every \& Lating, 2002; Foa et al., 2000). The 22-item revised scale (Weiss \& Marmar, 1997) represents a more comprehensive version of the original 15-item Impact of Event Scale (IES) (Horowitz, Wilner, \& Alvarez, 1979). Everly and Lating (2002) suggested that the revised measure requires about 10 minutes to complete.

The IES was originally developed by Horowitz and colleagues as a measure of subjective distress experienced in the aftermath of traumatic events. The pilot study was conducted on 66 persons who were either clients at an outpatient clinic seeking relief from distress related to critical life events, or medical students reacting to their first experience with a human cadaver (Horowitz et al., 1979). The IES was designed as a selfreport measure that could be used to explore the impact of any traumatic life event. The scale items focused on two of the three main categories associated with post-traumatic 
stress: avoidance and intrusive symptomatology (Zilberg, Weiss, \& Horowitz, 1982).

Respondents utilized a Likert scale to rate the frequency with which they found themselves responding in certain ways to the traumatic incident.

Although the initial version of the IES demonstrated acceptable reliability and validity, and was deemed an effective measure for assessing the psychological impact of traumatic events (Saigh, 1992), researchers determined that items exploring hyperarousal were needed to complete the triad of diagnostic criteria for PTSD as outlined in the Diagnostic and Statistical Manual of Mental Disorders (APA, 1994). Weiss and Marmar (1997) revised the IES through the addition of six items addressing hyperarousal. These items asked respondents to rate items describing anger and irritability, exaggerated startle response, impaired concentration, physiological arousal, and hypervigilance. An item formerly housed in the intrusion category was redesignated a hyperarousal item because it pertained to difficulty in dropping off to sleep. Additionally, an item addressing the experience of flashbacks was incorporated into the intrusion category of the IES-R. The IES-R was piloted with survivors of natural disasters (Friedman, 2001).

Whereas the original IES asked respondents to assign a rating of 0 (not at all), 1 (rarely), 3 (sometimes), or 5 (often), describing the frequency with which the scale items depicted the respondents' daily life experiences in the aftermath of the traumatic event, the IES-R asks respondents to assign a rating of 0 to 4 indicating the intensity of their trauma responses. Respondents reflect on the degree to which the traumatic event has affected them over the past seven days and then select an intensity rating of 0 (not at all), 1 (a little bit), 2 (moderately), 3 (quite a bit), or 4 (extremely). This change in scoring acknowledges that a frequent low-intensity response is qualitatively different than an 
infrequent but high intensity response. The scoring of subscales has also been modified to the mean of the non-missing items. Consequently, it is now possible to compare results on the IES-R and the Symptom Checklist 90-Revised, thus enhancing the validity and applicability of the IES-R (Weiss \& Marmar, 1997).

Scores on the Intrusive Symptoms subscale of the IES-R range from 0 to 28 and are simply summed from responses to items $1,2,3,6,9,16$, and 20 . The items address unintended or unwelcome cognitions and images, disturbing dreams, intense affect, and repetitive behaviors. Scores on the Avoidant Symptoms scale range from 0 to 32 and are derived from responses to items $5,7,8,11,12,13,17$, and 22 . These items explore constricted thoughts or emotions, behavioral inhibition, and psychological numbing. The recently added subscale of Hyperarousal Symptoms offers scores of 0 to 28 based on responses to items $4,10,14,15,18,19$, and 21 . These items focus on anger and irritability, exaggerated startle response, impaired concentration, physiological arousal, hypervigilance, and difficulty dropping off to sleep.

A Traumatic Stress Response total scale score is calculated by summing the three subscale scores, resulting in a global score ranging from 0 to 88 . Higher scores represent more significant degrees of distress (Pfefferbaum, et al., 2000). Definitive cut-off scores have not formally been identified that would place a respondent in a particular diagnostic category (Cornille \& Meyers, 1999). Wu refers to the measure's function as “capturing the level of symptomatic response to specific traumatic stressors, manifested in the past week" (2002, p. 21).

Some researchers, however, have opted to attach meaningfulness to IES-R scores. Steed and Bicknell (2001) declared a subscale score of 26 or more to be clinically 
significant. Lavack-Pambrun (2000) adopted a cut-off total score of 26 as an indicator of a traumatic stress reaction. Otte and colleagues (2002) commented on an individual's IES-R total score of 46, stating that it was indicative of severe PTSD. However, they did not identify a clinically significant cut-off score. Previous Australian research on the IES concluded that scores exceeding 19 and 29 were indicative of significant and extreme post-trauma stress, respectively. In their research using the IES-R, Dean and colleagues reported that "threshold scores, proportionally extrapolated from those of the IES, greater than 28 and greater than 43 , have been used in this study to indicate significant and extreme posttraumatic stress respectively" (2003, p. 6). Creamer and colleagues (2003) found a high correlation between the PTSD Checklist and the IES-R $(r=.84)$ and thus determined that a total score of 33 or greater on the IES-R offered diagnostic accuracy for Posttraumatic Stress Disorder.

The psychometric properties of the IES-R have been documented and have demonstrated the internal consistency of the three subscales of Intrusive, Avoidant, and Hyperarousal Symptoms to be substantial. Two studies were summarized by Weiss and Marmar (1997). The first study included police, firefighter, emergency medical technicians, and Department of Highway workers from three sites: those responding to the aftermath of the I-880 freeway collapse during the 1989 Loma Prieta earthquake, those living and working in the San Francisco Bay area at the time of the earthquake, and emergency personnel from San Diego. The second study involved individuals working in the insurance field following the 1994 Northridge earthquake near Los Angeles. Two sets of data for each of these studies provided four sets of Cronbach's alpha coefficients estimated at $.91, .92, .87, .87$ for the Intrusive Symptoms subscale, $.84, .85, .85, .86$ for 
the Avoidant Symptoms subscale, and $.90, .89, .79, .79$ for the Hyperarousal Symptoms subscale. These findings are consistent with internal consistency data documented on the original IES where the Cronbach's alpha coefficient was calculated at .78 for the IES Intrusive Symptoms subscale and .82 for the Avoidant Symptoms subscale (Horowitz et al., 1979). Creamer and colleagues (2003) reported high internal consistency on the IES-R with an alpha of .96. They noted, however, a lack of support for a threefactor solution corresponding to each of the subscales. Rather, their factor analysis suggested a single factor, or possibly a two-factor solution of intrusion/hyperarousal and avoidance.

Assessment of IES-R test-retest reliability in the Weiss and Marmar (1997) studies yielded coefficients of .94 for Intrusive Symptoms, .89 for Avoidant Symptoms, and .92 for Hyperarousal Symptoms data in the Northridge study $(n=197)$, with a sixmonth interval between tests. Data from the I- 880 study $(n=429)$ produced considerably lower test-retest coefficients of .57 for Intrusive Symptoms, .51 for Avoidant Symptoms, and .59 for Hyperarousal Symptoms. It bears noting that the I-880 study involved two control groups who were asked to reflect on critical incidents of their own choosing. The average post-critical incident intervals were 1.5 years for the I- 880 group, 3.3 years for the Bay Area controls, and 4.1 years for the San Diego controls. The higher Northridge stability coefficients were attributed to a shorter interval between assessments and more recent traumatic experiencing. Results from the first IES-R sample were congruent with exploration of test-retest reliability on the IES, which yielded coefficients of .87 for the Traumatic Stress Response total scale, .89 for the Intrusive Symptoms subscale, and .79 for the Avoidant Symptoms subscale (Horowitz et al., 1979). 
Briere (1997) reported that the IES-R Hyperarousal Symptoms subscale demonstrates good predictive validity with respect to degree of traumatization. The Intrusive Symptoms and Avoidant Symptoms subscales monitor changes in clinical status and distinguish between traumatic events varying in severity (Weiss \& Marmar, 1997). Construct validity was supported by item-to-subscale correlations wherein nineteen of the twenty-two items were more highly correlated with their assigned subscales than with the other two subscales.

For the purposes of the current study participants were asked to respond to the IES-R twice, and the Traumatic Stress Response total score in each case was used to measure the current level of traumatic stress related to trauma history. On the first occasion participants were to identify a directly experienced (primary) traumatic event or events in their lives and to respond to the impact of this event over the past month. A directly experienced traumatic event is defined as one in which they were a victim or witness. On the second occasion they were to respond to the impact of any indirectly experienced (secondary) traumatic event or events over the past month. An indirectly experienced traumatic event is defined as one in which the educator heard or learned about a traumatic incident from another person or source.

Thus, the modifications to the original instructions of the IES-R were that participants would complete the scale twice, reflecting first on primary and then secondary traumatic events; participants could consider more than one event when responding; and would answer in the context of the past month rather than the past week. The rationale behind these modifications is that the current study wished to consider both primary and secondary traumata. Additionally, focusing on a single traumatic event if 
there had been more than one, may not have painted an accurate portrait of the participant's experiences. Finally, it was hoped that extending the period of reflection to the past month rather than past week would also enhance the accuracy of the self-reported post-traumatic stress experience. This time frame would permit the instrument to address to some extent the vacillation of trauma responses between intrusion and avoidance. It is also congruent with the time frame utilized by the ProQOL-CSF-R III.

Unfortunately, as was the case with the original IES (Saigh, 1992), cut-off scores have not been established for the IES-R to clearly delineate when criteria for PTSD or STSD have been met (Cornille \& Meyers, 1999). Therefore, this study has adopted the threshold score identified by Creamer and colleagues (2003) because it appears to represent a midrange of those identified in the research and was determined by a correlational procedure using another well-established measure of PTSD. A total scale score equal to or higher than 33 is held to represent significant traumatic stress.

Another possible limitation with the IES-R relates to terminology. The measure asks respondents to reflect on stressful life events that may or may not be the equivalent of traumatic events. However, even if the term traumatic were used, the request still would have elicited a subjective response. This limitation has been addressed in part by the sequence of completing the research instruments. Prior to responding to the IES-R items, participants complete the History of Traumatic Experiences (HTE) to indicate whether they have experienced traumatic life events as defined in the trauma literature. In this manner, participants reflect on their trauma histories prior to completing the IES-R. Professional Quality of Life - Compassion Satisfaction and Fatigue Subscales Revised III. The ProQOL-CSF-R III is a modified version of the Compassion 
Satisfaction/Fatigue Test, and its predecessor, the Compassion Fatigue Self-Test. Charles Figley and Beth Hudnall Stamm developed the original two-scale self-report measure to assess burnout and compassion fatigue in helping professionals. As it became apparent that career satisfaction might serve as a buffer against the deleterious effects of occupational stress and bearing witness to others' traumatic tales, Stamm developed the Compassion Satisfaction subscale and expanded the original measure to a three-scale version. (Collins \& Long, 2003; Figley, 2002b). Further explication of the three-scale version will be provided below, as it is still commonly encountered in the research and practice literature (Collins \& Long, 2003; Figley, 2000a; Jenkins \& Baird, 2002; Kochevar, 2002; Pinto, 2003; Stamm, 2002; Struwig, 2002; Thompson, 2003a; White, 2001). The Pro-QOL-CSF-R III was introduced by Stamm in 2003 with refinements intended to address challenges in separating burnout and secondary or vicarious trauma. Additionally, demands on research participants were lessened with the reduction of test items by more than half.

The ProQOL-CSF-R III retained 21 of the original 66 items on the Compassion Satisfaction/Fatigue Test. These were selected on the basis of item-to-scale criteria and theoretical salience. In addition to the seven items retained per scale, three new items per scale were added, such that each scale now contained 10 items. In designing the new items, the intent was to close the gap between the subscale content and diagnostic criteria for PTSD as identified in the Diagnostic and Statistical Manual of Mental Disorders, Fourth Edition, for PTSD (APA, 1994), and the professional literature on career satisfaction and burnout.

In the instructions for the ProQOL-CSF-R III, Stamm (2003) directed participants 
to respond to each item using a Likert scale, indicating the frequency with which the item described their life experiences in the past 30 days. This represented a change from the original time frame of reflection of one week on the Compassion Satisfaction/Fatigue Test. Possible item ratings range from 0 to 5, indicating never, rarely, a few times, somewhat often, often, and very often, respectively.

The ProQOL-CSF-R III yields subscale scores for Compassion Satisfaction, Burnout, and Compassion Fatigue. The subscale score for Compassion Satisfaction is derived from the sum of the item ratings for items $3,6,12,16,18,20,22,24,27$, and 30 with the possible total ranging from $0-50$. The subscale score for Burnout is calculated by adding the ratings for items $1,4,8,10,15,17,19,21,26$, and 29 and ranges between 0 and 50. The subscale score for Compassion Fatigue is obtained by summing the ratings for items 2, 5, 7, 9, 11, 13, 14, 23, 25, and 28 resulting in a Compassion Fatigue score from 0 to 50 . Reverse scoring applies to items $1,4,15,17$, and 29 . In contrast to the original measures, the revised measure uses an equal number of items (10 per subscale) to arrive at each of the subscale scores.

Based on a data sample of $n=400$, internal consistency for the three subscales of the ProQOL-CSF-R III was assessed using Cronbach's alpha (Stamm, 2003). A coefficient of .87 was estimated for the Compassion Satisfaction subscale, .72 for the Burnout subscale, and .80 for the Compassion Fatigue subscale. While Stamm acknowledged lower absolute values than for the Compassion Satisfaction/Fatigue Test, she noted that the new alpha coefficients are actually stronger indicators of internal consistency, given that the length of the scales has been decreased by half.

Means and standard deviations for each of the subscales were calculated as 
follows: Compassion Satisfaction $(M=37, S D=7)$, Burnout $(M=23, S D=6)$, and Compassion Fatigue $(M=13, S D=6)$. Based on these data, theoretical cut-off scores were set by Stamm at low (bottom 25\%), middle 50\%, and high (upper 25\%). These cutoff scores represent low, average, and high risk for the three subscale constructs measured. On the Compassion Satisfaction subscale approximately $25 \%$ of respondents scored higher than 41 or lower than 32 . On the Burnout subscale approximately $25 \%$ scored higher than 28 or lower than 19. On the Compassion Fatigue subscale approximately $25 \%$ of the sample scored higher than 17 or lower than 8 (Stamm, 2003).

Stamm (2003) noted that the ProQOL-CSF-R III is under development, and with a limited research base for the new measure, test scores should be considered suggestive rather than confirmatory of career satisfaction, burnout, and compassion fatigue. Theoretical cut-points and scoring directions for the ProQOL-CSF-R III were revised as of July 12,2003 . Stamm contends that the revised assessment is more theoretically sound than its predecessor, and more effectively discriminates between burnout and compassion fatigue due to increased item specificity and reduced collinearity.

For the purposes of the current study, educators were asked to respond to the items on the ProQOL-CSF-R III in the context of their roles as helpers within the public school teaching profession. In the interest of facilitating statistical analysis at an exploratory level, those receiving scores at or above the test author's theoreticallyderived upper cut-points (top 25\%) on a subscale were deemed to demonstrate high likelihood or risk of meeting criteria for that particular construct and its corresponding category of quality of career engagement. Additionally, the lower cut-point (lower 25\%) on the Compassion Satisfaction subscale was employed as an indicator of career 
dissatisfaction. The reader is reminded that the current study contends that quality of career engagement exists on a continuum and is not experienced in a categorical fashion.

Table 3 summarizes the subscales and cut-off scores of the ProQOL-CSF-R III and corresponding category of quality of career engagement as applied in this study. Table 3

ProQOL-CSF-R III Cut-Off Scores and Career Engagement Categories

\begin{tabular}{|c|c|c|}
\hline Subscale & Cut-Off Score & $\begin{array}{l}\text { Corresponding Category of } \\
\text { Quality of Career } \\
\text { Engagement }\end{array}$ \\
\hline Compassion Satisfaction & $\begin{array}{l}R S>41 / 50 \text { (highest quartile) } \\
\text { indicating high satisfaction } \\
\text { derived from being a helper }\end{array}$ & Healthy Career Engagement \\
\hline Compassion Satisfaction & $\begin{array}{l}R S<32 / 50 \text { (lowest quartile) } \\
\text { indicating dissatisfaction } \\
\text { related to being a helper }\end{array}$ & Healthy Career Engagement \\
\hline Burnout & $\begin{array}{l}R S>28 / 50 \text { (highest quartile) } \\
\text { indicating high risk of } \\
\text { burnout }\end{array}$ & Career Disengagement \\
\hline Compassion Fatigue & $\begin{array}{l}R S>17 / 50 \text { (highest quartile) } \\
\text { indicating high risk of } \\
\text { compassion fatigue }\end{array}$ & Career Overengagement \\
\hline
\end{tabular}

In a personal e-mail, Stamm (October 26, 2003) indicated that the ProQOL-CSF-

R III databank had reached approximately 500, including a sample of urban teachers.

Stamm offered permission for the ProQOL-CSF-R III to be employed in the current study and invited this researcher to share the raw data obtained so that it could be incorporated into the growing database. She also indicated that she would inform this researcher when findings on the urban teacher sample were published. To date, confirmation of publication of those findings has not been received, nor have any articles been located 
describing ProQOL-CSF-R III data derived from an educator sample.

Compassion Satisfaction/Fatigue Test. The Compassion Satisfaction/Fatigue Test, also referred to as the Compassion Fatigue \& Satisfaction Self-Test for Helpers, was designed by Figley and Stamm (1996) to explore the degree to which those in the helping professions manifest signs of satisfaction with helping others, as well as indicators of burnout and compassion fatigue.

The Compassion Satisfaction/Fatigue Test is a 66-item survey divided into two sections. The sections are subtitled Items About You, and Items About Being a Helper and Your Helping Environment. Participants are asked to respond to each item using a Likert scale, indicating the frequency with which the item has described their life experiences over the past week. Possible item ratings range from 0 to 5, indicating never, rarely, a few times, somewhat often, often, and very often, respectively.

The Compassion Satisfaction/Fatigue Test yields subscale scores for Compassion Satisfaction, Burnout, and Compassion Fatigue. The subscale score for Compassion Satisfaction is derived from the sum of the item ratings for items $1,2,3,5,9,10,11,14$, $19,26,27,30,35,37,43,46,47,50,52,53,54,55,57,59,61$, and 66 , with the possible total ranging from $0-130$. The subscale score for Burnout is calculated by adding the ratings for items $17,23,24,25,41,42,45,48,49,51,56,58,60,62,63,64$, and 65 and ranges between 0 and 85. The subscale score for Compassion Fatigue is obtained by summing the ratings for items $4,6,7,8,12,13,15,16,18,20,21,22,28,29,31,32,33$, 34, 36, 38, 39, 40, and 44, resulting in a Compassion Fatigue score from 0 to 115.

The test authors determined subscale score ranges for the potential for Compassion Satisfaction as follows: 118 and above suggests extremely high potential, 
100-117 suggests high potential, 82-99 suggests good potential, 64-81 suggests modest potential, and a score of 63 or below suggests low potential for compassion satisfaction. On the Burnout subscale, a score of 36 or less is indicative of extremely low risk for burnout, while a score from 37-50 indicates moderate risk, 51-75 indicates high risk, and 76-85 indicates extremely high risk. On the Compassion Fatigue subscale, risk for compassion fatigue is designated as extremely low with a score of 26 or below, low for scores of 27-30, moderate for scores of 31-35, high for scores of 36-40, and extremely high for scores of 41 or greater (Figley, 1995).

Figley and Stamm (1996) provided a psychometric review of the Compassion Satisfaction/Fatigue Test which was based on a pooled sample of 370 respondents. Multivariate analysis of variance did not denote differences based on country of origin, line of work, or gender, when age was used as a control variable. The mean age of respondents was 35.4 with a median age of 36 , and a standard deviation of 12.16 . The sample was comprised of $33 \%$ males $(n=121), 56 \%$ females $(n=207)$, and $11 \%$ gender unknown $(n=42)$. Work backgrounds represented included: 16\% trauma professionals $(n=58), 35 \%$ business volunteers $(n=130), 8 \%$ Red Cross employees $(n=30), 27 \%$ caregivers-in-training $(n=102)$, and $13 \%$ not identified $(n=50)$. The percentage of respondents based on country of origin included $43 \%$ from the United States $(n=160)$, $8 \%$ from Canada $(n=30), 35 \%$ from South Africa $(n=130)$, and $13 \%$ unknown origin $(n=50)$.

Internal consistency for the three subscales of the Compassion Satisfaction/ Fatigue Test was assessed using Cronbach's alpha (Figley \& Stamm, 1996). A coefficient of .87 was estimated for the Compassion Satisfaction subscale, .90 for the Burnout 
subscale, and .87 for the Compassion Fatigue subscale. Means and standard deviations were as follows: Compassion Satisfaction $(M=92.10, S D=16.04)$, Burnout $(M=24.18$, $S D=10.78)$, and Compassion Fatigue $(M=28.78, S D=13.15)$.

Test-retest information was gathered from a group of lay mental health caregivers in rural Africa $(n=16)$ that completed the first two scales of the Compassion Satisfaction/ Fatigue Test after a minimum of three months' work. Figley and Stamm (1996) noted that the means and standard deviations for this sample on the two subscales were as follows: Compassion Satisfaction $(M=45, S D=14.4)$, and Burnout $(M=32$, $S D=11.3)$. A retest three months later garnered the following data: Compassion Satisfaction $(M=44, S D=13.6)$, and Burnout $(M=28.86, S D=19.6)$. A test-retest reliability coefficient was not offered based on these data. Data Analysis

Data from each of the Demographic Information questionnaire, History of Traumatic Experiences (HTE) survey, Impact of Event Scale - Revised (IES-R) for direct trauma, Impact of Event Scale - Revised (IES-R) for indirect trauma, and Professional Quality of Life - Compassion Satisfaction and Fatigue Subscales - Revised III (ProQOLCSF-R III) were analyzed using descriptive statistics. Results are presented in both tabular and narrative form in Chapters 4 and 5.

Frequencies and percentages are presented for the demographic characteristics of: current position, assignment level (elementary, middle, high, technical or alternate school), school population, school population, school location (Nova Scotia, West Virginia), employment status (full-time, part-time, substitute), gender, ethnicity, current salary, and highest level of education attained. Means, standard deviations, and ranges are 
provided for the demographic characteristics of number of years in field of education, number of years in current position, and age.

Information regarding the participants' trauma history is summarized.

Frequencies and percentages are presented for primary and secondary traumatic experiences in participants' personal and work environments. Traumatic incidents are reported under the categories of: bullying, stalking, or swarming; robbery, burglary, mugging with theft, or identity theft; child abuse or assault; physical assault as adult; sexual assault as adult; abduction, hostage-taking, confinement, or torture; shooting, stabbing, or bombing; homicide; suicide; accident; accidental or other sudden death; serious injury; serious medical or mental illness; invasive medical procedures; disaster due to human error; natural disaster; mauling or attack by animal; unexpected loss of life to pet, livestock, or other animal; war, combat, or terrorism; unexpected unemployment; end of a marriage or partnership; and other. Data from the HTE were entered and tabulated using the four methods of recording discussed earlier in this chapter. For purposes of correlational analysis, traumatic history was coded as 0 for no reported history, 1 for indirect (or secondary) trauma history, 2 for direct (or primary) trauma history, and 3 for both indirect and direct trauma history.

The means, standard deviations, and ranges of scores for the Traumatic Stress Response total score of the IES-R are reported. The Traumatic Stress Response total score has been used to measure the current level of traumatic stress related to trauma history. Similar descriptive data are provided for the Compassion Satisfaction, Burnout, and Compassion Fatigue subscales of the ProQOL-CSF-R III. 
A description of the data analysis conducted with the seven research questions follows. Due to the exploratory nature of the current study, an alpha level of .05 was used. While the potential for Type I error is increased by the large number of comparisons, the rationale for employing such a quantity was to permit opportunity for discovery of information that might not have come to light in a less liberal investigation. It is hoped that directions for future study might be clarified using this approach.

\section{Research Question 1}

RQ1. To what degree are educators reporting signs of healthy career engagement, career disengagement, and career overengagement?

RQ1a. To what degree are educators reporting signs of healthy career engagement? With what frequency do they surpass the upper quartile cut-off score of $\mathbf{4 1}$ on the Compassion Satisfaction subscale of the ProQOL-CSF-R III, thus endorsing this aspect of career satisfaction? Additionally, with what frequency did educators score below the lower quartile cut-off score of $\mathbf{3 2}$, indicating dissatisfaction? These data are reported as frequencies and percentages. RQ1b. To what degree are educators reporting signs of career disengagement? With what frequency do they surpass the upper quartile cut-off score of 28 on the Burnout subscale of the ProQOL-CSF-R III? These data are reported as frequencies and percentages.

RQ1c. To what degree are educators reporting signs of career overengagement? With what frequency do they surpass the upper quartile cut-off score of $\mathbf{1 7}$ on the Compassion Fatigue subscale of the ProQOL-CSF-R III? These data are reported as frequencies and percentages. 


\section{Research Question 2}

RQ2. What is the relationship between career fulfillment, burnout, compassion fatigue, and level of traumatic stress in those respondents with an identified history of primary trauma? Specifically, what is the correlation between each of the subscales (Compassion Satisfaction, Burnout, and Compassion Fatigue) of the ProQOL-CSF-R III, and the Traumatic Stress Response total score of the IES-R for those who identified a history of primary trauma? Correlations have been computed between each of the subscales (Compassion Satisfaction, Burnout, and Compassion Fatigue) of the ProQOL-CSF-R III, and the Traumatic Stress Response total score of the IES-R for those with a history of primary trauma. Previous research has suggested that a history of primary trauma increases susceptibility to secondary traumatic stress or compassion fatigue (Cornille \& Meyers, 1999; Follette et al., 1994; Hales \& Hales, 1995; Jenkins \& Baird, 2002; Kassam-Adams, 1995; Pearlman \& MacIan, 1995; Pearlman \& Saakvitne, 1995; Pinto, 2003; Schauben \& Frazier, 1995). However, Elliott and Guy's (1993) findings were to the contrary. In their study of mental health professionals versus non-mental-health professionals, the former group reported more extensive trauma history but fewer current trauma symptoms, suggesting that training in the mental health field may confer some protection from compassion fatigue.

\section{Research Question 3}

RQ3. What is the relationship between career fulfillment, burnout, compassion fatigue, and level of traumatic stress in those respondents with an identified history of secondary trauma? Specifically, what is the correlation between each 
of the subscales (Compassion Satisfaction, Burnout, and Compassion Fatigue) of the ProQOL-CSF-R III, and the Traumatic Stress Response total score of the IES-R for those who have identified a history of secondary trauma? Correlations have been computed between each of the subscales (Compassion Satisfaction, Burnout, and Compassion Fatigue) of the ProQOL-CSF-R III, and the Traumatic Stress Response total score of the IES-R for those who identified a history of secondary trauma.

\section{Research Question 4}

RQ4. Are elementary educators more inclined to experience compassion fatigue than those in middle school, high school, or technical school settings? Specifically, what does an analysis of variance (ANOVA) indicate when three categories of elementary school, middle school, and high/technical school educators are utilized as the independent variable (Educator Level), and the Compassion Fatigue subscale of the ProQOL-CSF-R III operates as the dependent variable? A one-way ANOVA was conducted to explore this question. Due to the small sample size for technical school educators $(n=5)$, and the fact that the participating technical school educators work with secondary school students, high school and technical school data were combined into one school level category. Although the literature yields little evidence, the author's clinical experience led to the hypothesis that elementary educators would report higher levels of compassion than educators at the other levels. This would be presumed due to greater intimacy derived from greater amounts of time spent with the same group of students. 


\section{Research Question 5}

RQ5. Are classroom teachers (including subject and specialist teachers) at all levels more inclined to experience compassion fatigue than guidance counselors and administrators? Specifically, what does an analysis of variance indicate when the three categories of classroom teacher, guidance counselor, and administrator were used as the independent variable (Educator Category), and the Compassion Fatigue subscale of the ProQOL-CSF-R III serves as the dependent variable? A one-way ANOVA was conducted. Again, although the literature yields little evidence, the author's clinical experience led to the hypothesis that teachers would report higher levels of compassions fatigue than counselors and administrators, as a function of training and/or exposure.

\section{Research Question 6}

RQ6. To what degree do the demographic characteristics of current position, assignment level, school population, school location, number of years in the field of education, number of years in current position, employment status, age, gender, ethnicity, current salary, and highest level of education attained, relate to measured levels of career satisfaction, burnout, and compassion fatigue? A correlation matrix has been computed that crosses demographics with the three indicators of quality of career engagement (Compassion Satisfaction, Burnout, and Compassion Fatigue) to determine if any significant correlations exist. Of particular interest is whether a clear relationship exists between years of experience and quality of career engagement. Previous research in the area of burnout supported the notion that younger age and fewer years of experience 
correlated positively with burnout (Ackerly et al., 1988). Prior exploratory research conducted with trauma counselors suggested that the risk for compassion fatigue was negatively correlated with years of experience (Pearlman \& MacIan, 1995). However, similar research carried out with generalist counselors did not discriminate compassion fatigue on the basis of novice or expert status (Pinto, 2003). Additionally, a gender factor appears related to the manifestation of trauma symptoms in those who work with trauma victims. Females have been more likely to demonstrate secondary traumatization (Cornille \& Meyers, 1999; KassamAdams, 1995), and thus would be anticipated to exhibit higher risk for compassion fatigue.

\section{Research Question 7}

RQ7. Considering the potential predictors of (1) demographic characteristics (current position, assignment level, school population, school location, number of years in the field of education, years in current position, employment status, age, gender, current salary, level of education), (2) trauma history, and (3) current traumatization status as depicted by the IES-R Traumatic Stress Response total scores, what are the significant contributors to the criterion variables of (1) Compassion Satisfaction, (2) Burnout, and (3) Compassion Fatigue? Multiple regression analyses have been used to address this research question. 


\section{CHAPTER 4}

Results

This chapter presents results of analyses of participant responses to the Demographic Information questionnaire, History of Traumatic Experiences (HTE) survey, Impact of Event Scale - Revised (IES-R) for direct trauma, Impact of Event Scale - Revised (IES-R) for indirect trauma, and Professional Quality of Life Compassion Satisfaction and Fatigue Subscales - Revision III (ProQOL-CSF-R III). Quantitative results are summarized in narrative and tabular form. The chapter begins with sample characteristics and descriptive data for the HTE, IES-R, and ProQOL-CSF-R III. Analyses relevant to specific research questions follow and are organized by question.

The total number of public school educators who participated in this research was 184 , representing an overall response rate of $26.29 \%$. Of the 700 research packets distributed, 187 were returned, and 184 of those were usable. Response rate by location was 30.33\% for West Virginia (91 of 300 usable packets returned) and 23.25\% for Nova Scotia (93 of 400 usable packets returned).

The following frequency and percentage demographic data are also presented in tabular form in Table 4. All tables are located at the end of the chapter. The current positions held by the educators included 80 (43.5\%) classroom teachers, $44(23.9 \%)$ subject teachers, $32(17.4 \%)$ who identified other positions such as resource or special education, $16(8.7 \%)$ school counselors, five (2.7\%) assistant or vice-principals, and seven $(3.8 \%)$ principals. Among the school levels identified by the educators, $85(46.2 \%)$ held positions in elementary schools, $45(24.5 \%)$ in middle schools, $49(26.6 \%)$ in secondary schools, and five $(2.7 \%)$ in technical or alternate schools affiliated with the 
public school system. The schools represented included $14(7.6 \%)$ with a population under 200, $22(12.0 \%)$ with a population from 200 to 399,55 (29.9\%) with a population of 400 to $599,46(25.0 \%)$ with a population from 600 to $799,19(10.3 \%)$ with a population of 800 to 999 , two $(1.1 \%)$ with a population of 1,000 to 1,199 , one $(0.5 \%)$ with a population of 1,200 to 1,399 , and $24(13.0 \%)$ with a population of 1,600 to 1,799 students. Data were missing for one school. School location was almost equally split between 93 (50.5\%) located in Nova Scotia and 91 (49.5\%) located in West Virginia.

The majority of the participants $(n=169,91.8 \%)$ reported full-time teaching status, a minority reported part-time status $(n=11,6.0 \%)$, and a few identified substitute teacher status $(n=4,2.2 \%)$. The sample was comprised of $140(76.1 \%)$ female participants and 44 (23.9\%) male participants. Ethnicity data were missing for 38 (20.7\%) of the participants. The majority of those who entered ethnicity data $(n=144$, 78.3\%) identified as Euro-American/Canadian. One participant identified as AfricanAmerican/Canadian, and one as American/Canadian Native, with each representing 0.5\% of the participant sample.

With respect to salary, five participants $(2.7 \%)$ reported a salary under $\$ 20,000$, 17 (9.2\%) between $\$ 20,000$ and $\$ 29,999,40(21.7 \%)$ between $\$ 30,000$ and $\$ 39,999$, $46(25.0 \%)$ between $\$ 40,000$ and $\$ 49,999,36(19.6 \%)$ between $\$ 50,000$ and $\$ 59,999$, $25(13.6 \%)$ between $\$ 60,000$ and $\$ 69,999$, and $10(5.4 \%)$ between $\$ 70,000$ and $\$ 79,999$. Data were missing for five (2.7\%) of the participants. Salary was reported in each country's respective currency, with no attempt made to compare on the basis of exchange rates. On the whole, the Nova Scotian educators reported higher salaries than their West Virginian counterparts. 
Education levels attained by educators in the sample included $71(38.6 \%)$ with a Bachelor's degree, 103 (56.0\%) with a Master's degree, six (3.3\%) with a Doctoral degree, and four $(2.2 \%)$ with another degree. The four responses of Other included two participants with an Associate of Education Diploma, one who was working on a Bachelor's degree, and one who had received two Bachelor's degrees in different teaching areas. Additional elaboration on responses included: two educators who had studied beyond a Bachelor's degree, one with a Bachelor's degree plus 15 credit hours, three working on a Master's degree, four with unspecified coursework beyond a Master's, three with Master's degrees plus 30 credit hours, nine with Master's degrees plus 45 credit hours, one with a Master's plus 56 credit hours, one with a Master's plus 60 credit hours, one with a Master's plus 72 credit hours, five with two Master's degrees, two working on a doctorate, one who was 6 hours of credit study away from receiving a doctorate, and one with a law degree. Overall, West Virginian educators reported higher levels of education attained than Nova Scotian educators.

A summary of descriptive data for number of years in the field of education, number of years in current position, and age is presented in Table 5. The number of years in the field of education ranged from 1 to 39 , with a mean of $18.90(S D=9.68)$. The number of years in the current position ranged from 1 to 39 , with a mean of 8.57 $(S D=8.34)$. The ages of participants ranged from 24 to 64 , with a mean of 45.49 $(S D=9.56)$

Data from the History of Traumatic Experiences survey are presented in Tables 6 through 9. Table 6 provides a more macroscopic summary of trauma history, while the three subsequent tables explore history more specifically. Table 6 summarizes direct and 
indirect history of trauma in personal and work life spheres. In the sample of educators, $160(87.0 \%)$ endorsed direct trauma history in their personal lives, while $11(6.0 \%)$ denied history, and $13(7.1 \%)$ did not provide data. Direct trauma history associated with one's work life was endorsed by 89 (48.4\%) participants and denied by 80 (43.5\%), with data missing for $15(8.2 \%)$. Indirect personal trauma was reported by $122(66.3 \%)$ participants and denied by 46 (25.0\%), with data missing for $16(8.7 \%)$. A history of indirect trauma associated with the workplace was reported by $132(71.7 \%)$ participants and denied by 37 (20.1\%), with data missing for 15 (8.2\%). A history of direct trauma in both one's personal and work life was endorsed by 85 (46.20\%) participants, and a history of indirect trauma in both one's personal and work life was endorsed by 100 $(54.3 \%)$ participants. A history of at least one of these four categories of trauma was confirmed by $172(93.5 \%)$ of the study participants and denied by $2(1.1 \%)$, with data missing for $10(5.4 \%)$.

Table 7 summarizes direct and indirect trauma history by trauma category. Frequency and percentage data are provided for each of the 22 trauma categories on the History of Traumatic Experiences survey, indicating whether the participant recorded no history, indirect history, direct history, or history of both direct and indirect trauma. The trauma categories include: bullying, stalking, or swarming; robbery, burglary, mugging with theft, or identity theft; child abuse or assault (physical, sexual, emotional); physical assault as an adult; sexual assault as an adult; abduction, hostage-taking, confinement, or torture; shooting, stabbing, or bombing; homicide; suicide; accident (e.g., workplace, car, sporting); accidental or other sudden death; serious injury; serious medical or mental illness; invasive medical procedures (e.g., surgery, chemotherapy, radiation); disaster due 
to human error (e.g., fire, building collapse); natural disaster (e.g., flood, hurricane, avalanche); mauling or attack by an animal; unexpected loss of a pet, livestock, or other animal; war, combat, or terrorism; unexpected unemployment; end of a marriage or partnership; and other trauma. Usable data were available for 181 of the 184 participants. Participants endorsed each of the 22 categories of trauma for indirect, direct, or both direct and indirect history. The least frequently experienced of the traumatic incidents were abduction, hostage-taking, confinement or torture $(n=22,11.9 \%$ for indirect, direct, both) and the most frequently experienced were accidents ( $n=150$, $81.5 \%$ for indirect, direct, both). Participants elaborated on traumatic incidents endorsed under the Other category. The participants described learning of attempted suicides of students, watching someone die, witnessing a daughter's mental breakdown, being called upon to care for a mother with Alzheimer's, being expected to provide care for a mother in a nursing home, experiencing several miscarriages, experiencing marital discord, undergoing an unexpected job change, being the victim of a home invasion, and trauma related to an eating disorder.

Table 8 depicts the frequency and percentage of direct or primary trauma in participants' personal and work life spheres for each of the 22 trauma categories of the History of Traumatic Experiences. Direct trauma history is recorded as absent, associated with work life, associated with personal life, or associated with both work and personal life. Usable data were provided by $171(92.9 \%)$ and were missing for $13(7.1 \%)$ participants. The least frequently experienced of the direct traumatic incidents was homicide ( $n=2,1.0 \%$ in work and personal life spheres) and the most frequently 
experienced were bullying, stalking, or swarming $(n=108,58.6 \%$ in work, personal, or both life spheres).

Table 9 depicts the frequency and percentage of indirect or secondary trauma in participants' personal and work life spheres for each of the 22 trauma categories of the History of Traumatic Experiences. Indirect trauma history is recorded as absent, associated with work life, associated with personal life, or associated with both work and personal life. Usable data for each category were provided by 168 to $170(91.3-92.4 \%)$ participants and missing for 14 to $16(7.6-8.7 \%)$ participants. The least frequently experienced indirect traumatic incidents were abduction, hostage-taking, confinement or torture ( $n=19,10.3 \%$ in work, personal, or both life spheres) and the most frequently experienced were child abuse or assault $(n=102,55.5 \%)$ in work, personal, or both life spheres).

Table 10 offers descriptive statistics for the Impact of Event Scale - Revised (IES-R). Scores on the IES-R for direct trauma $(n=184)$ ranged from 0 to 76 , with a mean of $25.88(S D=17.28)$. Scores on the IES-R for indirect trauma $(n=176)$ ranged from 0 to 64 , with a mean of $16.45(S D=12.96)$. On the IES-R for direct trauma, 57 of $184(31.0 \%)$ participants exceeded the cut score of 33 adopted for this study. A smaller proportion, 19 of $176(10.8 \%)$, exceeded the cut score of 33 on the IES-R for indirect trauma.

Table 11 presents descriptive data for the ProQOL-CSF-R III for each of the subtests of Compassion Satisfaction, Burnout, and Compassion Fatigue. Subscale scores ranged from 15 to $50(M=36.83, S D=7.44)$ on the Compassion Satisfaction subscale, 
from 5 to $40(M=23.88, S D=6.8)$ on the Burnout subscale, and from 1 to $43(M=$ 15.33, $S D=7.33$ ) on the Compassion Fatigue subscale.

\section{Research Questions}

\section{Research Question 1}

The first research question sought to determine the degree to which educators are reporting signs of healthy career engagement, career disengagement, and career overengagement. These results are presented in Table 12.

RQ1a. Specifically, the first segment of the question asked for the frequency with which educator participants surpassed the upper quartile cut-off score of 41 on the Compassion Satisfaction subscale of the ProQOL-CSF-R III, thus endorsing high career satisfaction and healthy career engagement, and the frequency with which they received scores below the lower quartile cut-off score of 32, suggesting career dissatisfaction. In this research sample, 48 of 184 (26.09\%) participants exceeded the upper quartile score of 41 , and 40 of 184 (21.74\%) scored below the lower quartile cut-off of 32 . The remaining portion ( $n=96,52.17 \%)$ received scores in the mid-range, suggesting moderate career satisfaction and relatively healthy career engagement.

RQ1b. The second part of the first research question asked for the frequency with which participants surpassed the upper quartile cut-off score of 28 on the burnout subscale, indicating risk for burnout and evidence of disengagement. In this research sample, 46 of 184 (25.00\%) participants surpassed the upper quartile cut-off score of 28.

RQ1c. The final section of the first research question asked for the frequency with which participants surpassed the upper quartile cut-off score of 17 on the Compassion Fatigue subscale, indicating risk for compassion fatigue and evidence of overengagement. 
In the current sample, 61 of $184(33.15 \%)$ participants surpassed the upper quartile cutoff score of 17 .

Frequency and percentage data for those exceeding cut-off scores in combinations of Compassion Satisfaction, Burnout, and Compassion Fatigue subscales are presented in Table 19 and summarized later in this chapter under Supplemental Analyses.

\section{Research Question 2}

The second research question sought to examine the correlations between scores on the Compassion Satisfaction, Burnout, and Compassion Fatigue subscales of the ProQOL-CSF-R III and the Traumatic Stress Response total score of the IES-R for direct trauma. These results are summarized in Table 13. The Pearson correlation between scores on the Compassion Satisfaction subscale and the IES-R for direct trauma was .015 $(p=.839)$, a nonsignificant finding. The correlation between scores on the Burnout subscale and the IES-R for direct trauma was significant at $.458(p<.001)$. The correlation for Compassion Fatigue and IES-R for direct trauma was .535, also a significant correlation $(p<.001)$. Although statistically significant, from a practical significance perspective, the latter two correlations represent only moderate associations between scores on the respective measures.

\section{Research Question 3}

The third research question sought to explore the correlations between scores on the Compassion Satisfaction, Burnout, and Compassion Fatigue subscales of the ProQOL-CSF-R III and the Traumatic Stress Response total score of the IES-R for indirect trauma. Table 14 presents the results associated with this research question. 
The Pearson correlation between scores on the Compassion Satisfaction subscale and the IES-R for indirect trauma was .043 $(p=.569)$, a nonsignificant finding. The correlation between scores on the Burnout subscale and the IES-R for indirect trauma was significant at $.327(p<.001)$. The correlation for Compassion Fatigue and IES-R for indirect trauma was .580 , also a significant correlation $(p<.001)$. Again, while statistically significant, the latter two correlations represent only low moderate to moderate associations between scores on the respective measures.

\section{Research Question 4}

The fourth research question sought to determine whether significant intergroup differences exist between elementary, middle, and secondary/technical school educators with respect to risk for compassion fatigue. A one-way Analysis of Variance (ANOVA) was conducted with the three school level categories utilized as the independent variable (educator level) and the Compassion Fatigue subscale of the ProQOL-CSF-R III as the dependent variable. The ANOVA was not statistically significant, $F(2,181)=.460$, $p=.632$. Thus, significant differences were not found between elementary educators $(M=15.86, S D=7.60)$, middle school educators $(M=15.11, S D=6.96)$, and secondary/technical school educators $(M=14.67, S D=7.26)$.

\section{Research Question 5}

The fifth research question examined whether significant intergroup differences exist between teachers, school guidance counselors, and administrators with respect to risk for compassion fatigue. The three demographic categories of classroom teacher, subject teacher, and other (specialist) teacher were subsumed under a consolidated teacher category, and principals, vice-principals, and assistant principals were combined 
into an administrator category. A one-way ANOVA was conducted with the three recategorizations of educators utilized as the independent variable (educator category) and the Compassion Fatigue subscale of the ProQOL-CSF-R III as the dependent variable. The ANOVA was not statistically significant, $F(2,181)=.525, p=.592$. Thus, significant differences were not found between teachers $(M=15.44, S D=7.19)$, counselors $(M=13.63, S D=5.08)$, and administrators $(M=16.17, S D=11.13)$. Research Question 6

The sixth research question explored relationships between demographic characteristics and scores on the Compassion Satisfaction, Burnout, and Compassion Fatigue subscales of the ProQOL-CSF-R III. Table 15 presents descriptive statistics for each subscale of the ProQOL-CSF-R III for each level of the nine non-ratio demographic areas surveyed. Partial data representing lower, middle, and upper end of the participant range are displayed for the ratio demographic variables of Number of Years in the Field of Education and Number of Years in Current Position. A cross-sampling of data is presented for the variable of Age.

Correlations between each of the twelve demographics and subscale scores of the ProQOL-CSF-R III are displayed in a correlation matrix in Table 16. Of particular interest was the question of whether a clear relationship exists between years of experience and quality of career engagement in any of the three areas of career satisfaction, burnout, and compassion fatigue. A second query related to the possible interplay of gender and risk for compassion fatigue.

Three types of correlations were computed in the preparation of the correlation matrix in Table 16. The Pearson product-moment correlation procedure was implemented 
to explore relationships between the dependent variable subscales and the following ratio demographics: number of years in field of education, number of years in current position, and age. Spearman's rank order correlations were applied to non-interval data that could be conceptualized ordinally, including: assignment level (elementary, middle, secondary, technical or alternate school); school population, current salary, and highest level of education attained. For purposes of calculating correlations with non-interval demographic data that were not amenable to rank ordering, the remaining demographics were recoded. Recoding these variables as dummy variables (Brace, Kemp, \& Snelgar, 2003, p. 208; Howell, 2002, p. 606) permitted the creation of a dichotomized structure and the calculation of point-biserial correlations using the Pearson procedure (Gravetter \& Wallnau, 2000, p. 552; Howell, 2002, p. 298). The demographic of current position was recategorized as teacher and other, employment status became full-time and other, and ethnicity was recoded as White and other. The dummy variable nomenclature reflected the predominant participant endorsements of teacher, full-time, and White. The demographic characteristics of school location and gender were already naturally coded as dichotomous variables.

None of the correlations between the twelve demographics and subscale scores of the ProQOL-CSF-R III proved to be significant at $p<.05$. No correlational support was obtained for the hypotheses of a relationship between gender and risk for compassion fatigue, or years of experience and quality of career engagement as manifested in satisfaction, and risk for burnout and compassion fatigue. 


\section{Research Question 7}

The seventh research question explored the ability of demographic measures, trauma history, and current level of traumatization to predict status on the quality of career engagement measures. Non-interval and non-ordinal data were recoded into dummy variables as outlined above. Ethnicity was not included as a regression variable because of the limited diversity comprised by the sample.

The reader is reminded that Tables 13 and 14 summarize correlations between scores on the Compassion Satisfaction, Burnout, and Compassion Fatigue subscales of the ProQOL-CSF-R III and the Traumatic Stress Response total scores of the IES-R for direct and indirect trauma respectively. Significant correlations were found between: Burnout scores and IES-R scores for direct trauma $(r=.458, p<.001)$, Compassion Fatigue scores and IES-R scores for direct trauma $(r=.535, p<.001)$, Burnout scores and IES-R scores for indirect trauma $(r=.327, p<.001)$, and Compassion Fatigue scores and IES-R scores for indirect trauma $(r=.580, p<.001)$. Table 16 presents a correlation matrix crossing demographics with the Compassion Satisfaction, Burnout, and Compassion Fatigue subscales of the ProQOL-CSF-R III. None of these was significant. Table 17 presents correlations between the three ProQOL-CSF-R III subscales. Two of the three correlations were significant. The correlation between Compassion Satisfaction and Burnout scores was -.368 $(p<.01)$. The correlation between Burnout and Compassion Fatigue scores was $.650(p<.01)$

Three stepwise regression analyses were conducted using 17 predictor variables to determine their respective contributions to scores on the criterion variable measures of the Compassion Satisfaction, Burnout, and Compassion Fatigue subscales of the 
ProQOL-CSF-R III. The predictor variables included: 11 of the 12 demographic characteristics (ethnicity was excluded due to limited diversity), four types of trauma history as recorded on the HTE survey (direct personal, direct workplace, indirect personal, indirect workplace), and two levels of current traumatization as depicted by Traumatic Stress Response total scores on the IES-R for direct and indirect trauma. The results of the multiple regressions are presented in Table 18.

The minimum recommended ratio of participants to predictor variables for multiple regression is 5:1, which would equal 85 for the 17 predictors used in this study. The participant sample of 184 meets the criterion of 10:1 for "a more acceptable ratio"(Brace et al., 2003, p. 208).

The stepwise method of regression was selected because it is the most parsimonious of the approaches, one that delineates the most efficient combination of predictor variables. It is also considered to be the most sophisticated of the statistical regression methods (Brace et al., 2003). The predictor variable that is most highly correlated with the criterion variable is added first, and the variables that do not make a significant contribution are excluded.

Compassion Satisfaction. An initial multiple regression analysis was conducted using the stepwise method to evaluate how well demographic characteristics, the HTE survey, and the IES-R for direct and indirect trauma predicted compassion satisfaction. One model emerged. The linear relationship between one predictor, HTE Indirect Work trauma history, and the criterion variable was significant, $F(1,150)=5.717, p=.018$. Using $R^{2}$, the model accounts for $3.7 \%$ of the variance in compassion satisfaction. Despite statistical significance, this model represents a poor fit $(<25 \%$ of variance 
accounted for) with respect to prediction of the criterion variable of compassion satisfaction.

The standardized beta weight for HTE Indirect Work trauma history was -.192. This measure describes the contribution of each variable to the model by calculating how much change in standard deviation units will accrue in the criterion variable following a change of one standard deviation in the predictor variable (Brace et al., 2003). The $t$ value of $-2.391(p=.018)$ provided an estimate of the impact of HTE Indirect Work trauma history on the criterion variable of compassion satisfaction.

Burnout. Using the stepwise method, a second multiple regression analysis was conducted to evaluate how well demographic characteristics, the HTE survey, and the IES-R scores for direct and indirect trauma predicted burnout. Two models emerged. In the first, the linear relationship between one predictor, IES-R scores for direct trauma, and the criterion variable was significant, $F(1,150)=36.381, p<.001$. Using $R^{2}$, this model accounted for $19.5 \%$ of the variance in burnout.

The standardized beta weight for IES-R scores for direct trauma was .442, which depicted a moderate contribution to the model. The $t$ value of $6.032(p<.001)$ provided an estimate of the impact of IES-R scores for direct trauma on the criterion variable of burnout.

In the second model, the linear relationship between two of the predictors, IES-R scores for direct trauma and HTE Direct Work trauma history, and the criterion variable was significant, $F(2,149)=21.031, p<.001$. Using $R^{2}$, this model accounted for $22.0 \%$ of the variance in burnout. 
The standardized beta weights were .437 and -.158 for IES-R scores for direct trauma and HTE Direct Work trauma history, respectively. Corresponding $t$ values of $6.044(p<.001)$ and $-2.184(p=.031)$ provided estimates of the impact of these two predictors on the criterion variable of burnout.

Overall, regression was a poor fit (with less than $25 \%$ of variance accounted for) when IES-R scores for direct trauma and HTE Direct Work trauma history were used as regressors to predict burnout. Collinearity diagnostics were undertaken to assess the correlation between the predictor variables. Tolerance values fell within acceptable parameters, at .999 each. Tolerance values range from 0 to 1 , with low values corresponding to a strong relationship between predictor variables. The tolerance values in this regression confirmed that high correlations were not detected between predictor variables. Therefore, inferences could be validly drawn about relative contributions of predictor variables to the model.

Compassion Fatigue. A third multiple regression analysis was conducted using the stepwise method to evaluate how well demographic characteristics, the HTE survey, and the IES-R scores for direct and indirect trauma predicted compassion fatigue. Three models emerged. In the first, the linear relationship between one predictor, IES-R scores for indirect trauma, and the criterion variable was significant, $F(1,150)=84.117$, $p<.001$. Using $R^{2}$, this model accounted for $35.9 \%$ of the variance in compassion fatigue.

The standardized beta weight for IES-R scores for indirect trauma was .599, which represented a moderately strong contribution to the model. The $t$ value of 9.172 
$(p<.001)$ provided an estimate of the impact of IES-R scores for indirect trauma on the criterion variable of compassion fatigue.

In the second model, the linear relationship between two of the predictors, IES-R scores for indirect trauma and IES-R scores for direct trauma, and the criterion variable was significant, $F(2,149)=48.362, p<.001$. Using $R^{2}$, this model accounted for $39.4 \%$ of the variance in compassion fatigue.

The standardized beta weights were .437 and .247 for IES-R scores for indirect trauma and direct trauma, respectively. Corresponding $t$ values of $5.146(p<.001)$ and $2.904(p=.004)$ provided estimates of the impact of these two predictors on the criterion variable of compassion fatigue.

In the third model, the linear relationship between three of the predictors, IES-R scores for indirect trauma, IES-R scores for direct trauma, and school level, and the criterion variable was significant, $F(3,148)=35.760, p<.001$. Using $R^{2}$, this model accounted for $42.0 \%$ of the variance in compassion fatigue.

The standardized beta weights were $.432, .267$ and -.164 for IES-R scores for indirect trauma, IES-R scores for direct trauma, and school level respectively. Corresponding $t$ values of $5.185(p<.001), 3.192(p=.002)$, and -2.607 $(p=.010)$ provided estimates of the impact of these three predictors on the criterion variable of compassion fatigue.

Overall, regression was a fair fit (fair $=25-50 \%$ of variance accounted for) when IES-R scores for indirect and direct trauma and school level were used as regressors to predict compassion fatigue. Collinearity diagnostics were undertaken to assess the correlation between the predictor variables. Tolerance values fell within acceptable 
parameters, at $.565, .560$, and .989 . Tolerance values range from 0 to 1 , with low values corresponding to a strong relationship between predictor variables. The tolerance values in this regression confirmed that high correlations were not detected between predictor variables. Therefore, inferences could be validly drawn about relative contributions of predictor variables to the model.

\section{Supplemental Analyses}

In Research Question 1, descriptive analyses were conducted to determine the extent to which participants surpassed upper quartile cut-off scores on each of the Compassion Satisfaction, Burnout, and Compassion Fatigue subtests, and the lower quartile cut-off score for the Compassion Satisfaction subtest of the ProQOL-CSF-R III. Additional analyses were carried out to determine similar frequency and percentage data for combinations of the subtests as follows: (1) Compassion Satisfaction (upper quartile scores) and Burnout; (2) Compassion Satisfaction (upper quartile scores) and Compassion Fatigue; (3) Compassion Satisfaction (lower quartile scores) and Burnout; (4) Compassion Satisfaction (lower quartile scores) and Compassion Fatigue; (5) Burnout and Compassion Fatigue; (6) Compassion Satisfaction (upper quartile), Burnout, and Compassion Fatigue; and (7) Compassion Satisfaction (lower quartile scores), Burnout, and Compassion Fatigue. These analyses were conducted to determine whether interesting and informative patterns might emerge. Corresponding data are presented in Table 19.

In Research Question 4, a one-way ANOVA was conducted to explore mean score differences on the Compassion Fatigue subtest of the ProQOL-CSF-R III when category of assignment level (school level) was used as the independent variable. 
Similarly, a one-way ANOVA was conducted in Research Question 5, to explore mean score differences on the Compassion Fatigue subtest of the ProQOL-CSF-R III when the recategorization of the demographic variable of current position from six levels into three levels of teacher, counselor, and administrator, was utilized as the independent variable. The resulting F-ratios were not significant for either procedure.

As an extension of Research Questions 4 and 5, three supplemental one-way ANOVAs were conducted to ascertain whether any significant mean score differences existed on the Compassion Fatigue subtest of the ProQOL-CSF-R III when the levels of school population, current salary, and highest level of education attained, were entered as independent variables. No significance emerged in the corresponding $F$-ratios.

The results of the ANOVA for school population were $F(7,175)=1.260$, $p=.273$. Significant differences on Compassion Fatigue scores were not found for school population: $<200(M=15.86, S D=4.66), 200-399(M=13.82, S D=6.22)$, 400-599 $(M=16.82, S D=8.32), 600-799(M=15.89, S D=6.80), 800-999(M=12.37$, $S D=6.24), 1,000-1,199(M=8.00, S D=2.83), 1,200-1,399(M=15.00, n=1)$, and $1,600-1,799(M=15.38, S D=8.29)$.

The results of the ANOVA for current salary were $F(6,172)=.449, p=.845$. Significant differences on Compassion Fatigue scores were not found for current salary: $<\$ 20,000(M=16.00, S D=9.19), \$ 20,000-29,999(M=14.94, S D=9.68), \$ 30,000-$ 39,999 $(M=15.63, S D=6.10), \$ 40,000-49,999(M=14.20, S D=6.63), \$ 50,000-59,999$ $(M=16.08, S D=7.37), \$ 60,000-69,999(M=16.40, S D=7.04)$, and $\$ 70,000-79,999$ $(M=17.20, S D=10.69)$. 
The results of the ANOVA for education level were $F(3,180)=.683, p=.563$.

Significant differences on Compassion Fatigue scores were not found for education level: Bachelor's $(M=14.85, S D=7.47)$, Master's $(M=15.84, S D=7.32)$, Doctoral $(M=$ $12.00, S D=4.94)$, and Other $(M=15.50, S D=8.58)$.

Finally, independent samples t-tests were conducted to determine whether or not gender or location (Nova Scotia versus West Virginia) played a role in level of career satisfaction, and risk for burnout or compassion fatigue. The resulting sample statistics did not meet critical values.

With respect to gender, significant score differences were not found for Compassion Satisfaction, $t(182)=.890, p=.375$, two-tailed, between Nova Scotia $(M=37.10, S D=7.46)$ and West Virginia $(M=35.95, S D=7.41)$. Similarly, significant score differences were not found for Burnout, $t(182)=.196, p=.845$, two-tailed, between Nova Scotia $(M=23.94, S D=7.02)$ and West Virginia $(M=23.70, S D=6.14)$. Nor were significant score differences found for Compassion Fatigue, $t(182)=.644$, $p=.520$, two-tailed, between Nova Scotia $(M=15.52, S D=6.98)$ and West Virginia $(M=14.70, S D=8.39)$.

With respect to location, significant score differences were not found for Compassion Satisfaction, $t(182)=.339, p=.735$, two-tailed, between Nova Scotia $(M=37.01, S D=7.14)$ and West Virginia $(M=36.64, S D=7.78)$. Similarly, significant score differences were not found for Burnout, $t(182)=1.350, p=.179$, two-tailed, between Nova Scotia $(M=24.55, S D=6.05)$ and West Virginia $(M=23.20, S D=7.46)$. Nor were significant score differences found for Compassion Fatigue, $t(182)=1.202$, $p=.231$, two-tailed, between Nova Scotia $(M=15.97, S D=7.68)$ and West Virginia 
$(M=14.67, S D=6.93)$.

Tables 4 through 19 are located on the succeeding pages. The tables provide visual summaries intended to clarify relationships between the independent and dependent variables. The independent variables comprise participant demographic characteristics (Demographic Information), history of traumatic experiences (HTE), and current trauma status (total scores on the IES-R for direct and indirect trauma). The dependent variables are scores on the Compassion Satisfaction, Burnout, and Compassion Fatigue subscales of the ProQOL-CSF-R III. While the Burnout and Compassion Fatigue subscales are used to measure constructs of the same name, the Compassion Satisfaction subscale is used to measure the construct of career satisfaction. 
Table 4

Frequency and Percent of Educators' Demographic Responses

\begin{tabular}{ll}
\hline Variable & Frequency \\
\end{tabular}

Current Position

Classroom Teacher

Subject Teacher

$80 \quad 43.5$

Other (Specialist) Teacher

$44 \quad 23.9$

School/Guidance Counselor

$32 \quad 17.4$

Vice-principal

Principal

$\begin{array}{ll}16 & 8.7\end{array}$

$\begin{array}{ll}5 & 2.7\end{array}$

$7 \quad 3.8$

Assignment Level

Elementary

46.2

Middle

85

24.5

Secondary

Technical or Alternate School

$\begin{array}{rr}49 & 26.6 \\ 5 & 2.7\end{array}$

School Population

$<200$

$14 \quad 7.6$

200-399

$22 \quad 12.0$

400-599

$55 \quad 29.9$

600-799

$46 \quad 25.0$

800-999

$19 \quad 10.3$

1000-1199

1200-1399

$2 \quad 1.1$

1400-1599

$1 \quad 0.5$

1600-1799

$\begin{array}{ll}0 & 0.0\end{array}$

1800-1999

$24 \quad 13.0$

Missing

$0 \quad 0.0$

$1 \quad 0.5$

$\underline{\text { School Location }}$

Nova Scotia

West Virginia

$93 \quad 50.5$

$91 \quad 49.5$

Employment Status

Full-time

$169 \quad 91.8$

Part-time

$11 \quad 6.0$

Substitute

$4 \quad 2.2$

(table continues) 
Table 4 continued

Frequency and Percent of Educators' Demographic Responses

\begin{tabular}{lrr}
\hline Variable & Frequency & Percent \\
\hline & & \\
Gender & 140 & 76.1 \\
Female & 44 & 23.9 \\
Male & & \\
& & \\
Ethnicity & 144 & 78.3 \\
White or Euro-American/Canadian & 1 & 0.5 \\
Black or African-American/Canadian & 1 & 0.5 \\
Native American/Canadian & 0 & 0.0 \\
Asian-American/Canadian & 0 & 0.0 \\
Latino/Latina or Hispanic & 38 & 20.7 \\
Missing & & \\
& & \\
Current Salary & 5 & 2.7 \\
<20,000 & 17 & 9.2 \\
20,000-29,999 & 40 & 21.7 \\
30,000-39,999 & 46 & 25.0 \\
40,000-49,999 & 36 & 19.6 \\
6,000-59,999 & 25 & 13.6 \\
70,000-69,999 & 10 & 5.4 \\
$80,000-89,999$ & 0 & 0.0 \\
$90,000+$ & 0 & 0.0 \\
Missing & 5 & 2.7 \\
Highest Level of Education Attained & & \\
Bachelor's degree & & \\
Master's degree & 71 & 38.6 \\
Doctoral degree & 63 & 56.0 \\
Other & 4 & 3.3 \\
& & 2.2 \\
\hline & & \\
\hline
\end{tabular}

Note. Salaries do not reflect adjustments for US-Canada exchange rates or cost of living. 
Table 5

Means and Standard Deviations of Educators' Demographic Responses

\begin{tabular}{lcccc}
\hline Variable & Minimum & Maximum & $M$ & $S D$ \\
\hline Number of Years in Field of Education & 1 & 39 & 18.90 & 9.68 \\
Number of Years in Current Position & 1 & 39 & 8.57 & 8.34 \\
Age & 24 & 64 & 45.49 & 9.56 \\
\hline
\end{tabular}


Table 6

Frequency and Percent of Direct and Indirect Trauma History in Personal and Work Life

Variable

Frequency Percent

Direct Trauma Experienced in Personal Life

Yes

No

Missing

160

87.0

$11 \quad 6.0$

$13 \quad 7.1$

Direct Trauma Experienced in Work Life

Yes

89

48.4

No

80

Missing

$\underline{\text { Indirect Trauma Experienced in Personal Life }}$

Yes

122

66.3

No

Missing

Indirect Trauma Experienced in Work Life

Yes

132

71.7

No

Missing

Direct Trauma in Both Personal and Work Life

Yes

85

46.2

No

Missing

Indirect Trauma in Both Personal and Work Life

Yes

100

54.3

No

Missing

Trauma History in Any of

Direct or Indirect, Personal or Work Life

Yes

No

172

93.5

Missing 
Table 7

Frequency and Percent of Direct and Indirect Trauma History by Trauma Category

\begin{tabular}{|c|c|c|c|c|c|}
\hline Variable & Missing & None & Indirect & Direct & Both \\
\hline Bullying, stalking, or swarming & $\begin{array}{l}3 \\
1.6 \%\end{array}$ & $\begin{array}{l}43 \\
23.4 \%\end{array}$ & $\begin{array}{l}27 \\
14.7 \%\end{array}$ & $\begin{array}{l}52 \\
28.3 \%\end{array}$ & $\begin{array}{l}59 \\
32.1 \%\end{array}$ \\
\hline $\begin{array}{l}\text { Robbery, burglary, mugging } \\
\text { with theft, identity theft }\end{array}$ & $\begin{array}{l}3 \\
1.6 \%\end{array}$ & $\begin{array}{l}77 \\
41.8 \%\end{array}$ & $\begin{array}{l}39 \\
21.2 \%\end{array}$ & $\begin{array}{l}38 \\
20.7 \%\end{array}$ & $\begin{array}{l}27 \\
14.7 \%\end{array}$ \\
\hline Child abuse or assault & $\begin{array}{l}3 \\
1.6 \%\end{array}$ & $\begin{array}{l}46 \\
25.0 \%\end{array}$ & $\begin{array}{l}78 \\
42.4 \%\end{array}$ & $\begin{array}{l}27 \\
14.7 \%\end{array}$ & $\begin{array}{l}30 \\
16.3 \%\end{array}$ \\
\hline Physical assault as adult & $\begin{array}{l}3 \\
1.6 \%\end{array}$ & $\begin{array}{l}112 \\
60.9 \%\end{array}$ & $\begin{array}{l}38 \\
20.7 \%\end{array}$ & $\begin{array}{l}19 \\
10.3 \%\end{array}$ & $\begin{array}{l}12 \\
6.5 \%\end{array}$ \\
\hline Sexual assault as adult & $\begin{array}{l}3 \\
1.6 \%\end{array}$ & $\begin{array}{l}128 \\
69.6 \%\end{array}$ & $\begin{array}{l}44 \\
23.9 \%\end{array}$ & $\begin{array}{l}6 \\
3.3 \%\end{array}$ & $\begin{array}{l}3 \\
1.6 \%\end{array}$ \\
\hline $\begin{array}{l}\text { Abduction, hostage-taking, } \\
\text { confinement, torture }\end{array}$ & $\begin{array}{l}3 \\
1.6 \%\end{array}$ & $\begin{array}{l}159 \\
86.4 \%\end{array}$ & $\begin{array}{l}18 \\
9.8 \%\end{array}$ & $\begin{array}{l}3 \\
1.6 \%\end{array}$ & $\begin{array}{l}1 \\
0.5 \%\end{array}$ \\
\hline Shooting, stabbing, or bombing & $\begin{array}{l}3 \\
1.6 \%\end{array}$ & $\begin{array}{l}131 \\
71.2 \%\end{array}$ & $\begin{array}{l}44 \\
23.9 \%\end{array}$ & $\begin{array}{l}4 \\
2.2 \%\end{array}$ & $\begin{array}{l}2 \\
1.1 \%\end{array}$ \\
\hline Homicide & $\begin{array}{l}3 \\
1.6 \%\end{array}$ & $\begin{array}{l}147 \\
79.9 \%\end{array}$ & $\begin{array}{l}32 \\
17.4 \%\end{array}$ & $\begin{array}{l}1 \\
0.5 \%\end{array}$ & $\begin{array}{l}1 \\
0.5 \%\end{array}$ \\
\hline Suicide & $\begin{array}{l}3 \\
1.6 \%\end{array}$ & $\begin{array}{l}64 \\
34.8 \%\end{array}$ & $\begin{array}{l}101 \\
54.9 \%\end{array}$ & $\begin{array}{l}12 \\
6.5 \%\end{array}$ & $\begin{array}{l}4 \\
2.2 \%\end{array}$ \\
\hline Accident & $\begin{array}{l}3 \\
1.6 \%\end{array}$ & $\begin{array}{l}31 \\
16.8 \%\end{array}$ & $\begin{array}{l}39 \\
21.2 \%\end{array}$ & $\begin{array}{l}56 \\
30.4 \%\end{array}$ & $\begin{array}{l}55 \\
29.9 \%\end{array}$ \\
\hline Accidental or other sudden death & $\begin{array}{l}3 \\
1.6 \%\end{array}$ & $\begin{array}{l}49 \\
26.6 \%\end{array}$ & $\begin{array}{l}69 \\
37.5 \%\end{array}$ & $\begin{array}{l}33 \\
17.9 \%\end{array}$ & $\begin{array}{l}30 \\
16.3 \%\end{array}$ \\
\hline Serious injury & $\begin{array}{l}3 \\
1.6 \%\end{array}$ & $\begin{array}{l}66 \\
35.9 \%\end{array}$ & $\begin{array}{l}62 \\
33.7 \%\end{array}$ & $\begin{array}{l}29 \\
15.8 \%\end{array}$ & $\begin{array}{l}24 \\
13.0 \%\end{array}$ \\
\hline
\end{tabular}


Table 7 continued

Frequency and Percent of Direct and Indirect Trauma History by Trauma Category

\begin{tabular}{|c|c|c|c|c|c|}
\hline Variable & Missing & None & Indirect & Direct & Both \\
\hline Serious medical or mental illness & $\begin{array}{l}3 \\
1.6 \%\end{array}$ & $\begin{array}{l}38 \\
20.7 \%\end{array}$ & $33.2 \%$ & $\begin{array}{l}43 \\
23.4 \%\end{array}$ & $\begin{array}{l}39 \\
21.2 \%\end{array}$ \\
\hline Invasive medical procedures & $\begin{array}{l}3 \\
1.6 \%\end{array}$ & $\begin{array}{l}32 \\
17.4 \%\end{array}$ & $\begin{array}{l}51 \\
27.7 \%\end{array}$ & $\begin{array}{l}58 \\
31.5 \%\end{array}$ & $\begin{array}{l}40 \\
21.7 \%\end{array}$ \\
\hline Disaster due to human error & $\begin{array}{l}3 \\
1.6 \%\end{array}$ & $\begin{array}{l}119 \\
64.7 \%\end{array}$ & $\begin{array}{l}50 \\
27.2 \%\end{array}$ & $\begin{array}{l}8 \\
4.3 \%\end{array}$ & $\begin{array}{l}4 \\
2.2 \%\end{array}$ \\
\hline Natural disaster & $\begin{array}{l}3 \\
1.6 \%\end{array}$ & $\begin{array}{l}92 \\
50.0 \%\end{array}$ & $\begin{array}{l}54 \\
29.3 \%\end{array}$ & $\begin{array}{l}27 \\
14.7 \%\end{array}$ & $\begin{array}{l}8 \\
4.3 \%\end{array}$ \\
\hline Mauling or attack by animal & $\begin{array}{l}3 \\
1.6 \%\end{array}$ & $\begin{array}{l}128 \\
69.6 \%\end{array}$ & $\begin{array}{l}34 \\
18.5 \%\end{array}$ & $\begin{array}{l}15 \\
8.2 \%\end{array}$ & $\begin{array}{l}4 \\
2.2 \%\end{array}$ \\
\hline $\begin{array}{l}\text { Unexpected loss of life to pet, } \\
\text { livestock, or other animal }\end{array}$ & $\begin{array}{l}3 \\
1.6 \%\end{array}$ & $\begin{array}{l}57 \\
31.0 \%\end{array}$ & $\begin{array}{l}25 \\
13.6 \%\end{array}$ & $\begin{array}{l}76 \\
41.3 \%\end{array}$ & $\begin{array}{l}23 \\
12.5 \%\end{array}$ \\
\hline War, combat, or terrorism & $\begin{array}{l}3 \\
1.6 \%\end{array}$ & $\begin{array}{l}110 \\
59.8 \%\end{array}$ & $34.2 \%$ & $\begin{array}{l}4 \\
2.2 \%\end{array}$ & $\begin{array}{l}4 \\
2.2 \%\end{array}$ \\
\hline Unexpected unemployment & $\begin{array}{l}3 \\
1.6 \%\end{array}$ & $\begin{array}{l}86 \\
46.7 \%\end{array}$ & $\begin{array}{l}38 \\
20.7 \%\end{array}$ & $\begin{array}{l}37 \\
20.1 \%\end{array}$ & $\begin{array}{l}20 \\
10.9 \%\end{array}$ \\
\hline End of marriage or partnership & $\begin{array}{l}3 \\
1.6 \%\end{array}$ & $\begin{array}{l}73 \\
39.7 \%\end{array}$ & $\begin{array}{l}54 \\
29.3 \%\end{array}$ & $\begin{array}{l}31 \\
16.8 \%\end{array}$ & $\begin{array}{l}23 \\
12.5 \%\end{array}$ \\
\hline Other & $\begin{array}{l}3 \\
1.6 \%\end{array}$ & $\begin{array}{l}171 \\
92.9 \%\end{array}$ & $\begin{array}{l}1 \\
0.5 \%\end{array}$ & $\begin{array}{l}8 \\
4.3 \%\end{array}$ & $\begin{array}{l}1 \\
0.5 \%\end{array}$ \\
\hline
\end{tabular}


Table 8

Frequency and Percent of Direct Trauma in Personal and Work Life by Trauma Category

\begin{tabular}{|c|c|c|c|c|c|}
\hline Variable & Missing & None & Work & Personal & Both \\
\hline Bullying, stalking, or swarming & $\begin{array}{l}13 \\
7.1 \%\end{array}$ & $\begin{array}{l}63 \\
34.2 \%\end{array}$ & $\begin{array}{l}42 \\
22.8 \%\end{array}$ & $\begin{array}{l}33 \\
17.9 \%\end{array}$ & $\begin{array}{l}33 \\
17.9 \%\end{array}$ \\
\hline $\begin{array}{l}\text { Robbery, burglary, mugging } \\
\text { with theft, identity theft }\end{array}$ & $\begin{array}{l}13 \\
7.1 \%\end{array}$ & $\begin{array}{l}110 \\
59.8 \%\end{array}$ & $\begin{array}{l}11 \\
6.0 \%\end{array}$ & $\begin{array}{l}37 \\
20.1 \%\end{array}$ & $\begin{array}{l}13 \\
7.1 \%\end{array}$ \\
\hline Child abuse or assault & $\begin{array}{l}13 \\
7.1 \%\end{array}$ & $\begin{array}{l}116 \\
63.0 \%\end{array}$ & $\begin{array}{l}13 \\
7.1 \%\end{array}$ & $\begin{array}{l}29 \\
15.8 \%\end{array}$ & $\begin{array}{l}13 \\
7.1 \%\end{array}$ \\
\hline Physical assault as adult & $\begin{array}{l}13 \\
7.1 \%\end{array}$ & $\begin{array}{l}140 \\
76.1 \%\end{array}$ & $\begin{array}{l}8 \\
4.3 \%\end{array}$ & $\begin{array}{l}20 \\
10.9 \%\end{array}$ & $\begin{array}{l}3 \\
1.6 \%\end{array}$ \\
\hline Sexual assault as adult & $\begin{array}{l}13 \\
7.1 \%\end{array}$ & $\begin{array}{l}162 \\
88.0 \%\end{array}$ & $\begin{array}{l}0 \\
0.0 \%\end{array}$ & $\begin{array}{l}9 \\
4.9 \%\end{array}$ & $\begin{array}{l}0 \\
0.0 \%\end{array}$ \\
\hline $\begin{array}{l}\text { Abduction, hostage-taking, } \\
\text { confinement, torture }\end{array}$ & $\begin{array}{l}13 \\
7.1 \%\end{array}$ & $\begin{array}{l}167 \\
90.8 \%\end{array}$ & $\begin{array}{l}1 \\
0.5 \%\end{array}$ & $\begin{array}{l}3 \\
1.6 \%\end{array}$ & $\begin{array}{l}0 \\
0.0 \%\end{array}$ \\
\hline Shooting, stabbing, or bombing & $\begin{array}{l}13 \\
7.1 \%\end{array}$ & $\begin{array}{l}165 \\
89.7 \%\end{array}$ & $\begin{array}{l}3 \\
1.6 \%\end{array}$ & $\begin{array}{l}3 \\
1.6 \%\end{array}$ & $\begin{array}{l}0 \\
0.0 \%\end{array}$ \\
\hline Homicide & $\begin{array}{l}14 \\
7.6 \%\end{array}$ & $\begin{array}{l}168 \\
91.3 \%\end{array}$ & $\begin{array}{l}1 \\
0.5 \%\end{array}$ & $\begin{array}{l}1 \\
0.5 \%\end{array}$ & $\begin{array}{l}0 \\
0.0 \%\end{array}$ \\
\hline Suicide & $\begin{array}{l}13 \\
7.1 \%\end{array}$ & $\begin{array}{l}155 \\
84.2 \%\end{array}$ & $\begin{array}{l}3 \\
1.6 \%\end{array}$ & $\begin{array}{l}12 \\
6.5 \%\end{array}$ & $\begin{array}{l}1 \\
0.5 \%\end{array}$ \\
\hline Accident & $\begin{array}{l}13 \\
7.1 \%\end{array}$ & $\begin{array}{l}65 \\
35.3 \%\end{array}$ & $\begin{array}{l}8 \\
4.3 \%\end{array}$ & $\begin{array}{l}79 \\
42.9 \%\end{array}$ & $\begin{array}{l}19 \\
10.3 \%\end{array}$ \\
\hline Accidental or other sudden death & $\begin{array}{l}13 \\
7.1 \%\end{array}$ & $\begin{array}{l}111 \\
60.3 \%\end{array}$ & $\begin{array}{l}5 \\
2.7 \%\end{array}$ & $\begin{array}{l}42 \\
22.8 \%\end{array}$ & $\begin{array}{l}13 \\
7.1 \%\end{array}$ \\
\hline Serious injury & $\begin{array}{l}13 \\
7.1 \%\end{array}$ & $\begin{array}{l}119 \\
64.7 \%\end{array}$ & $\begin{array}{l}6 \\
3.3 \%\end{array}$ & $\begin{array}{l}39 \\
21.2 \%\end{array}$ & $\begin{array}{l}7 \\
3.8 \%\end{array}$ \\
\hline
\end{tabular}


Table 8 continued

Frequency and Percent of Direct Trauma in Personal and Work Life by Trauma Category

\begin{tabular}{|c|c|c|c|c|c|}
\hline Variable & Missing & None & Work & Personal & Both \\
\hline Serious medical or mental illness & $\begin{array}{l}13 \\
7.1 \%\end{array}$ & $\begin{array}{l}94 \\
51.1 \%\end{array}$ & $\begin{array}{l}4 \\
2.2 \%\end{array}$ & $\begin{array}{l}58 \\
31.5 \%\end{array}$ & $\begin{array}{l}15 \\
8.2 \%\end{array}$ \\
\hline Invasive medical procedures & $\begin{array}{l}13 \\
7.1 \%\end{array}$ & $\begin{array}{l}75 \\
40.8 \%\end{array}$ & $\begin{array}{l}5 \\
2.7 \%\end{array}$ & $\begin{array}{l}84 \\
45.7 \%\end{array}$ & $\begin{array}{l}7 \\
3.8 \%\end{array}$ \\
\hline Disaster due to human error & $\begin{array}{l}13 \\
7.1 \%\end{array}$ & $\begin{array}{l}160 \\
87.0 \%\end{array}$ & $\begin{array}{l}2 \\
1.1 \%\end{array}$ & $\begin{array}{l}7 \\
3.8 \%\end{array}$ & $\begin{array}{l}2 \\
1.1 \%\end{array}$ \\
\hline Natural disaster & $\begin{array}{l}13 \\
7.1 \%\end{array}$ & $\begin{array}{l}137 \\
74.5 \%\end{array}$ & $\begin{array}{l}1 \\
0.5 \%\end{array}$ & $\begin{array}{l}33 \\
17.9 \%\end{array}$ & $\begin{array}{l}0 \\
0.0 \%\end{array}$ \\
\hline Mauling or attack by animal & $\begin{array}{l}13 \\
7.1 \%\end{array}$ & $\begin{array}{l}152 \\
82.6 \%\end{array}$ & $\begin{array}{l}0 \\
0.0 \%\end{array}$ & $\begin{array}{l}19 \\
10.3 \%\end{array}$ & $\begin{array}{l}0 \\
0.0 \%\end{array}$ \\
\hline $\begin{array}{l}\text { Unexpected loss of life to pet, } \\
\text { livestock or other animal }\end{array}$ & $\begin{array}{l}13 \\
7.1 \%\end{array}$ & $\begin{array}{l}75 \\
40.8 \%\end{array}$ & & $\begin{array}{l}92 \\
50.0 \%\end{array}$ & $\begin{array}{l}4 \\
2.2 \%\end{array}$ \\
\hline War, combat, or terrorism & $\begin{array}{l}13 \\
7.1 \%\end{array}$ & $\begin{array}{l}163 \\
88.6 \%\end{array}$ & $\begin{array}{l}0 \\
0.0 \%\end{array}$ & $\begin{array}{l}8 \\
4.3 \%\end{array}$ & $\begin{array}{l}0 \\
0.0 \%\end{array}$ \\
\hline Unexpected unemployment & $\begin{array}{l}13 \\
7.1 \%\end{array}$ & $\begin{array}{l}115 \\
62.5 \%\end{array}$ & $\begin{array}{l}9 \\
4.9 \%\end{array}$ & $\begin{array}{l}42 \\
22.8 \%\end{array}$ & $\begin{array}{l}5 \\
2.7 \%\end{array}$ \\
\hline End of marriage or partnership & $\begin{array}{l}13 \\
7.1 \%\end{array}$ & $\begin{array}{l}120 \\
65.2 \%\end{array}$ & $\begin{array}{l}3 \\
1.6 \%\end{array}$ & $\begin{array}{l}46 \\
25.0 \%\end{array}$ & $\begin{array}{l}2 \\
1.1 \%\end{array}$ \\
\hline Other & $\begin{array}{l}13 \\
7.1 \%\end{array}$ & $\begin{array}{l}162 \\
88.0 \%\end{array}$ & $\begin{array}{l}0 \\
0.0 \%\end{array}$ & $\begin{array}{l}8 \\
4.3 \%\end{array}$ & $\begin{array}{l}1 \\
0.5 \%\end{array}$ \\
\hline
\end{tabular}


Table 9

Frequency and Percent of Indirect Trauma in Personal and Work Life by Trauma Category

\begin{tabular}{|c|c|c|c|c|c|}
\hline Variable & Missing & None & Work & Personal & Both \\
\hline Bullying, stalking, or swarming & $\begin{array}{l}14 \\
7.6 \%\end{array}$ & $\begin{array}{l}87 \\
47.3 \%\end{array}$ & $\begin{array}{l}51 \\
27.7 \%\end{array}$ & $\begin{array}{l}9 \\
4.9 \%\end{array}$ & $\begin{array}{l}23 \\
12.5 \%\end{array}$ \\
\hline $\begin{array}{l}\text { Robbery, burglary, mugging } \\
\text { with theft, identity theft }\end{array}$ & $\begin{array}{l}15 \\
8.2 \%\end{array}$ & $\begin{array}{l}108 \\
58.7 \%\end{array}$ & $\begin{array}{l}21 \\
11.4 \%\end{array}$ & $\begin{array}{l}21 \\
11.4 \%\end{array}$ & $\begin{array}{l}19 \\
10.3 \%\end{array}$ \\
\hline Child abuse or assault & $\begin{array}{l}14 \\
7.6 \%\end{array}$ & $\begin{array}{l}68 \\
37.0 \%\end{array}$ & $\begin{array}{l}69 \\
37.5 \%\end{array}$ & $\begin{array}{l}13 \\
7.1 \%\end{array}$ & $\begin{array}{l}20 \\
10.9 \%\end{array}$ \\
\hline Physical assault as adult & $\begin{array}{l}14 \\
7.6 \%\end{array}$ & $\begin{array}{l}123 \\
66.8 \%\end{array}$ & $\begin{array}{l}25 \\
13.6 \%\end{array}$ & $\begin{array}{l}12 \\
6.5 \%\end{array}$ & $\begin{array}{l}10 \\
5.4 \%\end{array}$ \\
\hline Sexual assault as adult & $\begin{array}{l}14 \\
7.6 \%\end{array}$ & $\begin{array}{l}126 \\
68.5 \%\end{array}$ & $\begin{array}{l}22 \\
12.0 \%\end{array}$ & $\begin{array}{l}14 \\
7.6 \%\end{array}$ & $\begin{array}{l}8 \\
4.3 \%\end{array}$ \\
\hline $\begin{array}{l}\text { Abduction, hostage-taking, } \\
\text { confinement, torture }\end{array}$ & $\begin{array}{l}14 \\
7.6 \%\end{array}$ & $\begin{array}{l}151 \\
82.1 \%\end{array}$ & $\begin{array}{l}6 \\
3.3 \%\end{array}$ & $\begin{array}{l}10 \\
5.4 \%\end{array}$ & $\begin{array}{l}3 \\
1.6 \%\end{array}$ \\
\hline Shooting, stabbing, or bombing & $\begin{array}{l}15 \\
8.2 \%\end{array}$ & $\begin{array}{l}126 \\
68.5 \%\end{array}$ & $\begin{array}{l}23 \\
12.5 \%\end{array}$ & $\begin{array}{l}15 \\
8.2 \%\end{array}$ & $\begin{array}{l}5 \\
2.7 \%\end{array}$ \\
\hline Homicide & $\begin{array}{l}15 \\
8.2 \%\end{array}$ & $\begin{array}{l}139 \\
75.5 \%\end{array}$ & $\begin{array}{l}13 \\
7.1 \%\end{array}$ & $\begin{array}{l}13 \\
7.1 \%\end{array}$ & $\begin{array}{l}4 \\
2.2 \%\end{array}$ \\
\hline Suicide & $\begin{array}{l}15 \\
8.2 \%\end{array}$ & $\begin{array}{l}70 \\
38.0 \%\end{array}$ & $\begin{array}{l}38 \\
20.7 \%\end{array}$ & $\begin{array}{l}40 \\
21.7 \%\end{array}$ & $\begin{array}{l}21 \\
11.4 \%\end{array}$ \\
\hline Accident & $\begin{array}{l}16 \\
8.7 \%\end{array}$ & $\begin{array}{l}82 \\
44.6 \%\end{array}$ & $\begin{array}{l}23 \\
12.5 \%\end{array}$ & $\begin{array}{l}30 \\
16.3 \%\end{array}$ & $\begin{array}{l}33 \\
17.9 \%\end{array}$ \\
\hline Accidental or other sudden death & $\begin{array}{l}15 \\
8.2 \%\end{array}$ & $\begin{array}{l}77 \\
41.8 \%\end{array}$ & $\begin{array}{l}30 \\
16.3 \%\end{array}$ & $\begin{array}{l}35 \\
19.0 \%\end{array}$ & $\begin{array}{l}27 \\
14.7 \%\end{array}$ \\
\hline Serious injury & $\begin{array}{l}14 \\
7.6 \%\end{array}$ & $\begin{array}{l}92 \\
50.0 \%\end{array}$ & $\begin{array}{l}27 \\
14.7 \%\end{array}$ & $\begin{array}{l}24 \\
13.0 \%\end{array}$ & $\begin{array}{l}27 \\
14.7 \%\end{array}$ \\
\hline
\end{tabular}


Table 9 continued

Frequency and Percent of Indirect Trauma in Personal and Work Life by Trauma Category

\begin{tabular}{|c|c|c|c|c|c|}
\hline Variable & Missing & None & Work & Personal & Both \\
\hline Serious medical or mental illness & $\begin{array}{l}15 \\
8.2 \%\end{array}$ & $\begin{array}{l}78 \\
42.4 \%\end{array}$ & $\begin{array}{l}27 \\
14.7 \%\end{array}$ & $\begin{array}{l}34 \\
18.5 \%\end{array}$ & $\begin{array}{l}30 \\
16.3 \%\end{array}$ \\
\hline Invasive medical procedures & $\begin{array}{l}14 \\
7.6 \%\end{array}$ & $\begin{array}{l}87 \\
47.3 \%\end{array}$ & $\begin{array}{l}21 \\
11.4 \%\end{array}$ & $\begin{array}{l}35 \\
19.0 \%\end{array}$ & $\begin{array}{l}27 \\
14.7 \%\end{array}$ \\
\hline Disaster due to human error & $\begin{array}{l}16 \\
8.7 \%\end{array}$ & $\begin{array}{l}120 \\
65.2 \%\end{array}$ & $\begin{array}{l}14 \\
7.6 \%\end{array}$ & $\begin{array}{l}19 \\
10.3 \%\end{array}$ & $\begin{array}{l}15 \\
8.2 \%\end{array}$ \\
\hline Natural disaster & $\begin{array}{l}15 \\
8.2 \%\end{array}$ & $\begin{array}{l}113 \\
61.4 \%\end{array}$ & $\begin{array}{l}11 \\
6.0 \%\end{array}$ & $\begin{array}{l}34 \\
18.5 \%\end{array}$ & $\begin{array}{l}11 \\
6.0 \%\end{array}$ \\
\hline Mauling or attack by animal & $\begin{array}{l}14 \\
7.6 \%\end{array}$ & $\begin{array}{l}134 \\
72.8 \%\end{array}$ & $\begin{array}{l}6 \\
3.3 \%\end{array}$ & $\begin{array}{l}25 \\
13.6 \%\end{array}$ & $\begin{array}{l}5 \\
2.7 \%\end{array}$ \\
\hline $\begin{array}{l}\text { Unexpected loss of life to pet, } \\
\text { livestock, or other animal }\end{array}$ & $\begin{array}{l}14 \\
7.6 \%\end{array}$ & $\begin{array}{l}127 \\
69.0 \%\end{array}$ & $\begin{array}{l}10 \\
5.4 \%\end{array}$ & $\begin{array}{l}20 \\
10.9 \%\end{array}$ & $\begin{array}{l}13 \\
7.1 \%\end{array}$ \\
\hline War, combat, or terrorism & $\begin{array}{l}15 \\
8.2 \%\end{array}$ & $\begin{array}{l}107 \\
58.2 \%\end{array}$ & $\begin{array}{l}11 \\
6.0 \%\end{array}$ & $\begin{array}{l}35 \\
19.0 \%\end{array}$ & $\begin{array}{l}16 \\
8.7 \%\end{array}$ \\
\hline Unexpected unemployment & $\begin{array}{l}14 \\
7.6 \%\end{array}$ & $\begin{array}{l}114 \\
62.0 \%\end{array}$ & $\begin{array}{l}19 \\
10.3 \%\end{array}$ & $\begin{array}{l}20 \\
10.9 \%\end{array}$ & $\begin{array}{l}17 \\
9.2 \%\end{array}$ \\
\hline End of marriage or partnership & $\begin{array}{l}14 \\
7.6 \%\end{array}$ & $\begin{array}{l}95 \\
51.6 \%\end{array}$ & $\begin{array}{l}21 \\
11.4 \%\end{array}$ & $\begin{array}{l}26 \\
14.1 \%\end{array}$ & $\begin{array}{l}28 \\
15.2 \%\end{array}$ \\
\hline Other & $\begin{array}{l}14 \\
7.6 \%\end{array}$ & $\begin{array}{l}167 \\
90.8 \%\end{array}$ & $\begin{array}{l}1 \\
0.5 \%\end{array}$ & $\begin{array}{l}1 \\
0.5 \%\end{array}$ & $\begin{array}{l}1 \\
0.5 \%\end{array}$ \\
\hline
\end{tabular}


Table 10

Range, Means, and Standard Deviations of Impact of Event Scale - Revised

\begin{tabular}{lllll}
\hline Variable & Minimum & Maximum & $M$ & $S D$ \\
\hline $\begin{array}{l}\text { Impact of Event Scale - Revised } \\
\text { Total Score for Direct Trauma }\end{array}$ & 0.00 & 76.00 & 25.88 & 17.28 \\
$\begin{array}{l}\text { Impact of Event Scale - Revised } \\
\text { Total Score for Indirect Trauma }\end{array}$ & 0.00 & 64.00 & 16.45 & 12.96 \\
& & & & \\
\hline
\end{tabular}


Table 11

Range, Means, and Standard Deviations of ProQOL-CSF-R III Subscales

\begin{tabular}{lcccc}
\hline Variable & Minimum & Maximum & $M$ & $S D$ \\
\hline Compassion Satisfaction & 15.00 & 50.00 & 36.83 & 7.44 \\
Burnout & 5.00 & 40.00 & 23.88 & 6.80 \\
Compassion Fatigue & 1.00 & 43.00 & 15.33 & 7.33 \\
\hline
\end{tabular}


Table 12

Frequency and Percent of Cut-Off Scores Surpassed on the ProQOL-CSF-R III Subscales

Variable

Frequency Percent

Compassion Satisfaction Upper Quartile

48

26.09

Raw score $>4$ 1indicating likelihood of high satisfaction

Compassion Satisfaction Lower Quartile

40

21.74

Raw score $<32$ indicating likelihood of dissatisfaction

Burnout Upper Quartile

46

25.00

Raw score $>28$ indicating risk for burnout

Compassion Fatigue Upper Quartile

61

33.15

Raw score $>17$ indicating risk of compassion fatigue 
Table 13

Correlations Between the Subscales of the ProQOL-CSF-R III and IES - R Total Score for Direct or Primary Trauma

ProQOL-CSF-R III $\quad n \quad$ IES Direct Significance

Compassion Satisfaction

$184 \quad .015 \quad .839$

Burnout

$184 \quad .458 * * * \quad .0001$

Compassion Fatigue

$184 \quad .535 * * * \quad .0001$

Note. $* p<.05 \quad * * p<.01 \quad * * * p<.001$ 
Table 14

Correlations Between the Subscales of the ProQOL-CSF-R III and IES - R Total Score for Indirect or Secondary Trauma

ProQOL-CSF-R III $\quad n \quad$ IES Indirect Significance

Compassion Satisfaction

$176 \quad .043 \quad .569$

Burnout

$176 \quad .327 * * * \quad .0001$

Compassion Fatigue

$176 \quad .580 * * * \quad .0001$

Note. $* p<.05 \quad * * p<.01 \quad * * * p<.001$ 
Table 15

Means and Standard Deviations of ProQOL-CSF-R III Subscales by Demographic Level

\begin{tabular}{|c|c|c|c|c|c|c|c|}
\hline \multirow[b]{2}{*}{ Variable } & \multirow[b]{2}{*}{$n$} & \multicolumn{2}{|c|}{$\begin{array}{l}\text { Compassion } \\
\text { Satisfaction }\end{array}$} & \multicolumn{2}{|c|}{ Burnout } & \multicolumn{2}{|c|}{$\begin{array}{l}\text { Compassion } \\
\text { Fatigue }\end{array}$} \\
\hline & & $M$ & $S D$ & $M$ & $S D$ & $M$ & $S D$ \\
\hline \multicolumn{8}{|l|}{ Current Position } \\
\hline Classroom Teacher & 80 & 36.16 & 8.19 & 24.54 & 7.03 & 16.28 & 7.67 \\
\hline Subject Teacher & 44 & 36.09 & 6.66 & 23.70 & 6.56 & 14.00 & 6.82 \\
\hline Other Teacher & 32 & 38.81 & 7.20 & 22.50 & 6.80 & 15.31 & 6.27 \\
\hline School Counselor & 16 & 38.50 & 7.04 & 23.06 & 6.71 & 13.63 & 5.08 \\
\hline Vice-principal & 5 & 38.00 & 8.22 & 26.40 & 5.41 & 17.20 & 15.50 \\
\hline Principal & 7 & 35.29 & 3.09 & 23.86 & 7.67 & 15.43 & 8.08 \\
\hline \multicolumn{8}{|l|}{ Assignment Level } \\
\hline Elementary & 85 & 37.60 & 7.67 & 23.39 & 7.40 & 15.86 & 7.60 \\
\hline Middle & 45 & 36.18 & 7.69 & 23.44 & 5.48 & 15.11 & 6.96 \\
\hline Secondary & 49 & 36.14 & 6.98 & 25.06 & 6.94 & 14.73 & 7.39 \\
\hline Technical or Alternate & 5 & 36.20 & 6.22 & 24.60 & 5.77 & 14.00 & 6.40 \\
\hline \multicolumn{8}{|l|}{ School Population } \\
\hline$<200$ & 14 & 36.93 & 8.10 & 24.29 & 4.58 & 15.86 & 4.66 \\
\hline $200-399$ & 22 & 37.00 & 7.14 & 22.64 & 6.33 & 13.81 & 6.22 \\
\hline $400-599$ & 55 & 38.27 & 7.07 & 23.71 & 6.51 & 16.82 & 8.32 \\
\hline $600-799$ & 46 & 35.72 & 7.87 & 24.61 & 7.94 & 15.89 & 6.80 \\
\hline $800-999$ & 19 & 36.68 & 6.79 & 22.63 & 5.51 & 12.37 & 6.24 \\
\hline $1000-1199$ & 2 & 39.50 & 4.95 & 24.00 & 7.07 & 8.00 & 2.83 \\
\hline $1200-1399$ & 1 & 36.00 & -- & 22.00 & -- & 15.00 & -- \\
\hline $1400-1599$ & 0 & -- & -- & -- & -- & -- & -- \\
\hline $1600-1799$ & 24 & 35.29 & 8.38 & 24.96 & 8.07 & 15.38 & 8.29 \\
\hline 1800-1999 & 0 & -- & -- & -- & -- & -- & -- \\
\hline \multicolumn{8}{|l|}{ School Location } \\
\hline Nova Scotia & 93 & 37.01 & 7.14 & 24.55 & 6.05 & 15.97 & 7.68 \\
\hline West Virginia & 91 & 36.64 & 7.78 & 23.20 & 7.46 & 14.67 & 6.93 \\
\hline
\end{tabular}

(table continues) 
Table 15 continued

Means and Standard Deviations of ProQOL-CSF-R III Subscales by Demographic Level

\begin{tabular}{|c|c|c|c|c|}
\hline & & $\begin{array}{l}\text { Compassion } \\
\text { Satisfaction }\end{array}$ & Burnout & $\begin{array}{l}\text { Compassion } \\
\text { Fatigue }\end{array}$ \\
\hline Variable & $n$ & $M \quad S D$ & $S D$ & $M \quad S D$ \\
\hline
\end{tabular}

Number of Years in Field of Education (cross-sampling of data)

1
2
3
18
19
20
32
33
34

$\begin{array}{rrrrrrr}3 & 36.67 & 5.69 & 24.67 & 10.07 & 15.33 & 8.39 \\ 3 & 38.33 & 10.26 & 20.00 & 5.57 & 11.67 & 1.15 \\ 7 & 36.43 & 5.80 & 28.00 & 7.94 & 18.14 & 8.84 \\ 3 & 38.00 & 3.61 & 24.00 & 2.65 & 17.67 & 5.69 \\ 2 & 38.50 & 7.78 & 27.00 & 11.31 & 15.00 & 0.00 \\ 10 & 34.40 & 7.78 & 27.10 & 7.65 & 20.80 & 10.70 \\ 6 & 37.17 & 11.79 & 22.83 & 5.98 & 13.83 & 4.45 \\ 6 & 42.83 & 6.85 & 20.33 & 3.27 & 14.50 & 4.55 \\ 3 & 40.33 & 6.03 & 21.67 & 5.69 & 15.67 & 0.58\end{array}$

Number of Years in Current Position (cross-sampling of data)

$\begin{array}{lrrrrrrr}1 & 28 & 36.18 & 6.33 & 24.32 & 6.97 & 15.93 & 7.49 \\ 2 & 20 & 35.65 & 7.27 & 23.70 & 5.81 & 12.65 & 5.91 \\ 3 & 17 & 35.41 & 8.58 & 27.47 & 8.26 & 16.24 & 7.34 \\ 14 & 4 & 39.75 & 7.27 & 23.25 & 6.29 & 17.25 & 5.32 \\ 15 & 4 & 34.75 & 8.22 & 20.50 & 2.65 & 9.25 & 3.77 \\ 16 & 3 & 31.00 & 11.27 & 26.33 & 5.13 & 9.33 & 4.04 \\ 28 & 2 & 33.50 & 13.43 & 24.50 & 7.78 & 19.00 & 4.24 \\ 29 & 2 & 40.50 & 6.36 & 27.00 & 1.41 & 23.50 & 13.44 \\ 30 & 4 & 35.25 & 6.95 & 28.50 & 8.96 & 18.25 & 11.15 \\ & & & & & & & \\ \text { Employment Status } & & & & & & & \\ \text { Full-time } & 169 & 36.72 & 7.30 & 24.12 & 6.61 & 15.48 & 7.35 \\ \text { Part-time } & 11 & 39.64 & 9.46 & 19.18 & 6.93 & 12.18 & 5.60 \\ \text { Substitute } & 4 & 33.75 & 7.46 & 26.50 & 10.85 & 17.50 & 9.88\end{array}$

(table continues) 
Table 15 continued

Means and Standard Deviations of ProQOL-CSF-R III Subscales by Demographic Level

\begin{tabular}{|c|c|c|c|c|c|c|c|}
\hline \multirow[b]{2}{*}{ Variable } & \multirow[b]{2}{*}{$n$} & \multicolumn{2}{|c|}{$\begin{array}{l}\text { Compassion } \\
\text { Satisfaction }\end{array}$} & \multicolumn{2}{|c|}{ Burnout } & \multicolumn{2}{|c|}{$\begin{array}{l}\text { Compassion } \\
\text { Fatigue }\end{array}$} \\
\hline & & $M$ & $S D$ & $M$ & $S D$ & $M$ & $S D$ \\
\hline \multicolumn{8}{|l|}{$\frac{\text { Age }}{\text { (cross-sampling of data) }}$} \\
\hline 25 & 2 & 39.50 & 10.61 & 24.00 & 14.14 & 18.00 & 9.90 \\
\hline 30 & 2 & 24.00 & 7.07 & 20.50 & 2.12 & 13.00 & 4.24 \\
\hline 35 & 4 & 37.25 & 10.90 & 25.75 & 9.43 & 14.75 & 6.24 \\
\hline 40 & 7 & 39.29 & 5.88 & 24.43 & 6.68 & 13.71 & 5.99 \\
\hline 45 & 3 & 38.67 & 2.08 & 22.67 & 0.58 & 20.00 & 3.61 \\
\hline 50 & 11 & 34.55 & 7.38 & 25.36 & 8.27 & 13.09 & 4.28 \\
\hline 60 & 2 & 37.00 & 5.66 & 17.50 & 9.19 & 12.50 & 9.19 \\
\hline \multicolumn{8}{|l|}{ Gender } \\
\hline$\overline{\text { Female }}$ & 140 & 37.10 & 7.46 & 23.94 & 7.02 & 15.52 & 6.98 \\
\hline Male & 44 & 35.95 & 7.41 & 23.70 & 6.14 & 14.70 & 8.39 \\
\hline \multicolumn{8}{|l|}{ Ethnicity } \\
\hline Euro-American/Canadian & 144 & 36.24 & 7.68 & 24.30 & 7.13 & 15.44 & 7.29 \\
\hline African-American/Canadian & 1 & 43.00 & -- & 16.00 & -- & 5.00 & -- \\
\hline Native American/Canadian & 1 & 41.00 & -- & 21.00 & -- & 11.00 & -- \\
\hline Unidentified & 38 & 38.76 & 6.26 & 22.58 & 5.32 & 15.26 & 7.53 \\
\hline \multicolumn{8}{|l|}{ Current Salary } \\
\hline$<20,000$ & 5 & 35.40 & 7.44 & 24.40 & 10.50 & 16.00 & 9.19 \\
\hline $20,000-29,999$ & 17 & 38.76 & 6.16 & 23.24 & 8.11 & 14.94 & 9.68 \\
\hline $30,000-39,999$ & 40 & 33.20 & 8.12 & 24.45 & 8.34 & 15.63 & 6.10 \\
\hline $40,000-49,999$ & 46 & 37.20 & 8.06 & 23.00 & 5.86 & 14.20 & 6.63 \\
\hline $50,000-59,999$ & 36 & 39.72 & 6.42 & 23.94 & 5.15 & 16.08 & 7.37 \\
\hline $60,000-69,999$ & 25 & 35.32 & 6.02 & 25.28 & 5.84 & 16.40 & 7.04 \\
\hline $70,000-79,999$ & 10 & 37.60 & 4.60 & 26.90 & 5.99 & 17.20 & 10.69 \\
\hline Unidentified & 5 & 42.40 & 6.73 & 15.60 & 5.08 & 9.40 & 5.32 \\
\hline \multicolumn{8}{|c|}{ Highest Level of Education Attained } \\
\hline Bachelor's Degree & 71 & 37.49 & 7.66 & 23.00 & 6.73 & 14.85 & 7.47 \\
\hline Master's Degree & 103 & 36.15 & 7.44 & 24.51 & 6.92 & 15.84 & 7.32 \\
\hline Doctoral Degree & 6 & 39.83 & 5.31 & 23.17 & 6.43 & 12.00 & 4.94 \\
\hline Other & 4 & 38.00 & 5.89 & 24.25 & 5.85 & 15.50 & 8.58 \\
\hline
\end{tabular}


Table 16

Correlation Matrix Crossing Demographics with ProQOL-CSF-R III Subscales

Demographics Compassion Satisfaction Burnout Compassion Fatigue

\begin{tabular}{llll}
\hline Current Position & $.045_{\mathrm{PB}}$ & $-.001_{\mathrm{PB}}$ & $-.035_{\mathrm{PB}}$ \\
Assignment Level & $-.096_{\mathrm{S}}$ & $.078_{\mathrm{S}}$ & $-.091_{\mathrm{S}}$ \\
School Population & $-.089_{\mathrm{S}}$ & $.036_{\mathrm{S}}$ & $-.104_{\mathrm{S}}$ \\
School Location & $-.025_{\mathrm{PB}}$ & $-.100_{\mathrm{PB}}$ & $-.089_{\mathrm{PB}}$ \\
Number of Years in & & & $-.044_{\mathrm{P}}$ \\
Field of Education & $.130_{\mathrm{P}}$ & $-.119_{\mathrm{P}}$ & $.051_{\mathrm{P}}$ \\
$\begin{array}{l}\text { Number of Years in } \\
\text { Current Position }\end{array}$ & $.083_{\mathrm{P}}$ & $-.033_{\mathrm{P}}$ & $.070_{\mathrm{PB}}$ \\
Employment Status & $-.050_{\mathrm{PB}}$ & $.121_{\mathrm{PB}}$ & $-.121_{\mathrm{P}}$ \\
Age & $.127_{\mathrm{P}}$ & $-.140_{\mathrm{P}}$ & $-.048_{\mathrm{PB}}$ \\
Gender & $-.066_{\mathrm{PB}}$ & $-.015_{\mathrm{PB}}$ & $-.119_{\mathrm{PB}}$ \\
Ethnicity & $.088_{\mathrm{PB}}$ & $-.095_{\mathrm{PB}}$ & $.071_{\mathrm{S}}$ \\
Current Salary & $.080_{\mathrm{S}}$ & $.096_{\mathrm{S}}$ & \\
Highest Level Education & & & $.049_{\mathrm{S}}$ \\
\hline & $-.049_{\mathrm{S}}$ & & \\
\hline
\end{tabular}

Note. $\mathrm{P}=$ Pearson, $\mathrm{S}=$ Spearman, $\mathrm{PB}=$ point-biserial

Note. None of the correlations was significant at $p<.05$. 
Table 17

Correlations Between ProQOL-CSF-R III Subscales

\begin{tabular}{llll} 
Subscale & Compassion Satisfaction & Burnout & Compassion Fatigue \\
\hline Compassion Satisfaction & --- & $-.368^{* *}$ & -.109 \\
Burnout & --- & --- & $.650^{* *}$ \\
Compassion Fatigue & --- & --- & --- \\
\end{tabular}

Note. $* p<.05 \quad * * p<.01$ 
Table 18

Model Summaries of Stepwise Multiple Regression Analyses for the Dependent Variables of Compassion Satisfaction, Burnout, and Compassion Fatigue

Dependent Variable and $\quad F$ Predictor Variables

Compassion Satisfaction

HTE Indirect Work

$5.717 * \quad 1,150$

$.037-3.560$

$-.192$

$\underline{\text { Burnout }}$

IES-R Direct

$36.381 * * *$

1,150

.195

.173

.442

IES-R Direct,

$21.031 * * *$

2,149

.220

.171

.437

HTE Direct Work

$-2.134$

$-.158$

Compassion Fatigue

IES-R Indirect

$84.117^{* * *} \quad 1,150$

.359

.329

.599

IES-R Indirect,

$48.362^{* * *} \quad 2,149$

.394

.239

.437

IES-R Direct

IES-R Indirect,

$35.760 * * * \quad 3,148$

.103

.247

IES-R Direct,

School Level

$35.760^{* * *} \quad 3,148$

.420

.237

.112

.432

$-1.295$

.267

$-.164$

Note. ${ }^{*} p<.05 \quad * * p<.01 \quad * * * p<.001$

The seventeen predictor variables included: current position, assignment level, school population, school location, number of years in the field of education, the number of years in current position, employment status, age, gender, current salary, highest level of education attained, history of direct personal trauma, history of direct workplace trauma, history of indirect personal trauma, history of indirect workplace trauma, current traumatization status deriving from direct trauma, and current traumatization status deriving from indirect trauma. 
Table 19

Frequency and Percent of Combinations of Cut-Off Scores

Surpassed on the ProQOL-CSF-R III Subscales

Combinations of Variables

Frequency Percent

Compassion Satisfaction Upper Quartile $(R S>41)$

5

2.72

+ Burnout Upper Quartile $(R S>28)$

Compassion Satisfaction Upper Quartile $(R S>41)$

8

+ Compassion Fatigue $(R S>17)$

Compassion Satisfaction Lower Quartile $(R S<32)$

22

11.96

+ Burnout Upper Quartile $(R S>28)$

Compassion Satisfaction Lower Quartile $(R S<32)$

20

10.87

+ Compassion Fatigue $(R S>17)$

Burnout Upper Quartile $(R S>28)$

19.02

+ Compassion Fatigue $(R S>17)$

Compassion Satisfaction Upper Quartile $(R S>41)$

4

+ Burnout Upper Quartile $(R S>28)$

+ Compassion Fatigue $(R S>17)$

Compassion Satisfaction Lower Quartile $(R S<32)$

19

10.33

+ Burnout Upper Quartile $(R S>28)$

+ Compassion Fatigue $(R S>17)$ 


\section{Summary of Results}

Among those in the participant pool, 80 self-identified as classroom teachers, an educator position that entails extended periods of time with the same group of students. A similar number, 76, endorsed teaching positions involving rotations of students (e.g., Subject Teacher and Other Teacher). Each of these first three groups of teachers would be exposed to the same student body on a regular basis over the course of a semester or year. The nature of such involvement stands in contrast to those positions where no specific allocation of time would be devoted to a given group of students, as would be the case with school counselor or guidance counselor, vice-principal or assistant principal, and principal. The 28 participants who identified these latter positions would not regularly or predictably be exposed to the same group of students. The related hypothesis, to be explored later in this chapter, was that increased exposure would contribute to greater rapport and intimacy, thus heightening the risk for compassion fatigue. Regrettably, the number of administrators that participated in this study was small. Completed survey packets were forwarded by only seven principals, and five viceprincipals or assistant principals, despite the fact that the research project was presented at administrators' meetings for each of the two school boards involved. Future research should seek sufficiently large samples of school administrators so that the quality of career engagment of principals and vice-principals or assistant principals may be assessed with greater confidence.

Participants were drawn from nine schools in the Monongalia County Board of Education in West Virginia, and 15 schools in the Annapolis Valley Regional School Board in Nova Scotia. The West Virginia schools included four elementary schools (with 
student populations of 132, 163, 640,641), three middle schools (student populations of $399,492,815$ ), one secondary school (student population of 1,614), and one technical school (secondary and adult student population of approximately 200) affiliated with the public school system. Thus, the West Virginia educator participants in this study represented three groups of elementary, middle, and secondary students that were roughly equivalent in size. The Nova Scotia school sample was comprised of eight elementary schools, one elementary-middle school, two middle schools, two middle-secondary schools, and two secondary schools. Precise school populations were not obtained for the Nova Scotia sample of schools, but were estimated at 2,960 elementary students, 1,850 middle school students, and 3,100 secondary students. Educator participants were drawn almost equally from schools in West Virginia $(n=91)$ and Nova Scotia $(n=93)$, which contributed to the validity of intergroup comparisons based on location.

Given that the majority of participants identified full-time positions as educators ( $n=169)$, and only a small minority identified part-time $(n=11)$ and substitute positions $(n=4)$, future research is warranted to determine the extent to which career satisfaction, burnout, and compassion fatigue are predicated on full-time equivalent employment status. Cornille and Meyers (2002) posited a direct positive relationship between intensity of exposure (operationalized as number of hours worked per week) and degree of secondary traumatization in child protection services workers. In the school settings associated with the current research, the greater number of hours worked each week would translate into greater opportunity for students, students' families, and colleagues to share their traumatic history with educators. One might hypothesize that this would increase the risk for educator compassion fatigue. 
Gender representation in the participant sample was approximately one-quarter male $(23.9 \%)$ and three-quarters female $(76.1 \%)$. This gender composition is almost identical to the 2004-2005 proportions in the Monongalia County Board of Education of 23.5\% males and 76.5\% females as reported by Dan McGinnis (personal communication, September 1, 2005). Data on the representative gender proportions were not available for the Annapolis Valley Regional School Board sample of educators.

Bearing in mind that the male proportion of the participator sample was relatively small, and that caution should be exercised in interpreting findings, the gender demographic may nonetheless inform future practice. The nonsignificant statistical findings related to gender differences in quality of career engagement, in concert with significant rates of reporting of burnout and compassion fatigue, highlight the importance of preventative and responsive awareness campaigns and strategies targeting burnout and compassion fatigue in both males and females.

Due to the predominantly Euro-American/Canadian participant sample, no conclusions can be drawn about the impact of ethnic, racial, or cultural heritage on level of career satisfaction and risk for burnout or compassion fatigue. Future studies would benefit from greater diversity in participant background. Additionally, future studies should be designed in such a manner so as to ensure receipt of more complete ethnicity data. In this study, an open-ended response to ethnicity was invited, rather than a forcedchoice response. The rationale behind this format was to avoid restriction of response options. This may have contributed to the extent of missing data for this item $(n=38)$. However, the researcher's familiarity with the racial and ethnic composition of the two participating school districts assures an adequate level of confidence in the reporting of 
ethnic homogeneity of the sample. Another multicultural area of exploration would be the impact of religious affiliation and spirituality on quality of career engagement in the aforementioned three areas.

As noted in Chapter 4, Nova Scotian educators in this study tended to report higher salary levels than their West Virginian counterparts (with no adjustments calculated on the basis of exchange rates), while West Virginian participants were more likely than Nova Scotians to have attained a Master's or doctoral degree. However, these factors did not appear to contribute differentially to the educators' level of career satisfaction, or risk for burnout or compassion fatigue. Results of independent samples t-tests comparing means on the Compassion Satisfaction, Burnout, and Compassion Fatigue subscales of the ProQOL-CSF-R III did not indicate any significant differences between the Nova Scotian and West Virginian educator samples.

The assessment of participants' trauma history via the History of Traumatic Experiences survey garnered evidence of rather extensive exposure to traumatic events in this sample of public school educators whose ages ranged from 24 to 64, with a mean age of 45 . A substantial $87 \%$ reported direct traumatic event exposure in their personal lives, while $48.4 \%$ reported direct traumatic event exposure associated with the workplace. Indirect traumatic event exposure was endorsed by $66.3 \%$ in their personal lives, and by $71.7 \%$ in the work environment. Surprisingly, the reported rate of indirect traumatic event exposure did not reach $100 \%$, despite extensive media coverage of traumatic events such as natural disasters, human error disasters, terrorism, and war. It is difficult to conceive that the participants in this study would not have been exposed to Internet, 
newspaper, and magazine text and photos, as well as radio and television reporting of local, national, and global events eliciting shock, horror, and empathy.

Overall, the participants' reported incidence of exposure to traumatic incidents is in line with the $70 \%$ lifetime exposure rate tallied by Keane (1998), and the $69-84 \%$ range of exposure rates summarized by Foa and colleagues (2000). Participants in the current study acknowledged a wide diversity of traumatic incidents. Each of the 22 categories on the HTE of traumatic events was endorsed for direct and indirect trauma. Caution is warranted in the making of comparisons across studies, however, given the differences in instruments used to assess trauma history.

The current trauma status of participants was ascertained by the degree of traumarelated distress acknowledged on the Impact of Event Scale - Revised for both direct and indirect trauma. Scores ranged from 0 to 76 out of a possible 88 on the IES-R for direct trauma, with a mean of 25.88. Almost one-third (30.97\%) of participants met or exceeded the cut-off score of 33 adopted for this study as a level indicative of significant traumagenic stress resulting from direct exposure. On the IES-R for indirect trauma, scores ranged from 0 to 64 out of a possible 88 , with a mean of 16.45 . On this measure, $10.8 \%$ of the participants met or exceeded the cut-off score of 33 adopted for this study, indicating a high level of distress generated by indirect trauma exposure.

These rates of current traumatic stress appear quite remarkable when one considers that almost one in three educators reported high residual trauma related to direct traumatization, and almost one in nine reported high residual trauma deriving from indirect traumatization. 
Future research might establish whether significant differences exist in degree of current traumatization between public school educators and other occupational groups. If so, possible explanations for these differences could be sought. Future qualitative research might explore the effect of associated intrusive, avoidant, and hyperarousal symptoms on educator functioning. The current study employed self-report measures to identify trauma history, current trauma status, and quality of career engagement in the areas of career satisfaction, burnout, and compassion fatigue, but did not adopt a phenomenonological approach to understanding educators' experiences. The findings in this study could have been enriched by the inclusion of anecdotal information submitted by participants in response to structured or unstructured questions. 


\section{CHAPTER 5}

\section{Discussion}

The intent of this exploratory study was to examine the quality of career engagement of public school educators with respect to career satisfaction, burnout, and compassion fatigue. The research questions sought to establish whether or not relationships exist between: 1) participant demographics, 2) history of trauma, 3) current traumatization status, and 4) degree of career satisfaction, 5) risk of burnout, and 6) risk of compassion fatigue. In particular, the research was conducted to augment the sparse literature and lack of empirical studies addressing compassion fatigue in the field of public education.

Given the exploratory nature of this research endeavor, instruments were adopted with a view to examining the characteristics of the population sample, establishing the existence and nature of direct and indirect trauma history, assessing current status with respect to traumatic residue, and identifying indicators of career satisfaction, burnout, and compassion fatigue. Independent variables were measured by the Demographic Information questionnaire, History of Traumatic Experiences (HTE) survey, Impact of Event Scale - Revised (IES-R) for direct trauma, and Impact of Event Scale - Revised (IES-R) for indirect trauma. The dependent variables of career satisfaction, burnout, and compassion fatigue were operationalized as the scores received on the Compassion Satisfaction, Burnout, and Compassion Fatigue subscales, respectively, of the Professional Quality of Life - Compassion Satisfaction and Fatigue Subscales - Revision III (ProQOL-CSF-R III). 
This chapter will expand upon the quantitative findings presented in the Results section in Chapter 4. The current chapter will adopt a parallel structure to that of the preceding chapter. There will be reflection on the significance of data related to the demographic information, trauma history and current trauma status, followed by discussion of relevant findings under corresponding research questions. Interpretation and implications of the results will be offered. This will be followed by considerations of study limitations and recommended directions for future research.

\section{Research Question 1}

The first research question sought to determine the degree to which educators are reporting signs of healthy career engagement, career disengagement, and career overengagement.

RQ1a. Specifically, the first segment of the research question asked for the frequency with which educator participants surpassed the upper quartile cut-off score of 41 on the Compassion Satisfaction subscale of the ProQOL-CSF-R III, thus endorsing high career satisfaction and healthy career engagement, and the frequency with which they received scores below the lower quartile score of 32 , suggesting career dissatisfaction and less than optimum career engagement. In this research sample, $26.09 \%(n=48)$ of the participants exceeded the upper quartile score and $21.74 \%$ $(n=40)$ scored below the lower quartile cut-off. The remaining portion, $52.17 \%(n=96)$ received scores in the mid-range, suggesting moderate career satisfaction and relatively healthy career engagement. This dispersion of scores approximates a normal distribution. The percentage of participants reporting high career satisfaction in the current study is considerably lower than the $54 \%$ of teachers in the 1995 MetLife survey who reported 
being very satisfied (Latham, 1998). The reasons for this discrepancy in career satisfaction levels warrants further investigation to determine whether it might be attributed to differences in instrumentation or to other factors.

RQ1b. The second part of the first research question asked for the frequency with which participants surpassed the upper quartile cut-off score of 28 on the burnout subscale. In this research sample, precisely one-quarter $(25 \%, n=46)$ of the participants surpassed the cut-off score, providing evidence of disengagement and risk for burnout. The $25 \%$ of participants in this study that endorsed a profile congruent with burnout is greater than the $5-20 \%$ reported by Farber in a meta-analysis of the literature on burnout in American teachers (as cited in Schaufeli \& Daamen, 1994), suggesting a possible increase in burnout rates over the past decade.

The percentage of participants exceeding the cut-off for burnout in the current study was greater than the $21.74 \%$ who reported career dissatisfaction on the Compassion Satisfaction subtest of the ProQOL-CSF-R III. Moreover, only $11.96 \%(n=22)$ of the participants met criteria for both career dissatisfaction and burnout, suggesting that a perfect relationship does not exist between the two. Additionally, 2.72\% $(n=5)$ of participants met criteria for burnout while reporting career satisfaction in the upper quartile of the Compassion Satisfaction subtest. The correlation between Compassion Satisfaction and Burnout subtest scores was -.368 , a modest but significant correlation, indicating that as career satisfaction increased, risk for burnout decreased. This is congruent with the career engagement model proposed in this study whereby disengagement is presumed to derive from career dissatisfaction and ultimately may manifest in burnout. 
RQ1c. The final section of the first research question asked for the frequency with which participants surpassed the upper quartile cut-off score of 17 on the Compassion Fatigue subscale. In the current sample, approximately one-third $(33.15 \%, n=61)$ of the participants surpassed the cut-off score, providing evidence of overengagement and risk for compassion fatigue. This finding would appear to contribute significantly to the research literature on two counts. First, no other reports on the incidence of compassion fatigue in educators were located in the process of conducting the literature search for this study. Second, the percentage of participants surpassing the cut-off score is not inconsequential.

A study conducted by Cornille and Meyers (1999) provides a contextual backdrop. Among a sample of child protection workers, in a profession noted for exposure to and focus on horrific abuses of children, $37 \%$ demonstrated signs of secondary traumatic stress. By contrast, public school educators dedicate their professional lives to meeting the academic needs of students representing diverse social strata, family histories, and circumstances. Yet, the $33.15 \%$ rate of compassion fatigue reported by the participants in the current study approached that of the child protection workers noted above. This comparison is made with caution, given differences in research instrumentation. Cornille and Meyers implemented a demographic survey, the Brief Symptom Inventory, Impact of Event Scale - Revised, and the Structural Family Interaction Scale (1999). The Cornille and Meyers (1999) sample was comprised of $82.4 \%$ females (versus $76.1 \%$ in the current study) with a mean age of 37.6 (versus 45.5 in the current study). 
Of the 61 participants meeting criteria for compassion fatigue, eight $(4.35 \%$ of the participant body) reported career satisfaction in the upper quartile and $20(10.87 \%$ of the participant body) reported career satisfaction in the lower quartile, as measured by the Compassion Satisfaction subtest. The remaining 33 who met criteria for compassion fatigue reported a degree of career satisfaction falling in the mid-range. Therefore, a full two-thirds (41/61) of those evidencing compassion fatigue depicted their level of career satisfaction as average or above average. The correlation between scores on the Compassion Satisfaction and Compassion Fatigue subtests was -.109, indicating a low and nonsignificant inverse relationship. This finding appears congruent with the model in the current study proposing that compassion fatigue is a manifestation of career overengagement. Clearly, educators can experience career satisfaction without accompanying compassion fatigue. However, those manifesting compassion fatigue still may be deriving fulfillment from their professional interactions with students, students' families, and colleagues. The sense of satisfaction and of being needed may be what fuels overeengagement, as boundaries become blurred and the educator dons a rescuer cape. The challenge is to maintain a healthy degree of intimacy and empathy without becoming swallowed up in another's trauma and grief.

\section{Research Question 2}

The second research question sought to examine the correlations between scores on the Compassion Satisfaction, Burnout, and Compassion Fatigue subscales of the ProQOL-CSF-R III, and the Traumatic Stress Response total score of the IES-R for direct trauma. Statistically significant correlations were found between IES-R Traumatic 
Stress Response total scores for direct trauma and both the Burnout and Compassion Fatigue subscale scores on theProQOL-CSF-III R.

The moderate but statistically significant positive correlations between the IES-R direct trauma scores and Compassion Fatigue subtest scores lends support to the contention that a history of primary or direct trauma predisposes a helping professional to compassion fatigue (Cornille \& Meyers, 1999; Follette et al., 1994; Hales \& Hales, 1995; Jenkins \& Baird, 2002; Kassam-Adams, 1995; Pearlman \& MacIan, 1995; Pearlman \& Saakvitne, 1995; Pinto, 2003; Schauben \& Frazier, 1995). This is due to the triggering of cognitive, affective, and somatic symptoms that occurs during work with traumatized clients (Campbell, 2000; Figley, 1995; O’Grady, 2004; Stamm, 1999). Elliott and Guy’s (1993) findings may also have been supported by the significant correlation of IES-R direct trauma scores and Compassion Fatigue scores in the current educator sample. In their study of mental health professionals and non-mental-health professionals, the former group reported more extensive trauma history but fewer current trauma symptoms, implying that training in the mental health field may confer some protection from compassion fatigue. In this study it is not anticipated that educators would have received specialized training such as Meichenbaum's stress inoculation training (1994).

The statistically significant correlation between the IES-R direct trauma scores and Burnout scores raises questions about confounding of burnout and compassion fatigue and the degree to which each can be measured discretely. If, as is proposed in this study, compassion fatigue and burnout exist on a continuum whereby extended experiencing of compassion fatigue may lead to burnout, then the moderate positive correlation might be explained. 


\section{Research Question 3}

The third research question sought to explore the correlations between scores on the Compassion Satisfaction, Burnout, and Compassion Fatigue subscales of the ProQOL-CSF-R III and the Traumatic Stress Response total scores of the IES-R for indirect trauma. The significant correlation between the IES-R indirect trauma scores and Compassion Fatigue scores appears inherently logical in that a positive relationship between current traumatization status due to secondary trauma, as depicted by the IES-R indirect trauma scores, and secondary traumatization, as depicted by the Compassion Fatigue subscale scores would be expected.

However, the significant correlation between the IES-R indirect trauma scores and Burnout scores raises questions about confounding of burnout and compassion fatigue and the degree to which each can be measured discretely. Again, as discussed under Research Question 2, if compassion fatigue and burnout are posited to exist on a continuum, it may be that an extended period of compassion fatigue potentially leads to burnout.

Interestingly, while $30.97 \%$ of participants reported significant current distress associated with direct trauma (as indicated by the cut-off score of 33 adopted for this study), $10.8 \%$ reported similar levels of distress associated with indirect trauma. Yet, $33.15 \%$ met criteria for compassion fatigue, which is primarily attributed to indirect trauma exposure. Future research is warranted to determine relative contributions of direct and indirect trauma to compassion fatigue given that both are considered to be ingredients (Campbell, 2000; Figley, 1995; O'Grady, 2004; Stamm, 1999). Perhaps participants were able to identify the more generalized impact of trauma exposure as 
measured by the Compassion Fatigue subtest of the ProQOL-CSF-R III, but were not consciously aware of specific physiological, cognitive, and affective reactions to a particular incident as assessed by the IES-R.

\section{Research Question 4}

The fourth research question sought to determine whether significant intergroup differences exist between elementary, middle, secondary, and technical school educators with respect to risk for compassion fatigue. The research hypothesis of a higher risk for compassion fatigue among elementary educators was not supported by the ANOVA results. The absence of significant differences in the group means on the Compassion Fatigue subtest of the ProQOL-CSF-R III suggests that it is not the quantity of time spent with a particular student group that leads to compassion fatigue. While degree of intimacy may be positively correlated with greater number of hours spent together, it appears that opportunities for educators at all grade levels to become privy to trauma material of school community members is not contingent on reaching a threshold of hours with the same students. This is congruent with the proposition of several researchers that onset of compassion fatigue may be sudden, following secondary exposure to one sufficiently horrendous event (Collins \& Long, 2003; Figley, 1995; Figley, 2002a; Figley 2002b; Jenkins \& Baird, 2002; Salston \& Figley, 2003; Stamm, 1999). It is also possible that compassion fatigue may result from the accumulation and internalization of trauma stories shared by various students, their families, and/or colleagues, congruent with the gradual onset model (James \& Gilliland, 2001; O'Grady, 2004; Struwig, 2002; Thompson, 2003a, 2003b, 2004; Wright, 2004). 


\section{Research Question 5}

The fifth research question examined whether significant intergroup differences exist between teachers, school guidance counselors, and administrators with respect to risk for compassion fatigue. The hypothesis that teachers would demonstrate higher rates of compassion fatigue was not supported by the ANOVA results. Again, similar to findings in Research Question 4, the lack of significance suggests that the numbers of hours spent on a regular basis with a particular student group does not predict compassion fatigue. Rather, it may be one occasion whereby a teacher, counselor, or administrator bears witness to another's traumatic victimization that heralds the acute and sudden onset of compassion fatigue (Collins \& Long, 2003; Figley, 1995; Figley, 2002a; Figley 2002b; Jenkins \& Baird, 2002; Salston \& Figley, 2003; Stamm, 1999). Alternatively, the process may be more gradual and insidious as the secondarily exposed educator internalizes a collection of traumatic retellings that lead to traumatic contamination (James \& Gilliland, 2001; O'Grady, 2004; Struwig, 2002; Thompson, 2003a; Thompson, 2003b; Thompson, 2004; Wright, 2004).

\section{Research Question 6}

The sixth research question explored correlational relationships between demographic characteristics and scores on the Compassion Satisfaction, Burnout, and Compassion Fatigue subscales of the ProQOL-CSF-R III. Of particular interest was the question of whether a clear relationship exists between years of experience and quality of career engagement in any of the three areas of career satisfaction, burnout, and compassion fatigue. A second query related to the possible interplay of gender and risk for compassion fatigue. 
None of the correlations between the twelve demographics and three subscale scores of the ProQOL-CSF-R III proved to be significant. No correlational support was obtained for the hypotheses of a relationship between years of experience and quality of career engagement as manifested in satisfaction, and risk for burnout and compassion fatigue, or gender and risk for compassion fatigue.

The absence of a statistically significant relationship between demographic characteristics and career satisfaction is congruent with Latham's (1998) findings that school level, and urban versus rural location, are inconsequential with respect to career fulfillment. Similarly, Baughman (1996) did not discover significant correlations between career satisfaction and age, level of education, gender, salary, or years of experience. However, contradictory findings were reported by Ma and MacMillan (1999) who identified greater career satisfaction for female teachers than male teachers, and decreased satisfaction with increased years taught.

Other studies have yielded mixed findings with respect to uncovering significant correlations between demographic information and burnout in educators. Burke and colleagues (1996) identified different components of burnout depending on gender and position. In their study, males and teachers (as opposed to administrators) received higher scores on the Depersonalization and Emotional Exhaustion subscales of the Maslach Burnout Inventory, while administrators received elevated scores on Personal Accomplishment burnout relative to teachers. With respect to burnout and career timeline, Friedman (1991) postulated an inverse curve, while Ackerly and colleagues (1988) concluded that younger age and fewer years of experience correlated positively 
with burnout. Rosenholtz and Simpson (1990) noted ongoing debate as to whether the highest incidence of burnout was to be found in beginning or mid-career educators.

Previous research conducted with trauma counselors suggested that the risk for compassion fatigue was negatively correlated with years of experience (Pearlman \& MacIan, 1995). However, similar research carried out with generalist counselors did not predict compassion fatigue on the basis of novice or expert status (Pinto, 2003). With respect to a gender factor for compassion fatigue, females have demonstrated higher rates of secondary traumatization in some studies (Cornille \& Meyers, 1999; Kassam-Adams, 1995), and thus might be anticipated to present a higher risk for compassion fatigue. It bears noting that research findings on compassion fatigue in educators are not yet available, and conclusions from research with mental health professionals should not be extrapolated to the education field.

Thus, the extant literature has not proffered a consensus on the relationship between educator demographics and career satisfaction and burnout. Nor have the results of the current study supported any significant relationships. Additionally, the preliminary and exploratory findings of this study in the area of compassion fatigue are not indicative of any significant correlations between educator demographics and risk for compassion fatigue. The absence of stable and clear-cut relationships between educator demographics and quality of career engagement becomes significant when designing proactive and responsive strategies for addressing career satisfaction, burnout, and compassion fatigue. If demographic risk factors cannot be accurately delineated, then all demographic characteristics should be accommodated in planning for prevention and intervention. 


\section{Research Question 7}

The seventh research question explored the ability of demographic characteristics, trauma history, and current level of traumatization to predict status on the quality of career engagement measures. Three stepwise regression analyses were conducted using the Demographic Information questionnaire, HTE survey, and IES-R for direct and indirect trauma, as predictor variables to determine their respective contributions to scores on the criterion variable measures of the Compassion Satisfaction, Burnout, and Compassion Fatigue subscales of the ProQOL-CSF-R III.

Compassion Satisfaction. An initial multiple regression analysis was conducted using the stepwise method to evaluate how well demographic characteristics, the HTE survey, and the IES-R for direct and indirect trauma predicted compassion satisfaction. One model emerged. A participant's history of indirect trauma associated with the work environment presented as a significant predictor of career satisfaction although it accounted only for $3.7 \%$ of the variance in Compassion Satisfaction scores on the ProQOL-CSF-III R. An increase in indirect work-related trauma was inversely related to scores on the Compassion Satisfaction subtest. This relationship, although weak, is inherently logical in that workplace stressors tend to be associated with decreased enjoyment of one's work.

Burnout. Using the stepwise method, a second multiple regression analysis was conducted to evaluate how well demographic characteristics, the HTE survey, and the IES-R scores for direct and indirect trauma predicted burnout. Two models emerged. In the first, current traumatic residue related to direct traumatization accounted for $19.5 \%$ of 
the variance in scores on the Burnout subtest of the ProQOL-CSF-III R. A positive relationship existed between the continuing impact of direct trauma sequelae and burnout.

A second model posited that current traumatic residue related to direct traumatization, and a reported history of direct trauma associated with the workplace accounted for $22.0 \%$ of the variance in Burnout scores. As in the first model, a positive relationship was identified between burnout and current level of traumatization related to direct trauma. However an inverse relationship was postulated to exist between a history of direct trauma in the work environment and burnout. This latter relationship contributed minimally $(2.5 \%$ increase $)$ to the explanation of the variability of Burnout scores. As in Research Questions 2 and 3, these results raise the issue of possible confounding of the constructs of burnout and compassion fatigue. Perhaps a career engagement continuum will be better suited to accommodation of a blend of traumatization and burnout symptoms than a model emphasizing discrete variables.

Compassion Fatigue. Using the stepwise method, a third multiple regression analysis was conducted to evaluate how well demographic characteristics, the HTE survey, and the IES-R scores for direct and indirect trauma predicted compassion fatigue. Three models emerged. In the first, current traumatic residue related to indirect traumatization accounted for $35.9 \%$ of the variance in scores on the Compassion Fatigue subtest of the ProQOL-CSF-III R. A positive relationship existed between the continuing impact of indirect trauma sequelae and compassion fatigue.

A second model posited that current traumatic residue related to both indirect and direct trauma accounted for $39.4 \%$ (an increase of $3.5 \%$ ) of the variance in Compassion Fatigue scores. Positive relationships were identified between current level of 
traumatization related to indirect and direct trauma, and compassion fatigue. This proposition is congruent with the research literature that suggests that compassion fatigue can be germinated both by absorption of indirect trauma, and triggering of direct trauma, leading to a status of current traumatization (Campbell, 2000; Figley, 1995; O’Grady, 2004; Stamm, 1999). Consistent with the emphasis on secondary traumatization in the conceptualization of compassion fatigue, this model attributes greater predictive value to current traumatization deriving from indirect sources.

The third model identifying significant predictor variables for compassion fatigue was comprised of current level of traumatization related to indirect and direct trauma, in addition to school level. This model accounted for $42.0 \%$ of the variance in Compassion Fatigue subtest scores, suggesting that the inverse relationship between school level and compassion fatigue contributed minimally (an increase of $2.6 \%$ ) to the explanation of variability in scores on the Compassion Fatigue subtest. This finding suggests that risk for compassion fatigue decreases somewhat as school level increases from elementary to middle to secondary. This may lend support to the hypothesis in Research Question 4 that the greater number of hours spent together (particularly at the elementary level) will foster increased intimacy and the chance that trauma histories will be shared with educators by students and their families.

\section{Supplemental Analyses}

The rationale for including the supplemental analyses to be discussed in this section was to ensure comprehensive exploration of any potential relationships between the independent and dependent variables. The aim was to provide direction to future research. Previous studies examining the relationship between participant demographics, 
trauma history and status, and quality of career engagement in the areas of career satisfaction, burnout, and compassion fatigue in an assortment of populations, have yielded mixed and often contradictory results. The following supplemental findings appear to confirm the complexity of this area of investigation.

In the current study, Research Question 1 examined the frequency of surpassing cut-off scores on each of the Compassion Satisfaction, Burnout, and Compassion Fatigue subtests of the ProQOL-CSF-R III. Supplemental analyses were conducted as an extension of this question. These were carried out to determine similar frequency and percentage data for combinations of the subtests as follows: 1) Compassion Satisfaction (upper quartile scores) and Burnout; 2) Compassion Satisfaction (upper quartile scores) and Compassion Fatigue; 3) Compassion Satisfaction (lower quartile scores) and Burnout; 4) Compassion Satisfaction (lower quartile scores) and Compassion Fatigue; 5) Burnout and Compassion Fatigue; 6) Compassion Satisfaction (upper quartile), Burnout, and Compassion Fatigue; and 7) Compassion Satisfaction (lower quartile scores), Burnout, and Compassion Fatigue. Data derived from the combinations of Compassion Satisfaction and Burnout scores, and Compassion Satisfaction and Compassion Fatigue scores were discussed earlier in this chapter under Research Question 1.

Analysis of combined Burnout and Compassion Fatigue subtest scores indicated that 35 participants (of 46 meeting criteria for burnout and 61 meeting criteria for compassion fatigue) surpassed cut-off scores for both burnout and compassion fatigue. This represented $19.02 \%$ of the total participant sample. The correlation coefficient for these subtests was .650 demonstrating a moderately strong positive relationship between 
the two. Therefore, participants exhibiting signs of burnout might well exhibit symptoms of compassion fatigue.

This relationship is congruent with the conceptualization of a compassion fatigueburnout continuum where the constellation of symptoms associated with compassion fatigue may overlap with indicators of burnout. The career engagement model espoused in this study is consistent with those of James and Gilliland (2001) and Thompson (2003a) who envisioned unidirectional movement due to compassion fatigue predisposing helpers to burnout. However, as noted in Chapter 1, historically there has been a confounding of the concepts of burnout and compassion fatigue, and a lack of construct clarity persists. Future research is needed to further explore their relationship and to clarify whether the shift between syndromes is unidirectional or bi-directional.

Examination of the combination of Compassion Satisfaction, Burnout, and Compassion Fatigue subtests revealed that 4 participants $(2.17 \%$ of the sample) met criteria for both burnout and compassion fatigue when scoring in the upper quartile on the Compassion Satisfaction subtest. These participants appeared able to derive high professional satisfaction from their helping roles, despite reporting considerable psychological distress. When Compassion Satisfaction subtest scores fell in the lower quartile, 19 of the participants $(10.33 \%$ of the sample) met criteria for both burnout and compassion fatigue. Given that 35 participants met criteria for both burnout and compassion fatigue, with 23 of these accounted for by high and low Compassion Satisfaction subtest scores, the 12 remaining participants reported distress related to both burnout and compassion fatigue while endorsing moderate career satisfaction. 
As an extension of Research Questions 4 and 5, three additional one-way analyses of variance (ANOVAS) were conducted to ascertain whether any significant differences in mean scores on the Compassion Fatigue subtest of the ProQOL-CSF-R III existed between levels for each of the demographic variables of school population, current salary, and highest level of education attained. No significance emerged in the corresponding $F$-ratios. This finding was supported by the results of analyses for Research Question 6 in which no significant correlations were found between demographic variables and scores received on the Compassion Fatigue subtest.

Lastly, independent samples $t$-tests were conducted to determine if significant intergroup differences existed between gender or location (Nova Scotia versus West Virginia) and scores on the Compassion Satisfaction, Burnout, or Compassion Fatigue subtests of the ProQOL-CSF-R III. The resulting sample statistics did not meet critical values. Thus, the differences in the sample means were not deemed to be significant. Being male or female, and living in Nova Scotia or West Virginia, did not contribute significantly to the likelihood of career satisfaction or dissatisfaction, and did not predict increased risk of burnout or compassion fatigue.

\section{Summary and Implications}

This research endeavor represents an initial foray into exploration of the incidence of compassion fatigue in the public education domain. A review of the literature yielded previous research studies and theoretical articles addressing career satisfaction and burnout in public school educators. However, this researcher was unable to locate empirical investigations of the collective existence and interplay of the three career 
engagement qualities of career satisfaction, burnout, and compassion fatigue in the educator population.

Data from the HTE suggest that a considerable proportion $(48.4 \%-87.0 \%)$ of public school educators have experienced direct and indirect trauma both in their personal and professional environments. While many appear to have processed the trauma and to have reestablished psychological equilibrium, others continue to be confronted with traumatic sequelae. Roughly one-third of the educator sample endorsed a current significant elevation of distress related to direct trauma experiences (with IES-R direct trauma scores $>33$ ), and more than one-tenth reported similar levels of distress emanating from indirect trauma experiences (IES-R indirect trauma scores $>33$ ). Scores of this magnitude might suggest that the participants are experiencing intrusive, avoidant, and hyperarousal post-trauma sequelae at a level in the vicinity of clinical significance.

Further analysis demonstrated that current traumatization status (evidenced by IES-R results) is significantly correlated with risk for burnout ( $r=.458$ for direct trauma and .327 for indirect trauma) and compassion fatigue ( $r=.535$ for direct trauma and .580 for indirect trauma). Perhaps the most enlightening and unsettling findings of the current study are the indications that one-quarter of the public educator sample meets the ProQOL-CSF-III R upper quartile cut-off for burnout, and one-third of the sample meets the upper quartile cut-off for compassion fatigue.

The current study has the potential to enhance awareness of risk for burnout in public school educators. Additionally, it confirms a substantial risk for compassion fatigue in this population. This is an important finding, given that the public school educator population has been accorded only cursory treatment in the trauma research 
literature to date. Data analysis was unsuccessful in identifying demographic risk factors for either burnout or compassion fatigue. Therefore, researchers and practitioners should exert effort in designing awareness, prevention, and intervention programs that target all educators regardless of position, school grade configuration, school size, school location, years of experience in current and previous positions, age, gender, income, and educational background.

As a result of ongoing immersion in the traumatology literature, and reflection on the results of the current study, this investigator's conceptualization of the educator career engagement continuum has evolved. In particular, the constructs of compassion fatigue and burnout appear to warrant revisiting. The remainder of the Summary and Implications section of this chapter will be devoted to a proposal of some preliminary modifications to these constructs, in addition to a review of related research response rates. Contemplation on such matters would appear to be of value because the validity of future research and the benefits to accrue from findings, hinge on clarity and consistency in construct operationalization and assessment, as well as adequate response rates.

The first recommendation relates to a unified secondary trauma terminology that would expand on the singular concept of compassion fatigue. The second recommendation would involve the restructuring of the construct of burnout into three strands to reflect varying etiology. The increased differentiation of compassion fatigue and burnout would be incorporated into an augmented career engagement continuum model.

Unified Secondary Trauma Terminology. There is widespread recognition that problems with terminology and semantics abound in the field of traumatology (Steed \& 
Bicknell, 2001). Stamm (1996) noted that four terms are commonly used to identify trauma arising in the helper as a result of empathic engagement with trauma survivors. These terms include: secondary traumatic stress, vicarious trauma, countertransference, and compassion fatigue. However, countertransference generally is held to be a universal phenomenon of the helper reaction to the helpee, and does not necessarily involve trauma-related material. Secondary traumatic stress and vicarious trauma may be perceived as umbrella terms that do not necessarily denote a helper-helpee relationship. These terms could apply to indirect exposure via family members, the media, or hearsay.

Given that the term compassion fatigue presupposes a helping relationship wherein empathy predisposes the helper to secondary traumatization, this researcher proposes that the term empathy become the semantically unifying element in the secondary trauma terminology. Additionally, this researcher believes that the construct of compassion fatigue deserves expansion in order to acknowledge various points on the secondary trauma continuum ranging from initial traumatic stress reactions to depletion of personal resources.

This expansion would combine elements of Figley's secondary traumatic stress and proposed Secondary Traumatic Stress disorder (STSD) (1995, 2002; Stamm, 1999), along with Hans Selye's General Adaptation Syndrome (GAS) model. Selye's GAS model is encountered frequently in the trauma literature. It is comprised of three stages: alarm, resistance, and exhaustion (Bisbey \& Bisbey, 1999; Everly \& Lating, 2002; James \& Gilliland, 2001; Kass et al., 1995; Scaer, 2001; Tamparo \& Lindh, 2000; Wilson et al., 2001). Drawing from the work of Figley and Selye, a three-stage reaction to secondary trauma exposure might be anticipated. 
Subsequent to initial exposure, an overengaged helper would manifest posttraumatic symptoms similar to those of Acute Stress Disorder (APA, 2000) but aroused in response to another's traumata as per Figley's secondary traumatic stress. This initial response would be akin to Selye's alarm stage. In the second phase, the helper would continue to exhibit trauma symptoms while attempting to muster psychological reserves needed to intervene on the helpee's behalf. Rescue fantasies might be triggered at this point. This phase would be congruent with Figley's STSD and Selye's resistance stage. Eventually, as in Selye's final stage, the helper's psychological energy would become depleted, leading to exhaustion and disengagement.

In the interest of unified language, the secondary trauma categories resulting from the meshing of Figley's (1995, 2002; Stamm, 1999) and Selye's (Bisbey \& Bisbey, 1999; Everly \& Lating, 2002; James \& Gilliland, 2001; Kass et al., 1995; Scaer, 2001; Tamparo \& Lindh, 2000; Wilson et al., 2001) models would be renamed. The modified nomenclature would include: empathic fulfillment (equated to satisfaction derived from a sense of efficacy in the helping role and associated with healthy career engagement), empathic stress (equated to secondary Acute Stress Disorder and associated with shortterm career overengagement), empathic trauma (equated to secondary Posttraumatic Stress Disorder and associated with longer-term career overengagement), and empathic burnout (equated to traumagenic burnout and career disengagement). The use of the term empathic would serve as the common language element to link these career engagement descriptors and would denote a helping relationship involving secondary trauma exposure. 
Restructuring of the Construct of Burnout. The conceptual evolution and attempts to refine the construct of compassion fatigue are apparent in the literature. Nonetheless, challenges have persisted with respect to the confounding of the construct of compassion fatigue with that of burnout. Chapter 1 summarized inter-author and intra-author discrepancies in defining compassion fatigue as similar to, or distinct from, burnout. For example, Wright (2004) used the terms compassion fatigue and burnout interchangeably, with a stated preference for the former because it did not connote irreversible psychic damage. This description of compassion fatigue would appear to be consistent with the trauma-generated form of burnout, empathic burnout, proposed in this study. Figley (2002a; 2002b) depicted compassion fatigue as a specialized form of burnout found in caregivers, as contrasted with simple or standard burnout that does not require a helping relationship. This stands in contrast with his definition of compassion fatigue as a mirroring or contagion effect whereby trauma is transmitted from the helpee to helper (Figley, 1995). Perhaps in suggesting that compassion fatigue is a form of burnout, Figley implicitly acknowledged a continuum whereby chronic experiencing of secondary trauma may lead to helper exhaustion. Both the latter stage of compassion fatigue and a state of standard burnout would thus refer to similar presentations of depleted personal resources but would be attributed to different paths of causality. The aforementioned continuum categories of empathic stress, empathic trauma, and empathic burnout might serve to address the historical confounding of compassion fatigue and burnout.

The evolved conceptualization of the current study depicts educator career engagement as a tri-component continuum model of: healthy engagement manifesting in empathic fulfillment (an aspect of career satisfaction), overengagement manifesting in 
empathic stress or empathic trauma (formerly compassion fatigue), and disengagement manifesting in either a standard form of burnout or empathic burnout (formerly referred to either as compassion fatigue or burnout). Despite the contention of some that onset of compassion fatigue is sudden and acute (Collins \& Long, 2003; Figley, 1995; Figley, 2002a; Figley, 2002b; Jenkins \& Baird, 2002; Salston \& Figley, 2003; Stamm, 1999), others espouse a more gradual and insidious onset (James \& Gilliland, 2001; O’Grady, 2004; Struwig, 2002; Thompson, 2003a; Thompson, 2003b; Thompson, 2004; Wright, 2004). Both could be accommodated by the career engagement continuum.

The continuum concept has been supported to a degree in the literature. Struwig (2002) depicted compassion fatigue as existing on a continuum rather than as a discrete variable. O'Grady (2004) described compassion fatigue as both a state of tension and preoccupation with client traumata that mimicks PTSD, and a physical and spiritual exhaustion that transpires over months or years, thus alluding to a continuum. Jenkins and Baird (2002) reported that a burnout component had been incorporated into the conceptualization of compassion fatigue to address the depletion of helping energy that would occur when demands remained high over time. Williams and Davis (2002) alluded to a continuum when they ascribed burnout to a pattern of emotional overinvolvement and overextension that eventually leads to detachment and indifferent response style. Adoption of a career engagement continuum would not deny the potential of indirect exposure to a single traumatic event to herald the sudden onset of empathic stress, but would acknowledge the possibility of a more gradual and cumulative effect of secondary trauma exposure. 
The concepts of healthy engagement, overengagement, and disengagement also have been supported in the professional literature. Jenkins and Baird referred to initial overinvolvement leading to emotional exhaustion (2002, p. 425). Williams and Davis (2002) described a shift from a pattern of overengagement to one characterized by disengagement. Maslach supported the concept of overengagement leading to disengagement when he wrote that the helper "gets overinvolved emotionally, overextends himself or herself, and feels overwhelmed by the emotional demands imposed" (1982, p.3). This researcher surmises that the nature of the helping interaction, specifically whether the sharing of trauma was present, would determine if the eventual disengagement would manifest as standard burnout or trauma-related burnout (empathic burnout).

To clarify the nomenclature associated with burnout, this researcher proposes that the construct be restructured to encompass three strands. Empathic burnout could result from untreated empathic trauma that over time depleted the helper's resources, leading to psychological exhaustion. Standard burnout, as exemplified by the Pines, Aronson, and Kafry (1981) and Maslach (1982) models, would be referred to as systemic burnout, alluding to disengagement resulting due to feeling overwhelmed by, and incapable of meeting, organizational demands. Systemic burnout could comprise either or both of task and interpersonal overload, but would not presume a helping relationship or profession. The third form of burnout would be poor-fit burnout, indicating a lack of optimal match between the individual and the organization right from the point of hiring. The failure to become engaged in one's work, due to lack of passion or interest in the assigned professional role, would lead to disengagement characterized by stagnation. 
This would be similar to concept of rustout coined by Kottler (1999). The three strands of burnout defined above would appear congruent with three forms of burnout identified by Farber (2000) in Chapter 2.

The revision of the secondary trauma nomenclature is proposed in the interest of attaining consistent terminology. The fanned expansion of the compassion fatigue and burnout constructs aims at identifying continuous as opposed to discrete variables. Combined, these would result in a career engagement continuum comprised of the elements in the table below. This model will require empirical testing and application in practice to determine its validity and value to the ongoing study of the quality of career engagement in educators and other helping professionals.

Table 20

Unified Language and Construct Restructuring

\begin{tabular}{|c|c|c|}
\hline $\begin{array}{l}\text { Category of Career } \\
\text { Engagement }\end{array}$ & $\begin{array}{l}\text { Quality of Career } \\
\text { Engagement }\end{array}$ & $\begin{array}{l}\text { Characteristics of Career } \\
\text { Engagement }\end{array}$ \\
\hline Empathic Fulfillment & Healthy Engagement & $\begin{array}{l}\text { Fulfillment derived from sense of } \\
\text { efficacy and reward in helper role }\end{array}$ \\
\hline Systemic Fulfillment & Healthy Engagement & General career fulfillment \\
\hline Empathic Stress & Overengagement & $\begin{array}{l}\text { Secondary trauma symptoms of up } \\
\text { to one month's duration }\end{array}$ \\
\hline Empathic Trauma & Overengagement & $\begin{array}{l}\text { Secondary trauma symptoms lasting } \\
\text { more than one month }\end{array}$ \\
\hline Empathic Burnout & Disengagement & $\begin{array}{l}\text { Resulting from untreated, chronic } \\
\text { secondary trauma }\end{array}$ \\
\hline Systemic Burnout & Disengagement & $\begin{array}{l}\text { Resulting from overload of } \\
\text { organizational demands }\end{array}$ \\
\hline Poor-fit Burnout & Disengagement & $\begin{array}{l}\text { Resulting from poor match of } \\
\text { individual and role }\end{array}$ \\
\hline
\end{tabular}


Response Rate. The response rate of $26.29 \%$ (184/187 usable packets returned of the 700 distributed) in this study is low, but does not appear unexpectedly so, given the research population of busy public school educators, the end-of-school-year administration of the measures, and the sensitive nature of the information sought from participants. Response rates can be compared with other types of research conducted with educator participants, and with trauma-focused research conducted with other professional populations. Response rates for trauma-focused research conducted with educators are not available due to the lack of such research to date.

Lang and colleagues (2000) engaged in research exploring teacher attitudes toward technology use in classrooms. Incentives for participation were offered. Response rates were $68 \%$ for paper-pencil surveys and $32 \%$ for web-based surveys. A similar study conducted by Mertler (2003) to explore assessment literacy in educators reported a $21 \%$ return rate for paper-pencil administration and $11 \%$ for web administration for a total sample size of 197. These two studies propose that higher response rates will be attained for paper-pencil based research than for web-based delivery.

Lunenburg and Cadavid's (1992) research in the area of locus of control and teacher burnout reported a high but unspecified response rate, and a sample size of 191 public school teachers. Gold and Rothman (1992) explored burnout in a sample of 133 California teachers but did not report the response rate. Likewise, Bryne (1998) examined burnout in teachers and neglected to identify the response rate for the sample of 138 high school and community college teachers. Friedman and Farber's (1992) research exploring professional self-concept as a burnout predictor garnered a $63 \%$ response rate from the sample of Israeli elementary school teachers. Brissie and colleagues' (1988) research into 
the individual and situational contributors to teacher burnout reported an average rate of response per school of 69\%. Berg's (1994) burnout research with Washington State teachers netted a sample size of 193 , representing a $45.08 \%$ return rate.

In the area of stress and burnout, research conducted by Ross, Altmaier, and Russell (1989) reported a response rate of $65.6 \%$ and a sample size of 169 among university counseling center staff. Raquepaw and Miller's (1989) exploration of burnout in psychotherapists yielded a $45 \%$ response rate and a sample size of 68 . Research conducted in the area of coping mechanisms used by psychotherapists in work with stressful clientele netted a return rate of $41 \%$ and a final sample size of 222 (Medeiros \& Prochaska, 1988). Mahoney (1997) examined psychotherapists' personal problems and self-care patterns in a sample of 155, which represented a response rate of approximately 48\%.

In the area of trauma, a study conducted with 75 career and 67 auxiliary Australian firefighters (Dean et al., 2003) calculated a 100\% response rate for surveys completed during the researchers' visits to fire stations, but $58 \%$ for those returned by mail. In their research with 188 self-identified trauma therapists, Pearlman and MacIan (1995) noted that their findings were to be generalized cautiously due to the $24 \%$ response rate. Responses from 67 therapists working with perpetrators of sexual abuse equaled a 38\% response rate for Steed and Bicknell (2001). Lavack-Pambrun (2000) mailed out 177 questionnaires to correctional nurses and received 77 back for a response rate of $44 \%$. In a study of secondary traumatic stress in Child Protective Services Workers, a $42 \%$ response rate from various offices of the Department of Family and Children Services permitted surveying of CPS workers, of whom 57\% responded for a 
final sample size of 183 (Cornille \& Meyers, 1999). Kadambi and Truscott (2004)

conducted an anonymous mail survey of therapists working with three different client groups: victims of sexual violence, cancer, and general practice. Their aim was to explore traumatic stress, vicarious traumatization, and burnout. Their overall response rate was $35 \%$ with a final sample size of 221.

\section{Limitations of the Study}

There are certain limitations associated with the nature and circumstances of this study that should be acknowledged. First, the homogeneity of the group precluded any analysis on the basis of racial or ethnic heritage. The sample was severely restricted with respect to this aspect of diversity. A related limitation emerged with respect to the demographic questionnaire. A number of participants did not respond to the question of ethnicity. It is unclear whether this was due to the item being a non-forced choice format whereby participants were asked to self-identify in an open-ended manner, or whether the lack of response was suggestive of discomfort in self-identifying. The item had been designed to allow flexibility of response, with the intent of categorizing responses at the level of data input. This researcher will employ categorical options in future research.

The employment status item (full-time, part-time, substitute) on the demographic questionnaire did not discriminate between participants holding a permanent versus a term contract. The uncertainty associated with being a term employee whose contract is rescinded each spring while the hiring cycle begins anew, has historically generated significant anxiety for those awaiting the promise of employment for the following year. This circumstance might have been reflected in the response patterns of term employees. 
The addition of permanent and term categories as a second employment status indicator might prove informative in the exploration of predictor variables in multiple regression.

The demographic item addressing highest level of education achieved did not appear to discriminate education level sufficiently, given that several participants reported their status as being well en route to the next level. Perhaps some intermediary classifications would prove helpful, such as: Additional Undergraduate Credits Beyond Initial Bachelor's Degree, Hold Two Bachelor's Degrees, Graduate Level Credits Toward Master's Degree, Additional Graduate Level Credits Beyond Initial Master's, Hold Two Master's Degrees, or Graduate Level Credits Toward Doctoral Degree.

The sample size and non-random composition exert a limiting influence on external validity. The participant sample of 184 public school educators approaches but does not reach Howell's (2002, p. 238) recommended sample size of 196 for power $=.80$, alpha $=0.05$, and small effect size of .20. Sufficient sample size reduces the likelihood of committing a Type I error of failing to reject the null hypothesis when it is, in fact, false. The sample in the current study cannot be considered random, despite the fact that the researcher distributed the participant packets to a cross-section of schools. The schools were not randomly selected, and potential participants were free to choose to participate or abstain from the research process. The reasons for individuals making either of these choices cannot be ascertained.

Two additional potential limitations - representative sampling and accurate reporting - relate to the sensitive nature of the material sought from participants. The research measures assessed participants' history of direct and indirect trauma, current status with respect to traumatization, and indicators of possible burnout or compassion 
fatigue. Apprehension about sharing such personal information was to be expected, despite assurances that anonymity and confidentiality would be maintained and that group findings only would be analyzed and reported. This may have resulted in inhibition and restricted reporting. Conversely, the end-of-year administration of the questionnaires may have been associated with fatigue and heightened stress levels, leading to elevated reporting of symptoms. While an overview of the data from the demographic questionnaire was used to determine the degree to which participants represented a crosssection of demographic categories, it is difficult to ascertain whether truly representative sampling and reporting has been attained.

This researcher's previous experience suggests that educators may be concerned about the potential impact on their employment status if administrators or members of central office staff are alerted to the educators' personal history or current distress. In confidential conversations, educators reported anxiety about raising any suspicion of impairment. Thus, in this study, perceived threat to personal and professional safety may have led to a low response rate and underreporting of concerns. Although evidence of burnout and compassion fatigue was noted in the data provided, response bias still may have been a factor. Educators who responded may have been those who felt they were not exposing vulnerabilities or divulging sensitive information. It is conceivable that nonparticipants may have been even more likely to endorse a history of trauma, ongoing traumatic sequelae, and symptoms of burnout and compassion fatigue.

In addition to possible discomfort at the prospect of disclosing sensitive information, some educators may have opted not to participate due to feeling overwhelmed with their current workload. One individual completed the first survey and 
then returned the incomplete participant packet with the words "too long" printed at the top. Due to these limitations related to sample size and composition, one must exercise caution with respect to generalizing the findings of this study.

Inherent in the challenge of exploring quality of career engagement is the fact that self-report measures are necessarily subjective and vulnerable to the vagaries of human perception, attention, thought, and mood. Additionally, construction of precise measures to assess burnout and compassion fatigue is impeded by semantic and construct conceptualization challenges discussed in Chapter 1. Researchers and authors have not yet reached consensus on operational definitions. It is important to bear in mind that the official recognition of Post-traumatic Stress Disorder dates back only to 1980, and the concerted exploration of secondary trauma to the 1990s. Measures exploring the construct of compassion fatigue are still evolving and will benefit from further research and refinement.

Limitations relevant to instrumentation implemented in the current research study relate to the fact that the demographic survey and trauma history questionnaire were designed specifically for the study. Normative, validity, and reliability data have not yet been established for the HTE. Although the IES-R is a widely-used measure, consensus has not been achieved on clinically significant, empirically-derived cut-off scores. The quartile scores adopted in the statistical analysis involving the newly-developed ProQOLCSF-R III are not based on validity studies. To a large degree, direct comparisons of results of the current study with those of prior research are precluded by the fact that the same combinations of measures have not been used. 
A final limitation derives from the research design and statistical analyses that were conducted. Due to the exploratory nature of this study and its correlational design, findings must be presented as preliminary and tentative. Any relationships discovered between the independent and dependent variables are correlational and not indicative of causality. Given that research on compassion fatigue in public school teachers is in its nascent phase, it will be important to emphasize the role of this research in spurring future studies of greater depth and specificity.

\section{Future Directions}

Considerations for future research directions and modifications have been dispersed throughout the preceding segments of this chapter. Additional recommendations follow below.

The History of Traumatic Experiences (HTE) survey was designed specifically for this study with the population of public school educators in mind. It was kept as brief as possible. Based on subsequent feedback and traumatology reading, recommended revisions to the instrument would include the addition of the following items: threat to marriage or partnership, domestic violence, miscarriage, stillbirth, birth of a child with cognitive or physical defect or disability, suicide attempt, witnessing death, exposure to body parts or mutilation, hate crime, and home invasion. These inclusions would appear to enhance the comprehensiveness of the instrument.

Some of the original 22 items of the HTE would also benefit from restructuring to allow for greater specificity of responding. Thus, the revised version would be comprised of the following 34 items: verbal/emotional child abuse; physical abuse or assault as a child; sexual abuse or assault as a child; verbal/emotional abuse as adult; physical assault 
as adult by non-family member; domestic violence or maltreatment; sexual assault as adult; bullying, stalking, mugging, or swarming; robbery, burglary, or home invasion; abduction, hostage-taking, confinement, or torture; shooting or stabbing; bombing; accident; serious injury; accidental or other sudden death; suicide attempt; suicide; homicide; exposure to mutilated bodies or body parts; witnessing death; serious medical illness; serious mental illness; invasive medical procedures; miscarriage or stillbirth; birth of a child with cognitive or physical defect or disability; disaster due to human error; natural disaster; mauling or attack by an animal; unexpected loss of life to pet, livestock, or other animal; hate crime; war, combat, or terrorism; unexpected unemployment; threat to or end of a marriage or partnership; identity theft; and other. The broadening of the HTE in this manner would hopefully permit the accommodation of a variety of populations.

Although the sequence of the measures completed in the survey packet was designed to encourage participants to reflect upon their trauma histories on the HTE prior to addressing current traumatization status on the IES-R, this was not explicitly stated. It may be beneficial in the future to ask participants to focus on one or more events endorsed on the HTE when completing the IES-R for direct and indirect trauma. The IES-R directs participants to respond to the impact of stressful life events rather than specifically targeting traumatic events. Asking participants to focus on an event or events in their personal trauma history would ensure that the responses to the HTE and IES-R are linked for each participant in a particular study.

Replication of this study utilizing an altered timeline would address the question of whether criteria for burnout and compassion fatigue are more likely to be met at a 
particular point in the academic year. The cyclical nature of the school calendar means that many educators anticipate starting a new school year feeling rested and rejuvenated. If energy levels decline by mid-year or the end of the year, while stress levels climb, perhaps this might be accompanied by a concomitant increase in predisposition to burnout or compassion fatigue. Educators in the current research endeavor received survey packets relatively close to the end of the school year. It would be interesting to determine whether their rates of burnout and compassion fatigue reflected end-of-year fatigue, or, on the other hand, eager anticipation of completion of the year and commencement of holidays. Conducting similar research shortly into the school year, mid-year, and near the end of the year, would clarify the impact of time-of-year administration.

A logical extension of this study might be to replicate it with non-teaching personnel associated with public school education. Of particular interest would be the quality of career engagement of educational assistants and teaching assistants who focus their attention on programming for students with special needs. These paraprofessionals often become intimately acquainted with their assigned students and assigned students' families. They also become familiar with other students at the class and school levels. Collection of data on their levels of career satisfaction, burnout, and compassion fatigue may inform school administrators and school boards of inservicing needs related to career engagement.

Some view compassion fatigue to be an inevitable occupational hazard resulting from empathic engagement with trauma survivors, whereas burnout is perceived as avoidable (McBratney, 2000). Sexton (1999) asserted that compassion fatigue is more 
amenable to treatment than burnout, leading to more rapid recovery. Future research could test these tenets by investigating both proactive and reactive program effectiveness. Studies might explore the degree to which awareness and prevention programs have the potential to either prevent or mitigate the severity of compassion fatigue and burnout. Additionally, the relative effectiveness of intervention programs in fostering recovery from compassion fatigue and burnout could be examined.

Figley (1995) observed that the personal and professional qualities of helpers that contribute to a strong therapeutic alliance, particularly empathy, increase the risk of developing compassion fatigue. Subsequently, Gentry, Baranowsky, and Dunning (1997, 2002) designed The Accelerated Recovery Program for Compassion Fatigue (ARP). As an extension of the proposed awareness and prevention research above, participants could be randomly assigned to an assessment-only group or an assessmentplus-prevention group. A baseline compassion fatigue score would be supplemented by assessment of personality and temperament risk factors for compassion fatigue. Those assigned to the treatment group would then participate in the ARP or a similar program with a focus on awareness and prevention. Compassion fatigue scores would be obtained at the end of the treatment period, at three months, six months, and one year, for both groups. The goal would be to identify the potential benefits of awareness and prevention programming and to seek research support for personality risk factors.

This researcher agrees with Stamm (2002) that exploration of career satisfaction, hardiness, and resiliency need to be incorporated in research on compassion fatigue and burnout since they allow for a more balanced picture of an individual's status and functioning and may serve as preventative or mitigating factors. 
Additionally, investigation of the concept of educator impairment as it relates to burnout and compassion fatigue would be a professionally responsible undertaking. O’Connor (2001) identified concerns about psychologists meeting standards of care and avoiding harm to the public. These concerns would appear germane to the public educator population also. Discriminating between distress and impairment may prove challenging given that the prevalence of impairment was estimated at $5-15 \%$ in psychologists (Laliotas \& Grayson, as cited in O'Connor, 2001), but 62\% of participants in a study conducted by Pope and colleagues (as cited in O'Connor, 2001) self-reported levels of stress that they felt rendered them professionally ineffective. The current study identified disconcerting rates of burnout and compassion fatigue in the educator participants. What remains unclear is the effect of these conditions on personal and professional functioning in the public education arena.

Compassion fatigue has been conceptualized by various researchers as similar to the construct of vicarious trauma (Figley, 1995; Figley, 2002b; Salston \& Figley, 2003; Stamm, 1999). Both represent responses to exposure to another's traumata such that traumatic contagion occurs. Salston and Figley (2003) identified differences between compassion fatigue and vicarious traumatization with respect to rates of onset and recovery. They purported more rapid onset and recovery from compassion fatigue. Pearlman and Saakvitne (1995) concurred that vicarious traumatization manifests in changes over time in a therapist's inner experiencing and belief systems, as contrasted with the potentially sudden onset of Figley's (1995; 2002a; 2002b) compassion fatigue symptom pattern. Further research is warranted to compare and contrast rates of onset and recovery. This would assist in identifying whether compassion fatigue and vicarious 
trauma should be viewed as a unitary construct, separate constructs, or perhaps different points on a continuum of trauma response.

The general consensus among those in the field of traumatology has been that the essence of compassion fatigue is PTSD-like symptoms while the heart of vicarious traumatization is alterations in cognitive schemata. However, Figley (2003) suggested that cognitive schemata related to social and interpersonal perceptions are implicated in compassion fatigue. This raises the question of whether compassion fatigue symptoms are likely to be experienced without concomitant alterations in core beliefs that are associated with vicarious traumatization. Should a new or revised secondary trauma construct comprise both development of PTSD symptomatology and changes in cognitive schemata related to self-identity, worldview, and spirituality? Can a secondarily traumatized individual experience intrusive ideation, avoidant behaviour, and hyperarousal without accompanying shattered assumptions in the areas of trust, safety, control, self- and other-esteem, and self- and other-intimacy?

Salston and Figley recommended that future research seek to "determine whether compassion fatigue and VT are mutually exclusive" (2003, p. 173). Perhaps this could be addressed via combined administration of measures assessing PTSD-like symptoms arising out of secondary trauma and changes in cognitive schemata related to core beliefs. Jenkins and Baird (2002) studied the associations between Figley and Stamm's Compassion Fatigue Self-Test (CFST) and Pearlman and Saakvitne's Traumatic Stress Institute Belief Scale, Revision L (TSI-BSL) and found concurrent validity between the two, as well as moderate convergence with burnout. 
Use of the CFST is no longer recommended from a psychometric perspective (Stamm, 2003). Future research might explore associations between compassion fatigue and vicarious trauma through analysis of scores and patterns on the ProQOL-CSF-R-III or the Secondary Traumatic Stress Scale, and the TSI-BSL. The Secondary Traumatic Stress Scale is a 17-item measure examining intrusive, avoidant, and arousal symptoms associated with indirect trauma exposure (Bride, Robinson, Yegidis, and Figley, 2003). The TSI-BSL assesses vicarious traumatization as evidenced by changes in cognitive schemata. It explores issues related to safety, trust, power, esteem, and intimacy using a six-point Likert scale, and is comprised of 80 items and ten subscales (Jenkins \& Baird, 2002; Wilson et al., 2001).

If research were to support the contention that compassion fatigue includes both PTSD symptoms and changes to the individual's core belief system and cognitive schemata, a research tangent to the compassion fatigue and vicarious trauma association would emerge. Given that changes in cognitive schemata would be presumed to accompany the PTSD symptoms, and that compassion fatigue is perceived to be quite amenable to treatment, the notion that vicarious trauma necessarily entails permanent changes in worldviews, spirituality, and self-identity would be called into question. Pearlman noted that disrupted schema serve as a self-protective defense mechanism for traumatized individuals (Wilson, Friedman, \& Lindy, 2001). Effective intervention addressing post-traumatic sequelae might eliminate the need for such a defense mechanism and allow the individual to reconsider and rewrite core beliefs. Future research might examine the alleged intractability of altered schemata in treated and untreated secondarily traumatized helping professionals. 
Earlier in this chapter, unified secondary trauma language and restructuring of the career engagement constructs and continuum were proposed. (See Table 20.) This revised model of career engagement in the helping professions requires research to explore its validity and utility. Such research should incorporate each of the career engagement categories that include: empathic fulfillment, systemic fulfillment, empathic stress, empathic trauma, empathic burnout, systemic burnout, and poor-fit burnout.

Perhaps the most crucial area for future secondary trauma research will be in the area of instrument refinement and design. The difficulty in arriving at semantic consensus and consistent operational definitions has rendered the development of accurate and precise assessment measures challenging, if not impossible. The greatest confounds appear to have arisen between compassion fatigue, vicarious trauma, traumagenic burnout and standard burnout. For example, Kadambi and Truscott (2004) conducted an anonymous mail survey of therapists working with three different client groups: victims of sexual violence, cancer, and general practice. Their aim was to explore traumatic stress using the Impact of Event Scale (IES), vicarious traumatization using the Traumatic Stress Institute Belief Scale, Revision M (TSI-BSM), and burnout using the Maslach Burnout Inventory (MBI). Surprisingly, the TSI-BSM vicarious trauma measure correlated more highly with the MBI measure of burnout than with the IES measure of traumatic stress. In another study, the weak correlations between the Maslach Burnout Inventory (MBI) subscales and total score and the Compassion Fatigue Self-Test Burnout subscale (CFST-BO) raised concerns for Jenkins and Baird (2002). Correlations ranged from .20 to .34 . The researchers suggested that there should be some convergence even though the CFST-BO purported to measure a qualitatively different form of trauma- 
induced burnout than the standard burnout associated with the MBI. Moderate correlations would suggest measurement of related constructs without demonstrating redundancy. These two examples of secondary trauma studies remind us that considerable research remains to be conducted in an effort to address construct definition and measurement.

Finally, future research would be enhanced by the inclusion of qualitative approaches and content. The restricted-response limitations imposed by questionnaires and surveys could be offset through inviting open-ended reflections and feedback from participants. This would garner a richer data set from which to work, and allow the researcher to capitalize on the unique strengths of each of quantitative and qualitative research.

The burgeoning field of traumatology has greatly benefited from passionate and dedicated researchers who are committed to clarifying what it is that transpires physiologically, cognitively, affectively, behaviourally, socially, and spiritually when an individual is confronted with a traumatic incident. The study of the aftermath of secondary traumatization has been a fairly recent offshoot of these research endeavors. The assessment and analysis of psychological sequelae is not as precise as the measurement of physiological response, and therefore will continue to evolve. Any research efforts in this regard will serve to augment the professional literature and to enhance our collective understanding of traumatic response phenomena. 


\section{References}

Ackerly, G.D., Burnell, J., Holder, D.C., \& Kurdek, L.A. (1988). Burnout among licensed psychologists. Professional Psychology: Research and Practice, 19, 624663.

Alexander, D.W. (1999). Children changed by trauma: A healing guide. Oakland: New Harbinger.

American Psychiatric Association. (1980). Diagnostic and statistical manual of psychiatric disorders ( $3^{\text {rd }}$ ed.). Washington, DC: Author.

American Psychiatric Association. (1994). Diagnostic and statistical manual of psychiatric disorders (4th ed.). Washington, DC: Author

American Psychiatric Association. (2000). Diagnostic and statistical manual of psychiatric disorders: Text revision (4th ed.). Washington, DC: Author.

Armsworth, M.W., \& Holaday, M. (1993). The effects of psychological trauma on children and adolescents. Journal of Counseling \& Development, 72, 49-56.

Arvay, M., \& Uhlemann, M. (1996). Counsellor stress in the field of trauma:

A preliminary study. Canadian Journal of Counselling/Revue Canadienne de Counseling, 2.

Ballon, D. (2001). Vicarious traumatization. The Journal of Addiction and Mental Health,4. Retrieved April 24, 2002 from http://www.camh.net/journalv4no5/questions.html

Barnhill, J. \& Rosen R.K. (1999). Why am I still afraid? Understanding post traumatic stress disorder. New York: Dell. 
Baughman, K.S. (1996). Increasing teacher job satisfaction: A study of the changing role of the secondary principal. American Secondary Education, 24, 19-22.

Beaton, R.D., \& Murphy, S.A. (1995). Working with people in crisis: Research implications. In C.R. Figley (Ed.), Compassion fatigue: Coping with secondary stress disorder in those who treat the traumatized (pp. 51-81). Levittown: Brunner/Mazel.

Berg, B.D. (1994). Educator burnout revisited: Voices from the staff room. Clearing House, 67, 185-188.

Bienenfeld, F. (1995). Helping your child through your divorce. Alameda: Hunter House. Bisbey, S. \& Bisbey, L.B. (1998). Brief therapy for post-traumatic stress disorder: Traumatic incident reduction and related techniques. Chichester: John Wiley.

Black, S., \& Weinreich, P. (2000). An exploration of counselling identity in counselors who deal with trauma. Traumatology, 6. Retrieved September 3, 2002 from http://www.fsu/ trauma/v6ila3.htm

Blair, T.D., \& Ramones, V.A. (1996). Understanding vicarious traumatization. Journal of Psychosocial Nursing, 34, 24-30.

Brace, N., Kemp, R., \& Snelgar, R. (2003). SPSS for psychologists: A guide to data analysis using SPSS for windows ( $2^{\text {nd }}$ ed.). Hampshire, England: Palgrave Macmillan

Bramblett, J. (1991). When good-bye is forever: Learning to live again after the loss of a child. New York: Random House. 
Bride, B.E., Robinson, M.M., Yegidis, B., \& Figley, C.R. (2003). Development and validation of the secondary traumatic stress scale. Research on Social Work Practice, 13, 1-16.

Briere, J. (1997). Psychological assessment of adult posttraumatic states. Washington, DC: American Psychological Association.

Brissie, J.S., Hoover-Dempsey, K.V., \& Bassler, O.C. (1988). Individual, situational contributors to teacher burnout. Journal of Educational Research, 82, 106-112.

Britzman, D.P., \& Dippo, D. (2000). On the future of awful thoughts in teacher education. Teaching Education, 11, 31-37.

Brock, B.L., \& Grady, M.L. (2000). Rekindling the flame: Principals combating teacher burnout. Thousand Oaks, CA: Corwin Press.

Brooks, B. \& Siegel, P. (1996). The scared child: Helping kids overcome traumatic events. New York: John Wiley.

Brown, C., \& O’Brien, K. (1998). Understanding stress and burnout in shelter workers. Professional Psychology: Research and Practice, 29, 383-385.

Brunet, A., St-Hilaire, A., Jehel, L., \& King, S. (2003). Validation of a French version of the impact of events scale-revised. Canadian Journal of Psychiatry, 48, 56-61.

Brunetti, G.J. (2001). Why do they teach? A study of job satisfaction among long-term high school teachers. Teacher Education Quarterly, 28, 49-74.

Bryne, J.J. (1998). Teacher as hunger artist: Burnout: Its causes, effects, and remedies. Contemporary Education, 69, 86-91. 
Burke, R.J., Greenglass, E.R., \& Schwarzer, R. (1996). Predicting teacher burnout over time: Effects of stress, social support, and self-doubts on burnout and its consequences. Anxiety, Stress, and Coping: An International Journal, 9, 261-275.

Campbell, J.M. (2000). Becoming an effective supervisor: A workbook for counselors and psychotherapists. Philadelphia, PA: Taylor \& Francis.

Carlson, E.B., \& Furby, L. (1997). A conceptual framework for the long-term psychological effects of traumatic childhood abuse. Child Maltreatment, 2, 272-295.

Catherall, D.R. (n.d.). Secondary stress and the professional helper. Retrieved September 6, 2002 from http://www.ctsn-rest.ca/Secondary.html

Cedoline, A.J. (1982). Job burnout in public education: Symptoms, causes, and survival skills. Teachers College, Columbia University.

Center for Mental Health in Schools at UCLA. (2004). An introductory packet on understanding and minimizing staff burnout. Los Angeles, CA: Author.

Charney, A.E., \& Pearlman, L.A. (1998). The ecstasy and the agony: The impact of disaster and trauma work on the self of the clinician. In P.M. Kleepsies (Ed.), Emergencies in mental health practice: Evaluation and management. New York, NY: Guilford Press.

Cheng, Y.C. (1996). Relationship between teachers' professionalism and job attitudes, educational outcomes, and organizational factors. The Journal of Educational Research, 89, 163-171. 
Chrestman, K.R. (1999). Secondary exposure to trauma and self-reported distress among therapists. In B.H. Stamm (Ed.), Secondary traumatic stress: Self-care issues for clinicians, researchers, and educators, (pp. 29-36). Lutherville, MD: Sidran Press.

Cohen, B.M., \& Cox, C.T. (1995). Telling without talking: Art as a window into the world of multiple personality. New York: W.W. Norton \& Company.

Cohen, J.A., \& Mannarino, A.P. (1998). Creating a curriculum on childhood traumatic stress. Child Maltreatment, 3, 53-62.

Collins, S., \& Long, A. (2003). Working with the psychological effects of trauma: Consequences for mental health-care workers- a literature review. Journal of Psychiatric and Mental Health Nursing, 10, 417-424.

Conrad, D.J., \& Perry, B.D. (2000). The cost of caring: Understanding and preventing secondary traumatic stress when working with traumatized and maltreated children. Retrieved September 3, 2002 from http://www.childtrauma.org/Cost_of_Caring_1.htm

Coon, D. (1998). Introduction to psychology: Exploration and application $\left(8^{\text {th }} \mathrm{ed}.\right)$. Pacific Grove, CA: Brooks/Cole.

Cornille, T.A., \& Meyers, T.W. (1999). Secondary traumatic stress among child protective service workers: Prevalence, severity, and predictive factors. Traumatology, 5, Article 2.

Corrigan, D.C. (1994). Creating the conditions for professional practice: Education's unfinished agenda. Journal of Teacher Education, 45, 71-75. 
Courtois, C.A. (1993). Vicarious traumatization of the therapist. NCP Clinical Newsletter, 3. Retrieved September 3, 2002 from http://www.ncptsd.org/treatment/cq/v3/n2/courtois.html

Creamer, M, Bell, R., \& Failla, S. (2003). Psychometric properties of the impact of event scale - revised. Behavior Research and Therapy, 41, 1489-1496.

Cuffe, S.P., \& Shugart, M. (2001). Child abuse and psychic trauma in children. In H.B. Vance \& A. Pumariega (Eds.), Clinical assessment of child and adolescent behavior (pp. 328-357). New York, NY: John Wiley \& Sons.

Cytryn, L., \& McKnew, D. (1996). Growing up sad: Childhood depression and its treatment. New York: W.W. Norton \& Company.

Dane, B. (2000). Child welfare workers: An innovative approach for interacting with secondary trauma. Journal of Social Work Education, 36, 27-38.

Danielson, L. (2002). Developing and retaining quality classroom teachers through mentoring. The Clearing House, 75, 183-185.

Dayton, T. (2000). Trauma and addiction: Ending the cycle of pain through emotional literacy. Deerfield Beach: Health Communications.

Dean, P.G., Gow, K.M., \& Shakespeare-Finch, J. (2003). Counting the cost: Psychological distress in career and auxiliary firefighters. The Australasian Journal of Disaster and Trauma Studies, 1. Retrieved December 15, 2004 from http://www.massey.ac.nz/ trauma/issues/2003-1/dean.htm

Deskin, G., \& Steckler, G. (1997). When nothing makes sense: Disaster, crisis, and their effects on children. Minneapolis, MN: Fairview Press. 
DiGiulio, R. \& Kranz, R. (1995). Straight talk about death and dying. New York: Facts on File.

Edelwich, J., \& Brodsky, A. (1982). Training guidelines: Linking the workshop experience to needs on and off the job. In W.S. Paine (Ed.), Job stress and burnout (pp. 133-154). Newbury Park, CA: Sage.

Edwards, D., Burnard, P., Coyle, D., Fothergill, A., \& Hannigan, B. (2000). Stress and burnout in community health nursing: A review of the literature. Journal of Psychiatric and Mental Health Nursing, 7, 7-14.

Edwards, R. (1995). Compassion fatigue: When listening hurts. American Psychological Association Monitor. Retrieved February 10, 2000 from http://www.apa.org/monitor/sep95/care.html

Elliott, D.M., \& Guy, J.D. (1993). Mental health professionals versus non-mental-health professionals: Childhood trauma and adult functioning. Professional Psychology: Research and Practice, 24, 83-90.

Etherington, K. (2000). Supervising counselors who work with survivors of childhood sexual abuse. Counseling Psychology Quarterly, 13, 377-389.

Evans, G.D., \& Rey, J. (2001). In the echoes of gunfire: Practicing psychologists' responses to school violence. Professional Psychology: Research and Practice, $32,157-164$.

Everly, G.S., \& Lating, J.M. (2002). A clinical guide to the treatment of the human stress response ( $2^{\text {nd }}$ ed.). New York, NY: Kluwer Academic.

Falasca, T., \& Caulfield, T.J. (1999). Childhood trauma. Journal of Humanistic Counseling \& Development, 37, 212-223. 
Faraone, S.V. (2003). Straight talk about your child's mental health: What to do when something seems wrong. New York, NY: Guilford Press.

Farber, B.A. (2000). Treatment strategies for different types of teacher burnout. Journal of Clinical Psychology, 56, 675-689.

Figley, C.R. (Ed.) (1995). Compassion fatigue: Coping with secondary stress disorder in those who treat the traumatized. Levittown: Brunner/Mazel.

Figley, C.R. (1998). Burnout in families: The systemic costs of caring. Boca Raton, FLA: CRC Press.

Figley, C.R. (1999). Compassion fatigue: Toward a new understanding of the costs of caring. In B.H. Stamm (Ed.), Secondary traumatic stress: Self-care issues for clinicians, researchers, and educators, (pp. 3-28). Lutherville, MD: Sidran Press.

Figley, C.R. (2002a). Compassion fatigue: Psychotherapists' chronic lack of self-care. Journal of Clinical Psychology, 58, 1433-1441.

Figley, C.R. (Ed.) (2002b). Treating compassion fatigue. New York: Brunner-Routledge. Figley, C.R. (2003). Compassion fatigue: An introduction. Retrieved October 9, 2004 from http://www.greencross.org/_Research/Compassion/Fatigue.asp

Figley, C.R., \& Stamm, B.H. (1996). Psychometric review of compassion fatigue self test. In B.H. Stamm (Ed.), Measurement of stress, trauma, and adaptation. Lutherville, MD: Sidran Press. Retrieved November 10, 2001 from http://www.isu.edu/ bhstamm/pdf/figleystamm.pdf

Fisher, D. (1999). Preventing childhood trauma resulting from exposure to domestic violence. Preventing School Failure, 44, 25-27. 
Fitzgerald, H. (1992). The grieving child: A parent's guide. New York: Simon \& Schuster.

Foa, E.B., Keane, T.M., \& Friedman, M.J. (Eds.). (2000). Effective treatments for PTSD. New York, NY: Guilford Press.

Follette, V.M., Polusny, M.M., \& Milbeck, K. (1994). Mental health and law enforcement professionals: Trauma history, psychological symptoms, and impact of providing services to child sexual abuse survivors. Professional Psychology: Research and Practice, 25, 275-282.

Freyd, J. (1996). Betrayal trauma: The logic of forgetting childhood abuse. Cambridge: Harvard University Press.

Friedman, I.A. (1991). High and low-burnout schools: School culture aspects of teacher burnout. Journal of Educational Research, 84, 325-333.

Friedman, I.A. (1993). Burnout in teachers: The concept and its unique core meaning. Educational \& Psychological Measurement, 93, 1035-1044.

Friedman, I.A. (1995). Student behavior patterns contributing to teacher burnout. Journal of Educational Research, 88, 281-290.

Friedman, I.A., \& Farber, B.A. (1992). Professional self-concept as a predictor of teacher burnout. Journal of Educational Research, 86, 28-35.

Friedman, M.J. (2001). Post traumatic stress disorder: The latest assessment and treatment strategies. Kansas City, MO: Compact Clinicals.

Gabriel, M.A. (2001). Surviving listening and witnessing: Vicarious traumatization in social workers practitioners. Retrieved April 8, 2002 from http://www.naswnyc.org/p30.html 
Gentry, J.E., Baranowsky, A.B., \& Dunning, T. (1997, November). Compassion fatigue: Accelerated recovery program (ARP) for helping professionals. Paper presented at the meeting of the International Society for Traumatic Stress Studies on Linking Trauma Studies to the Universe of Science and Practice, Montreal, Quebec.

Gentry, J.E., Baranowsky, A.B., \& Dunning, K. (2002). ARP: The accelerated recovery program (ARP) for compassion fatigue. In C.R. Figley (Ed.), Treating compassion fatigue (pp. 123-137). New York, NY: Brunner-Routledge.

Gibson, R.L., \& Mitchell, M.H. (1999). Introduction to counseling and guidance $\left(5^{\text {th }}\right.$ ed.). Upper Saddle River, NJ: Merrill.

Giggans, P.O., \& Levy, B. (1997). 50 ways to a safer world: Everyday actions you can take to prevent violence in neighborhoods, schools, and communities. Seattle, WA: Seal Press.

Giller, E. (1999, May). What is psychological trauma? Paper presented at the Annual Conference of the Maryland Mental Hygiene Administration, Passages to Prevention: Prevention Across Life's Spectrum.

Girdin, D.A., Everly, G.S., \& Dusek, D.E. (1996). Controlling stress and tension. Needham Heights, MA: Allyn \& Bacon.

Gold, Y., \& Rothman, R.A. (1992). The factorial validity of a teacher burnout measure (Educators Survey) administered to a sample of beginning teachers in elementary and secondary schools in California. Educational \& Psychological Measurement, $52,761-769$. 
Gravetter, F.J., \& Wallnau, L.B. (2000). Statistics for the behavioral sciences $\left(5^{\text {th }}\right.$ ed.). Belmont, CA: Wadsworth/Thompson Learning.

Grinspoon, L. (Ed.). (1991, February). Post-traumatic stress: Part I. Harvard Mental Health Letter, 7, 1-4).

Grollman, E. (1995). Bereaved children and teens: A support guide for parents and professionals. Boston: Beacon Press.

Hales, D. \& Hales, R.E. (1995). Caring for the mind: The comprehensive guide to mental health. New York: Bantam.

Hamilton, J. (1999). When a parent is sick: Helping parents explain serious illness to children. Halifax: Queen Elizabeth II Health Sciences Centre.

Hallowell, E.(1996). When you worry about the child you love: A reassuring guide to solving your child's emotional and learning problems. New York: Simon \& Schuster.

Harris, M. (1998). Trauma recovery and empowerment: A clinician's guide for working with women in groups. New York, NY: The Free Press.

Health Canada. (2000). Because life goes on...Helping children and youth live with separation and divorce. Ottawa: Author.

Herbert, C. \& Wetmore, A. (1999). Overcoming traumatic stress: A self-help guide using cognitive behavioural techniques. London: Robinson.

Herman, J. (1997). Trauma and recovery: The aftermath of violence-from domestic abuse to political terror. New York: BasicBooks.

Hodges, S. (2003). Borderline personality disorder and posttraumatic stress disorder: Time for integration? Journal of Counseling \& Development, 81, 409-417. 
Holaday, M., \& Smith, A. (1995). Coping skills training: Evaluating a training model. Journal of Mental Health Counseling, 17, 360-367.

Horney, K. (1950). Neurosis and human growth. New York, NY: Norton.

Hornyak, L.M. \& Green, J.P. (Eds.) (2000). Healing from within: The use of hypnosis in women's health care. Washington, DC: American Psychological Association.

Horowitz, M.J. (2001). Stress response syndromes: Personality styles and interventions ( $4^{\text {th }}$ ed.). Northvale, NJ: Jason Aronson.

Horowitz, M., Wilner, N., \& Alvarez, W. (1979). Impact of event scale: A measure of subjective stress. Psychosomatic Medicine, 41, 209-218.

Horton, C.B., \& Cruise, T.K. (2001). Child abuse and neglect: The school's response. New York, NY: Guilford Press.

Howell, D.C. (2002). Statistical methods for psychology ( $5^{\text {th }}$ ed.). Pacific Grove, CA: Duxbury.

Iliffe, G. (2000). Exploring the counselor's experience of working with perpetrators and survivors of domestic violence. Journal of Interpersonal Violence, 15, 393-412.

Ingersoll, B., \& Goldstein, S. (1995). Lonely, sad, and angry: A parent's guide to depression in children and adolescents. New York: Doubleday.

Isaacson, L.E. (1985). Basics of career counseling. Boston, MA: Allyn and Bacon.

James, R.K., \& Gilliland, B.E. (2001). Crisis intervention strategies (4 ${ }^{\text {th }}$ ed.). Stamford, CT: Brooks/Cole.

Janik, J. (1995). Overwhelmed corrections workers can seek therapy. Corrections Today, 57, 162-163. 
Janoff-Bulman, R. (1992). Shattered assumptions: towards a new psychology of trauma. New York, NY: Free Press.

Jenkins, S.R., \& Baird, S. (2002). Secondary traumatic stress and vicarious trauma: A validational study. Journal of Traumatic Stress, 15, 423-432.

Joinson, C. (1992). Coping with compassion fatigue. Nursing, 22, 116-121.

Johnson, J. (1999). Keys to helping children deal with death and grief. Hauppage: Barron's Educational Series, Inc.

Johnson, K. (1998). Trauma in the lives of children: Crisis and stress management techniques for counselors, teachers, and other professionals. Alameda: Hunter House.

Kadambi, M.A., \& Truscott, D. (2004). Vicarious trauma among therapists working with sexual violence, cancer, and general practice. Canadian Journal of Counselling, $38,260-276$.

Kahill, S. (1988). Interventions for burnout in the helping professions: A review of the empirical evidence. Canadian Journal of Counselling Review, 22, 310-342.

Kass, F.I., Oldham, J.M., Pardes, H., \& Morris, L.B. (1995). The Columbia university college of physicians and surgeons complete home guide to mental health. New York, NY: Henry Holt.

Kassam-Adams, N. (1999). The risks of treating sexual trauma: Stress and secondary trauma in psychotherapists. In B.H. Stamm (Ed.), Secondary traumatic stress: Self-care issues for clinicians, researchers, and educators, (pp. 37-48). Lutherville, MD: Sidran Press. 
Keane, T. (1998). Psychological and behavioral treatments of post-traumatic stress disorder. In P.E. Nathan \& J.M. Gorman (Eds.), A guide to treatments that work (pp. 398-407). New York, NY: Oxford University Press.

Kees, N.L., \& Lashwood, P.A. (1996). Compassion fatigue and school personnel: Remaining open to the affective needs of students. Educational Horizons, 75, 4144.

Kinzel, A. (2000). Education and debriefing: Strategies for preventing crises in crisis-line volunteers. The Journal of Crisis Intervention and Suicide, 21, 126-134.

Kleepsies, P.M. (Ed.). 1998). Emergencies in mental health practice: Evaluation and management. New York, NY: Guilford Press.

Kochevar, L. (2002). Healing for the healer. The Healing Path, 45, 34-35.

Kottler, J.A. (1999). The therapist's workbook: Self-assessment, self-care, and selfimprovement exercises for mental health professionals. San Franciso, CA: JosseyBass.

Kottler, J.A., \& Hazler, R. (1997). What you never learned in graduate school: A survival guide for therapists. New York: Norton.

Krueger, L. (1997, May). Teachers on the front lines. Today's Parent, 42-48.

Lang, T.R., Raver, R.A., White, J.A., Hogarty, K.Y., \& Kromrey, J.D. (2000, November). Survey data collection strategies: Response differences between webbased and paper-based methods. Paper presented at the annual meeting of the Florida Educational Research Association, Tallahassee, FL.

Lapp, T. (2002). Session explores 'vicarious impact' of Sept. 11. FR Report, 8. Retrieved April 8, 2002 from http://www.aafp.org/fpr/20020100/4.html 
Latham, A.S. (1998). Teacher satisfaction. Educational Leadership, 55, 82-83.

Lavack-Pambrun, S. (2000). The impact of traumatic events and post-traumatic disorder among correctional nurses. Master Thesis. Winnipeg, MB: University of Manitoba.

Levine, H. (1992). Prisoners of the past: Overcoming post-traumatic stress disorder. Santa Monica, CA: National Medical Enterprises.

Levine, P. (1997). Waking the tiger: Healing trauma. Berkeley: North Atlantic Books.

Lichenstein, R., Schonfeld, D.J., \& Kline, M. (1994, November). School crisis response: Expecting the unexpected. Educational Leadership, 79-83.

Lowenstein, L.B. (1995). The resolution scrapbook as an aid in the treatment of traumatized children. Child Welfare, 74, 889-905.

Lunenburg, F.C., \& Cadavid, V. (1992). Locus of control, pupil control ideology, and dimensions of teacher burnout. Journal of Instructional Psychology, 19, 13-22.

Ma, X., \& MacMillan, R.B. (1999). Influences of workplace conditions on teachers' job satisfaction. Journal of Educational Research, 93, 39-47.

Mahoney, M.J. (1997). Psychotherapists' personal problems and self-care patterns. Professional Psychology: Research and Practice, 28, 14-16.

Maloney, M., \& Kranz, R. (1991). Straight talk about anxiety and depression. New York, NY: Bantam Doubleday Dell.

Marcus, E. (1996). Why suicide? Answers to 200 of the most frequently asked questions about suicide, attempted suicide, and assisted suicide. New York: HarperCollins. Maslach, C. (1982). Burnout: The cost of caring. Englewood Cliffs, NJ: Prentice-Hall. 
Maslach, C. (1999). Progress in understanding teacher burnout. In R. Vandenberghe and M. Huberman (Eds.), Understanding and preventing teacher burnout: A sourcebook of international research and practice (pp. 211-222). New York, NY: Cambridge University Press.

Maslach, C., \& Leiter, M.P. (1999). Take this job and ... love it! Psychology Today, 32, $50-55$.

Maslach, C., Schaufeli, W.B., \& Leiter, M.P. (2001). Job burnout. Annual Review of Psychology, 52, 397-422.

Matsakis, A. (1996). I can't get over it: A handbook for trauma survivors. Oakland: New Harbinger.

McBratney, H. (2000). Vicarious trauma: An inside story. Psychologica, 20, 8-10.

McSwain, K., Robinson, R., \& Panteluk. L. (1998, April). Annotated bibliography on vicarious traumatization and forms of traumatic stress in the workplace of psychiatric nurses. Poster session presented at the annual poster session competition of the Registered Professional Nurses Association of Manitoba, Selkirk, Manitoba.

Medeiros, M.E., \& Prochaska, J.O. (1988). Coping strategies that psychotherapists use in working with stressful clients. Professional Psychology: Research and Practice, 19, 112-114.

Meichenbaum, D. (1994). A clinical handbook/ practical therapist manual for assessing and treating adults with post-traumatic stress disorder. Waterloo: Institute Press. 
Mertler, C.A. (2003). Patterns of response and nonresponse from teachers to traditional and web surveys. Practical Assessment, Research \& Evaluation, 8. Retrieved December 1, 2004 from http://pareonline.net/getvn.asp? $\mathrm{v}=8 \& \mathrm{n}=22$.

Monahon, C. (1993). Children and trauma: A guide for parents and professionals. San Francisco: Jossey-Bass.

Morrell, J.S., \& Rubin, L.J. (2001). The Minnesota multiphasic personality inventory-2, posttraumatic stress disorder, and women domestic violence survivors. Professional Psychology: Research and Practice, 32, 151-156.

Morrissette, P.J. (2001). Self-supervision: A primer for counselors and helping professionals. New York: Brunner-Routledge.

National Defence. (1994). Preparing for critical incident stress. Ottawa: Author.

Nelson, T.S. Vicarious trauma: Bearing witness to another's trauma. Retrieved April 8, 2002 from http://www.uic.edu/orgs.convening/vicarious.htm

Neuman, M.G. (1998). Helping your kids cope with divorce the Sandcastles way. New York: Random House.

Newman, F. (1993). Children in crisis: Support for teachers and parents. Toronto: Scholastic Canada Ltd.

Nias, J. (1999). Teachers' moral purposes: Stress, vulnerability, and strength. In R. Vandenberghe and M. Huberman (Eds.), Understanding and preventing teacher burnout: A sourcebook of international research and practice (pp. 223-237). New York, NY: Cambridge University Press.

Nunes, J., \& Simmie, S. (2002). Beyond crazy: Journeys through mental illness. Toronto, ON: McClelland \& Stewart. 
O’Connor, M.F. (2001). On the etiology and effective management of professional distress and impairment among psychologists. Professional Psychology: Research and Practice, 32, 345-350.

O'Grady, K. (2004). Compassion fatigue: Symptoms and prevention outlined. Vet Center Voice, 25, 44-45.

Otte, C., Arlt, J., Wiedemann, K., \& Kellner, M. (2002). Cortisol and imaginal exposure in posttraumatic stress disorder: A case report. German Journal of Psychiatry 5, $75-77$

Parkinson, F. (1993). Post-trauma stress: A personal guide to reduce the long-term effects and hidden emotional damage caused by violence and disaster. Tucson, AZ: Fisher.

Parkinson, F. (2000). Post-trauma stress: Reduce long-term effects and hidden emotional damage caused by violence and disaster. Tuscon, AZ: Fisher.

Parnell, L. (1997). Transforming trauma: EMDR: The revolutionary new therapy for freeing the mind, clearing the body, and opening the heart. New York: W.W. Norton.

Pearlman, L.A., \& MacIan, P.S. (1995). Vicarious traumatization: An empirical study of the effects of trauma work on trauma therapists. Professional Psychology: Research and Practice, 26, 558-565.

Pearlman L., \& Saakvitne, K. (1995). Trauma and the therapist: Countertransference and vicarious traumatization in psychotherapy with incest survivors. New York, NY: WW Norton. 
Pfefferbaum, B, Gurwitch, R.H., McDonald, N.B., Leftwich, M.J.T., Sconzo, G.M., Messenbaugh, A.K., \& Schultz, R.A. (2000). Posttraumatic stress among young children after the death of a friend or acquaintance in a terrorist bombing. Psychiatric Services, 51, 386-388.

Pfifferling, J-H., \& Gilley, K. (2000). Overcoming compassion fatigue. Family Practice Management, 7, 39-44.

Pines, A.M. (2002). Teacher burnout: A psychodynamic existential perspective. Teachers and Teaching: Theory and Practice, 8, 121-140.

Pines, A.M., \& Aronson, E. (1988). Career burnout: Causes and cures. New York, NY: Free Press.

Pines, A., Aronson, E., \& Kafry, D. (1981). Burnout: From tedium to personal growth. New York, NY: Free Press.

Pinto, R.M. (2003). The impact of secondary traumatic stress on novice and expert counselors with and without a history of trauma. Dissertation Abstracts International, 63, 9-A. (University Microfilms No. 0419-4209)

Porterfield, K.M. (1996). Straight talk about post-traumatic stress disorder. New York: Facts on File.

PTSD Alliance. (2000). Posttraumatic stress disorder: A guide for the frontline. Author. Quick, J.C., Murphy, L.R., \& Hurrell, J.J. (Eds.). (1997). Stress \& well-being at work: Assessments and interventions for occupational mental health. Washington, DC: American Psychological Association. 
Rainer, J.P. (2000). Compassion fatigue: When caregiving begins to hurt. In Vandecreek, L. and Jackson, T.L. (Eds.). Innovations in clinical practice: A source book. (pp. 441-453). Sarasota, FL: Professional Resource Press.

Raquepaw, J.M., \& Miller, R.S. (1989). Psychotherapist burnout: A componential analysis. Professional Psychology: Research and Practice, 20, 32-36.

Richards, T., \& Bates, C. (2000). Recognizing posttraumatic stress in children. Journal of School Health, 67, 441-443.

Robb, N. (1999). After Swissair 111, the helpers needed help. Canadian Medical Association Journal, 160, 394.

Rosenbloom, D. \& Williams, M.B. (1999). Life after trauma: A workbook for healing. New York: Guilford.

Rosenholtz, S.J., \& Simpson, C. (1990). Workplace conditions and the rise and fall of teachers' commitment. Sociology of Education, 63, 241-257.

Ross, R.R., Altmaier, E.M., \& Russell, D.W. (1989). Job stress, social support, and burnout among counselling center staff. Journal of Counseling Psychology, 36, 464-470.

Rudolph, J.M., Stamm, B.H., \& Stamm, H.E. IV (1997). Compassion fatigue: A Concern for mental health policy, providers, \& administration. Poster at the 13 th Annual Meeting of the International Society for Traumatic Stress Studies, Montreal, PQ.

Ruzek, J. (1993). Professionals coping with vicarious trauma. NCP Clinical Newsletter, 3. Retrieved September 3, 2002 from http://www.ncptsd.org/treatment/cq/v3/n2/ruzek.html 
Saakvitne, K., \& Pearlman, L.A. (1996). Transforming the pain: A workbook on vicarious traumatization for helping professionals who work with traumatized clients. New York: W.W. Norton \& Company.

Saigh, P.A. (Ed.). (1992). Posttraumatic stress disorder: A behavioral approach to assessment and treatment. Boston, MA: Allyn and Bacon.

Salston, M.D., \& Figley, C.R. (2003). Secondary traumatic stress effects of working with survivors of criminal victimization. Journal of Traumatic Stress, 16, 167-174.

Scaer, R.C. (2001). The body bears the burden: Trauma, dissociation, and disease. Binghamton, NY: The Haworth Press, Inc.

Schaefer, D., \& Lyons, C. (1993). How do we tell the children? A step-by-step guide for helping children two to teen cope when someone dies. New York; Newmarket Press.

Schauben, L., \& Frazier, P. (1995). Vicarious trauma: The effects on female counselors of working with sexual violence survivors. Psychology of Women Quarterly, 19, 49-64.

Schaufeli, W.B., \& Daamen, J. (1994). Burnout among Dutch teachers: An MBI validity study. Educational \& Psychological Measurement, 54, 803-812.

Schiraldi, G.R. (2000). The post-traumatic stress disorder sourcebook: A guide to healing, recovery, and growth. Los Angeles, CA: Lowell House.

Schlozman, S.C. (2001, November). Coping with the unthinkable. Educational Leadership, 86-88.

Sexton, L. (1999). Vicarious traumatisation of counsellors and effects on their workplaces. British Journal of Guidance \& Counselling, 27, 393-403. 
Shann, M.H. (1998). Professional commitment and satisfaction among teachers in urban middle schools. The Journal of Educational Research, 92, 67-73.

Shapiro, F. \& Forrest, M.S. (1997). EMDR: The breakthrough "eye movement" therapy for overcoming anxiety, stress, and trauma. New York: Basic.

Skovholt, T.M. (2001). The resilient practitioner: Burnout prevention and self-care strategies for counselors, therapists, teachers, and health professionals. Needham Heights, MA: Allyn and Bacon.

Smyth, L. (1999). Overcoming post-traumatic stress disorder: A cognitive-behavioral exposure-based protocol for the treatment of PTSD and the other anxiety disorders. Oakland: New Harbinger.

Son, S.E., \& Kirchner, J.T. (2000). Depression in children and adolescents. American Family Physician, 62, 2297-2308.

Stamm, B.H. (1996). Measurement of stress, trauma, and adaptation. Lutherville, MD: Sidran Press.

Stamm, B.H. (1997). Work-related secondary traumatic stress. PTSD Research Quarterly, 8, 1-3.

Stamm, B.H. (1999). Secondary traumatic stress: Self-care issues for clinicians, researchers, and educators. Lutherville: Sidran Press.

Stamm, B.H. (2002). Measuring compassion satisfaction as well as fatigue: Developmental history of the compassion satisfaction and fatigue test. In Figley, C.R. (Ed.). Treating compassion fatigue. (pp. 107-119). New York, NY: Brunner-Routledge. 
Stamm, B.H. (2003). Research information on the ProQOL-CSF-R-III professional quality of life: Compassion satisfaction and fatigue subscales. Retrieved August 28, 2003 from http://www.isu.edu/ bhstamm/tests/ProQOL_psychometric.htm

Stanford, B.H. (2001). Reflections of resilient, persevering urban teachers. Teacher Education Quarterly, 28, 75-87.

Steed, L., \& Bicknell, J. (2001). Trauma and the therapist: The experience of therapists working with the perpetrators of sexual abuse. The Australasian Journal of Disaster and Trauma Studies, 1. Retrieved December 15, 2004 from http://massey.ac.nz/ trauma/issues/2001-1/steed.htm

Steed, L.G., \& Downing, R. (1998). A phenomenological study of vicarious traumatisation amongst psychologists and professional counsellors working in the field of sexual abuse/assault. The Australasian Journal of Disaster and Trauma Studies, 2. Retrieved September 3, 2002 from http://www.massey.ac.nz/ trauma/issues/1998-2/steed.htm

Stern, A., \& Cox, J. (1993). Teacher burnout the dull reality. Music Educators Journal, 80, 33-37.

Stevenson, M., \& Black, K. (1996). How divorce affects offspring: A research approach. Boulder: Westview Press.

Stone, C.B. (1998). The wounded healer: Is there a price for caring? Retrieved February 10, 2000 from http://www.runet.edu/ lridener/courses/stone.html

Stronach-Buschel, B. (1990). Trauma, children, and art. American Journal of Art Therapy, 29, 48-52. 
Struwig, A. (2002, May). Does compassion fatigue exist in rural healthcare and how to address it? Paper presented at the 2002 International Conference of World Rural Health in Melbourne, Australia.

Super, D. E. (1990). A life-span, life-space approach to career development. In D. Brown, L. Brooks, \& Associates (Eds.), Career choice and development $\left(2^{\text {nd }}\right.$ ed.). San Franciso, CA: Jossey-Bass.

Surpuriya, T., \& Jordan, M. (1997, October 27). Teacher burnout. Memphis Flyer. Retrieved June 8, 2001 from wysiwyg://85/http://weeklywire.com/ww/10-27 97/memphis_cvr.html

Tamparo, C.T., \& Lindh, W.Q. (2000). Therapeutic communications for health professionals ( $2^{\text {nd }}$ ed.). Albany, NY: Delmar.

Terr, L. (1991). Childhood traumas: An outline and overview. American Journal of Psychiatry, 148, 10-20.

Terr, L. (1994). Unchained memories: True stories of traumatic memories, lost and found. New York, NY: HarperCollins.

Thompson, R. (2003a). Compassion fatigue: The professional liability for caring too much. Paper presented at The Human Side of School Crises- A Public Entity Risk Institute Symposium.

Thompson, R.A. (2003b). Counseling techniques: Improving relationships with others, ourselves, our families, and our environment ( $2^{\text {nd }}$ ed. $)$. New York, NY: BrunnerRoutledge.

Thompson, R.A. (2004). Crisis intervention and crisis management: Strategies that work in schools and communities. New York, NY: Brunner-Routledge. 
Tinker, R.H. \& Wilson, S.A. (1999). Through the eyes of a child: EMDR with children. New York: W.W. Norton.

Trozzi, M. (1999). Talking with children about loss: Words, strategies, and wisdom to help children cope with death, divorce, and other difficult times. New York: Berkley Publishing.

Truch, S. (1980). Teacher burnout and what to do about it. Novato, CA: Academic Therapy Publications.

Vandenberghe, R., \& Huberman, M.A. (Ed.) (1999). Understanding and preventing teacher burnout: A sourcebook of international research and practice. New York, NY: Cambridge University Press.

Vann, A.S. (1995). From burned out to fired up! Education Digest, 61, 22.

Visionary Productions (1994). Compassion fatigue: The stress of caring too much. Panama City: Author.

Volpe, J.S. (2003). A practical guide for crisis response in our schools. Commack, NY: The American Academy of Experts in Traumatic Stress.

Wearne, D. (1991). Reducing staff burnout through task sharing. Guidance \& Counselling, 6, 15-22.

Weiss, D.S., \& Marmar, C.R. (1997). The impact of event scale-revised. In J.P. Wilson \& T.M. Keane (Eds.), Assessing psychological trauma and PTSD (pp. 399-411). New York: Guilford.

White, G. (2001). Near ground zero: Compassion fatigue in the aftermath of September 11. Traumatology, 7, 1-3. 
Williams, M.B., \& Sommer, J.F. (1999). Self-care and the vulnerable therapist. In B.H. Stamm (Ed.), Secondary Traumatic Stress: Self-Care Issues for Clinicians, Researchers, and Educators (pp. 230-246). Lutherville, MD: Sidran Press.

Williams, P., \& Davis, D.C. (2002). Therapist as coach: Transforming your practice. New York, NY: W.W. Norton.

Wilson, J.P., Friedman, M.J., \& Lindy, J.D. (Eds.). (2001). Treating psychological trauma and PTSD. New York, NY: Guilford Press.

Wolfelt, A. (1991). A child's view of grief. Fort Collins: Companion Press.

Wolfelt, A. (1992). Sarah's journey: One child's experience with the death of her father. Fort Collins: Companion Press.

Wolfelt, A. (2002). Healing your traumatized heart: 100 practical ideas after someone you love dies a sudden, violent death. Fort Collins, CO: Companion Press.

Woods, A.M., \& Weasmer, J. (2002). Maintaining job satisfaction: Engaging professionals as active participants. The Clearing House, 75, 186-189.

Wright, B. (2004). Compassion fatigue: How to avoid it. Palliative Medicine, 18, 3-4.

Wu, K.K. (2002). Use of eye movement desensitization and reprocessing for treating post-traumatic stress disorder after a motor vehicle accident. Hong Kong Journal of Psychiatry, 12, 20-24.

Yehuda, R., Marshall, R., \& Giller, E.L. (1998). Psychopharmacological treatment of post-traumatic stress disorder. In P.E. Nathan \& J.M. Gorman (Eds.), A guide to treatments that work (pp. 377-397). New York, NY: Oxford University Press. 
Zilberg, N.J., Weiss, D.S., \& Horowitz, M.J. (1982). Impact of event scale: A crossvalidation study and some empirical evidence supporting a conceptual model of stress response syndrome. Journal of Consulting and Clinical Psychology, 50, 407-414.

Zimering, R., Munroe, J., \& Gulliver, S.B. (2003). Secondary traumatization in mental health providers. Psychiatric Times, 20, 1-7. 
Appendices 
Appendix A - Diagnostic Criteria for Posttraumatic Stress Disorder

(Reprinted with permission from the Diagnostic and Statistical Manual of Mental Disorders, Fourth Edition, Text Revision, Copyright 2000. American Psychiatric Association.)

309.81 Posttraumatic Stress Disorder

A. The person has been exposed to a traumatic event in which both of the following were present:

(1) the person experienced, witnessed, or was confronted with an event or events that involved actual or threatened death or serious injury, or a threat to the physical integrity of self or others

(2) the person's response involved intense fear, helplessness, or horror. Note: In children, this may be expressed instead by disorganized or agitated behavior.

B. the traumatic event is persistently reexperienced in one (or more) of the following ways:

(1) recurrent and intrusive distressing recollections of the event, including images, thoughts, or perceptions. Note: In young children, repetitive play may occur in which themes or aspects of the trauma are expressed.

(2) Recurrent distressing dreams of the event. Note: In children, there may be frightening dreams without recognizable content.

(3) Acting or feeling as if the traumatic event were recurring (includes a sense of reliving the experience, illusions, hallucinations, and dissociative flashback episodes, including those that occur on awakening or when intoxicated). Note: In young children, trauma-specific reenactment may occur.

(4) Intense psychological distress at exposure to internal or external cues that symbolize or resemble an aspect of the traumatic event

(5) Physiological reactivity on exposure to internal or external cues that symbolize or resemble an aspect of the traumatic event

C. Persistent avoidance of stimuli associated with the trauma and numbing of general responsiveness (not present before the trauma), as indicated by three (or more) of the following:

(1) efforts to avoid thoughts, feelings, or conversations associated with the trauma

(2) efforts to avoid activities, places, or people that arouse recollections of the trauma

(3) inability to recall an important aspect of the trauma

(4) markedly diminished interest or participation in significant activities

(5) feeling of detachment or estrangement from others

(6) restricted range of affect (e.g., unable to have loving feelings)

(7) sense of foreshortened future (e.g., does not expect to have a career, marriage, children, or a normal life span) 
D. Persistent symptoms of increased arousal (not present before the trauma), as indicated by two (or more) of the following:

(1) difficulty falling or staying asleep

(2) irritability or outbursts of anger

(3) difficulty concentrating

(4) hypervigilance

(5) exaggerated startle response

E. Duration of the disturbance (symptoms in Criteria B, C, and D) is more than 1 month.

F. The disturbance causes clinically significant distress or impairment in social, occupational, or other important areas of functioning.

Specify if:

Acute: if duration of symptoms is less than 3 months

Chronic: if duration of symptoms is 3 months or more

Specify if:

With Delayed Onset: if onset of symptoms is at least 6 months after the stressor 
Appendix B - Diagnostic Criteria for Acute Stress Disorder

(Reprinted with permission from the Diagnostic and Statistical Manual of Mental Disorders,

Fourth Edition, Text Revision, Copyright 2000. American Psychiatric Association.)

308.3 Acute Stress Disorder

A. The person has been exposed to a traumatic event in which both of the following were present:

(1) the person experienced, witnessed, or was confronted with an event or events that involved actual or threatened death or serious injury, or a threat to the physical integrity of self or others

(2) the person's response involved intense fear, helplessness, or horror

B. Either while experiencing or after experiencing the distressing event, the individual has three (or more) of the following dissociative symptoms:

(1) a subjective sense of numbing, detachment, or absence of emotional responsiveness

(2) a reduction in awareness of his surroundings (e.g., "being in a daze")

(3) derealization

(4) depersonalization

(5) dissociative amnesia (i.e.., inability to recall an important aspect of the trauma)

C. The traumatic event is persistently reexperienced in at least one of the following ways: recurrent images, thoughts, dreams, illusions, flashback episodes, or a sense of reliving the experience; or distress on exposure to reminders of the traumatic event.

D. Marked avoidance of stimuli that arouse recollections of the trauma (e.g., thoughts, feelings, conversations, activities, places, people).

E. Marked symptoms of anxiety or increased arousal (e.g., difficulty sleeping, irritability, poor concentration, hypervigilance, exaggerated startle response, motor restlessness).

F. The disturbance causes clinically significant distress or impairment in social, occupational, or other important areas of functioning or impairs the individual's ability to pursue some necessary task, such as obtaining necessary assistance or mobilizing personal resources by telling family members about the traumatic experience.

G. The disturbance lasts for a minimum of 2 days and a maximum of 4 weeks and occurs within 4 weeks of the traumatic event.

$\mathrm{H}$. The disturbance is not due to the direct physiological effects of a substance (e.g., a drug of abuse, a medication) or a general medical condition, is not better accounted for by Brief Psychotic Disorder, and is not merely an exacerbation of a preexisting Axis I or Axis II disorder. 


\section{Appendix C (West Virginia)}

April 14, 2004

\section{Dear Principal:}

I am a doctoral candidate in Counseling Psychology at West Virginia University. I am conducting research for my dissertation that will explore the quality of career engagement in public school educators in Nova Scotia and West Virginia. The concepts of career satisfaction, burnout, and compassion fatigue will be explored. Since entering the field of education in 1983, I have had the opportunity to work with approximately three hundred teachers. Over the years I have wondered if some of what we used to describe as burnout, might in fact be compassion fatigue. Compassion fatigue is a form of secondary trauma that results from working in a caring capacity in a profession where we encounter students, students' families, and co-workers who share their traumatic experiences with us. I am interested also in how our own personal histories of trauma affect us in our work as educators.

I am writing to ask your assistance in bringing this research to the awareness of the educators in your school in one or more of the following ways:

1) reading this letter and the attached rationale for the study in a faculty meeting or similar gathering,

2) asking your school counselor to present the research request to your faculty,

3) posting the enclosed 8 × 11 " posters in the staff room, and/or

4) placing the individual participant packets in faculty mailboxes, the staff room, or other accessible location.

It is important that your faculty know that participation in this study is completely voluntary. They are welcome to look through a participant packet before deciding whether they wish to take part. I realize that the nature of the topic being explored is rather personal, and wish to assure your faculty that I will make every effort to maintain confidentiality. Postage-paid envelopes have been included in each packet so that questionnaires may be returned individually. Analysis and reporting will address collective group data only. I am hoping to receive 500 sets of completed questionnaires in order for the data to be meaningful. Teachers, school counselors, vice-principals, and principals are invited to participate. There are no known or anticipated risks associated with participation, but there may be benefits associated with enhanced awareness and potential for early intervention.

I am only too aware of the incredibly busy days educators face. However, I would be extremely appreciative if they were able to devote approximately 15 minutes to respond to the demographic questionnaire and four surveys. These require only a check mark, circling a number, or entering a number, and so shouldn't be too time demanding. 
(2)

Dr. Vetere has granted permission for this research project to be presented to educators in the Monongalia County Board of Education. The research proposal has also been approved by West Virginia University’s Institutional Review Board.

Thank you for your assistance in helping me conduct research in an area of study about which I am very passionate. I am hopeful that the findings will prove helpful to our profession, perhaps through the identification of the need for preventative or responsive interventions. Please feel free to contact me with any queries.

Sincerely,

Beth Robinson, M.Ed., M.Ed.

206 Timberline

Morgantown, West Virginia 26505

(304)599-5477
After June 4, 2004

P.O. Box 1597

Middleton, Nova Scotia

Canada B0S 1P0

Dissertation Chairperson

Margaret Glenn, Ed.D.

Department of Counseling, Rehabilitation Counseling, and Counseling Psychology

P.O. Box 6122

West Virginia University

Morgantown, West Virginia 26506

(304)293-3807

Office of Research Compliance

West Virginia University

(304)293-7073 


\section{Appendix C (Nova Scotia)}

April 14, 2004

\section{Dear Principal:}

I am a doctoral candidate in Counseling Psychology at West Virginia University. I am conducting research for my dissertation that will explore the quality of career engagement in public school educators in Nova Scotia and West Virginia. The concepts of career satisfaction, burnout, and compassion fatigue will be explored. Since entering the field of education in 1983, I have had the opportunity to work with approximately three hundred teachers. Over the years I have wondered if some of what we used to describe as burnout, might in fact be compassion fatigue. Compassion fatigue is a form of secondary trauma that results from working in a caring capacity in a profession where we encounter students, students' families, and co-workers who share their traumatic experiences with us. I am interested also in how our own personal histories of trauma affect us in our work as educators.

I am writing to ask your assistance in bringing this research to the awareness of the educators in your school in one or more of the following ways:

5) reading this letter and the attached rationale for the study in a staff meeting or similar gathering,

6) asking your school counselor to present the research request to your staff,

7) posting the enclosed 8 _ 11 " posters in the staff room, and/or

8) placing the individual participant packets in teachers' mailboxes, the staff room, or other accessible location.

It is important that your staff know that participation in this study is completely voluntary. They are welcome to look through a participant packet before deciding whether they wish to take part. I realize that the nature of the topic being explored is rather personal, and wish to assure your staff that I will make every effort to maintain confidentiality. Postage-paid envelopes have been included in each packet so that questionnaires may be returned individually. Analysis and reporting will address collective group data only. I am hoping to receive 500 sets of completed questionnaires in order for the data to be meaningful. Teachers, school counselors, vice-principals, and principals are invited to participate. There are no known or anticipated risks associated with participation, but there may be benefits associated with enhanced awareness and potential for early intervention.

I am only too aware of the incredibly busy days educators face. However, I would be extremely appreciative if they were able to devote approximately 15 minutes to respond to the demographic questionnaire and four surveys. These require only a check mark, circling a number, or entering a number, and so shouldn't be too time demanding. 
(2)

Dr. Gunn has granted permission for this research project to be presented to educators in the Annapolis Valley Regional School Board. The research proposal has also been approved by West Virginia University's Institutional Review Board.

Thank you for your assistance in helping me conduct research in an area of study about which I am very passionate. I am hopeful that the findings will prove helpful to our profession, perhaps through the identification of the need for preventative or responsive interventions. Please feel free to contact me with any queries.

Sincerely,

Beth Robinson, M.Ed., M.Ed. 206 Timberline Morgantown, West Virginia 26505 (304)599-5477
After June 9, 2004

P.O. Box 1597

Middleton, Nova Scotia

B0S 1P0

Dissertation Chairperson

Margaret Glenn, Ed.D.

Department of Counseling, Rehabilitation Counseling, and Counseling Psychology

P.O. Box 6122

West Virginia University

Morgantown, West Virginia 26506

(304)293-3807

Office of Research Compliance

West Virginia University

(304)293-7073 


\title{
Appendix D
}

\section{Exploring Career Satisfaction, Burnout, and Compassion Fatigue as Indicators of the Quality of Career Engagement of Public School Educators}

\author{
Rationale for Proposed Study
}

Educators today are faced with multiple demands, arguably more than ever before in the history of public education. Concerns abound regarding class sizes, adequate staffing, financial resources committed to education, and environmental safety of facilities. Societal changes have conspired to present families with challenges in the areas of employment security, marital stability, and philosophies of child-rearing, the effects of which are evident in the school setting. Child abuse, domestic violence, and violence in schools have become well-documented issues. All of these factors have served to augment an already formidable task set before educators.

It would appear worthwhile to engage educators in reflection on the degree to which their career brings them a sense of fulfillment, and to explore whether they may be at risk for developing burnout or compassion fatigue. Burnout is manifested as a pervasive sense of discontent and dissatisfaction that may develop when overwhelmed with the demands of the job or because stagnation has set in. Compassion fatigue describes a condition that may develop in those who are responsible for ensuring the well-being of others. Caring is an essential component of effective teaching, but the cost of caring becomes evident when we begin to share or take on the burden of suffering of those in our school community. Compassion fatigue is the negative physical, emotional, and cognitive toll resulting from the accumulation of concerns about our students, their parents, and our co-workers, borne of our caring and compassionate involvement.

Public school educators spend the second greatest amount of time in the life of a child next to the child's primary caregivers. While burnout has been studied quite extensively in educators, researchers have not examined the nature, extent, or potential impact of primary and secondary trauma in the lives of school personnel. Studies exploring compassion fatigue in this group are conspicuously absent in the current body of research literature. It is the intent of this study to contribute to our collective understanding in this area. 
Appendix E

\section{Education Research}

\section{Can you spare 15 minutes?}

I am conducting research to advance our understanding of the concepts of career satisfaction, burnout, and compassion fatigue as indicators of the quality of career engagement in public school educators.

Please help yourself to a participant packet. Included are a cover letter, study rationale, demographic questionnaire, four surveys, resource material and a return envelope.

I am hoping to have 500 educators in Nova Scotia and West Virginia participate.

Thanks for your help!

Beth Robinson, M. Ed., M.Ed., West Virginia University 


\section{Appendix F}

April 14, 2004

Dear Colleague:

My name is Beth Robinson and I entered the field of education as a teacher in 1983. Currently, I am a doctoral candidate in Counseling Psychology at West Virginia University. I am conducting research for my dissertation under the supervision of Margaret Glenn, Ed.D. My research will explore the concepts of career satisfaction, burnout, and compassion fatigue as indicators of the quality of career engagement in public school educators.

\section{Purpose of the Study}

I am hoping to determine the degree to which educators are exhibiting career satisfaction, burnout, and compassion fatigue and how these might be related to personal histories of direct and indirect exposure to traumatic events.

\section{Description of Procedures}

I am requesting your help in advancing our understanding of career satisfaction, burnout, and compassion fatigue. Enclosed you will find a demographic questionnaire, and four other surveys that should take approximately 15 minutes to complete. These may be returned in the postage-paid envelope.

\section{Risks and Discomforts}

Although there are no known or anticipated risks from participating in this study, there is the potential for some psychological discomfort, given the focus of the surveys. If you find your level of stress elevated as a result of participating in the study, completing the enclosed Stress Management Strategies Checklist and/or considering a referral to one of the counseling resources may be helpful.

\section{Voluntary Participation and Alternatives}

Your participation in this study is entirely voluntary, and you may choose not to complete the survey packet after looking through it. Your return of the completed survey packet will indicate informed consent.

\section{Benefits}

It is hoped that the information gathered will enhance our understanding of the interplay between educator demographics, direct and indirect trauma history, and quality of career engagement as indicated by career satisfaction, burnout, and compassion fatigue. The need for preventative and responsive measures may be identified. There are early interventions that can ameliorate conditions of burnout and compassion fatigue.

\section{Confidentiality}

Confidentiality will be maintained with respect to participant materials and responses. Return envelopes will be destroyed so that point of origin will not be known. Information shared in the surveys will be analyzed for group patterns only, and only collective results will be reported in the final dissertation.

\section{Contact Persons}

Researcher

Beth Robinson, M. Ed., M. Ed.

206 Timberline

Morgantown, WV 26505

(304)599-5477

peter.beth@worldnet.att.net

\author{
Dissertation Chairperson \\ Margaret Glenn, Ed.D. \\ Dept. of Counseling, Rehabilitation \\ Counseling, and Counseling Psychology \\ P.O. Box 6122 \\ Morgantown, WV 26506 \\ (304)293-3807
}

\author{
Office of Research Compliance \\ West Virginia University \\ (304)293-7073
}

Sincerely,

Beth Robinson, M. Ed., M. Ed.

Doctoral Candidate, West Virginia University

B0S 1P0
After June 4, 2004:

P.O. Box 1597, Middleton, Nova Scotia 


\section{Appendix G}

\section{Demographic Information}

Please note that this information as well as responses to the questionnaires/surveys will be used to look for group patterns only, and only group findings will be reported. In this manner, anonymity will be preserved and confidentiality will be maintained.

\section{Current Position}

Classroom Teacher (specify grade):

Subject Teacher (specify subject):

Other Teacher (specify specialty):

School/Guidance Counselor

Vice-principal

Principal

\section{Assignment Level}

Elementary

Middle

Secondary

Technical or Alternate School

School Location

Nova Scotia

West Virginia

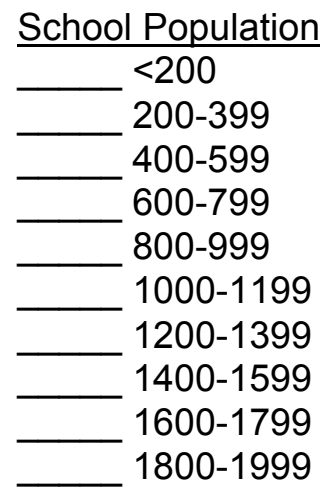

Number of Years in Field of Education:

Number of Years in Current Position:

Employment Status: full-time part-time substitute

Age:

Gender: female male

Ethnicity:

Current Salary: $<\$ 20,000$ $\$ 20,000-\$ 29,999$ $\$ 30,000-\$ 39,999$

$\$ 40,000-\$ 49,999$

$\$ 50,000$ - $\$ 59,999$

$\$ 60,000$ - \$69,999

$\$ 70,000$ - $\$ 79,999$

$\$ 80,000-\$ 89,999$

$\$ 90,000+$
Highest Level of Education Attained:

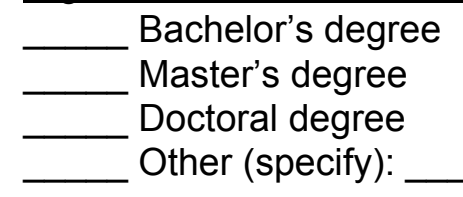




\section{Appendix $\mathrm{H}$ \\ History of Traumatic Experiences}

- Please indicate whether or not you have experienced the following events.

- Mark with a $\mathbf{P}$ if the event was experienced in your personal life environment.

- Mark with a $\mathbf{W}$ if the event was experienced in your work environment.

- Make as many entries as necessary to describe your experiences.

\begin{tabular}{|c|c|c|c|}
\hline Nature of Event & $\begin{array}{c}\text { Experienced } \\
\text { Directly } \\
\text { (victim or witness) }\end{array}$ & $\begin{array}{l}\text { Experienced Indirectly } \\
\text { (learned of event } \\
\text { affecting another) }\end{array}$ & $\begin{array}{c}\text { Have Not } \\
\text { Experienced }\end{array}$ \\
\hline 1. Bullying, stalking, or swarming & & & \\
\hline $\begin{array}{l}\text { 2. Robbery, burglary, mugging } \\
\text { with theft, or identity theft }\end{array}$ & & & \\
\hline $\begin{array}{l}\text { 3. Child abuse or assault } \\
\text { (physical, sexual, emotional) }\end{array}$ & & & \\
\hline 4. Physical assault as adult & & & \\
\hline $\begin{array}{l}\text { 5. Sexual assault as adult } \\
\text { (e.g., molestation, rape) }\end{array}$ & & & \\
\hline $\begin{array}{l}\text { 6. Abduction, hostage-taking, } \\
\text { confinement, or torture }\end{array}$ & & & \\
\hline 7. Shooting, stabbing, or bombing & & & \\
\hline 8. Homicide & & & \\
\hline 9. Suicide & & & \\
\hline $\begin{array}{l}\text { 10. Accident } \\
\text { (e.g., workplace, car, sporting) }\end{array}$ & & & \\
\hline 11. Accidental or other sudden death & & & \\
\hline 12. Serious injury & & & \\
\hline $\begin{array}{l}\text { 13. Serious medical or mental } \\
\text { illness }\end{array}$ & & & \\
\hline $\begin{array}{l}\text { 14. Invasive medical procedures } \\
\text { (e.g., surgery, chemo/radiation) }\end{array}$ & & & \\
\hline $\begin{array}{l}\text { 15. Disaster due to human error } \\
\text { (e.g., fire, building collapse) }\end{array}$ & & & \\
\hline $\begin{array}{l}\text { 16. Natural disaster } \\
\text { (e.g., flood, hurricane, avalanche) }\end{array}$ & & & \\
\hline 17. Mauling or attack by animal & & & \\
\hline $\begin{array}{l}\text { 18. Unexpected loss of life to pet, } \\
\text { livestock, or other animal }\end{array}$ & & & \\
\hline 19. War, combat, or terrorism & & & \\
\hline 20. Unexpected unemployment & & & \\
\hline 21. End of a marriage or partnership & & & \\
\hline 22. Other: & & & \\
\hline
\end{tabular}




\section{Appendix I \\ IMPACT OF EVENT SCALE - REVISED}

\section{PLEASE RESPOND TO THE ITEMS BELOW BY THINKING ABOUT A DISTRESSING EVENT OR EVENTS THAT YOU EXPERIENCED DIRECTLY (AS A VICTIM OR WITNESS).}

Instructions: The following is a list of difficulties people sometimes experience after stressful life events. Please read each item, and then indicate how distressing each difficulty has been for you during the past month with respect to the event or events. How much were you distressed or bothered by these difficulties?

\section{DISTRESSING EVENT(S) EXPERIENCED DIRECTLY (AS A VICTIM OR WITNESS)}

1 Any reminder brought back feelings about it.

2 I had trouble staying asleep.

3 Other things kept making me think about it.

4 I felt irritable and angry.

5 I avoided letting myself get upset when I thought about it or was reminded of it.

6 I thought about it when I didn't mean to.

7 I felt as if it hadn't happened or wasn't real.

8 I stayed away from reminders about it.

9 Pictures about it popped into my mind.

10 I was jumpy and easily startled.

11 I tried not to think about it.

12 I was aware that I still had a lot of feelings about it, but I didn't deal with them.

13 My feelings about it were kind of numb.

14 I found myself acting or feeling like I was back at that time.

15 I had trouble falling asleep.

16 I had waves of strong feelings about it.

17 I tried to remove it from my memory.

18 I had trouble concentrating.

19 Reminders of it caused me to have physical reactions, such as sweating, trouble breathing, nausea, or a pounding heart.

20 I had dreams about it.

21 I felt watchful and on guard.

22 I tried not to talk about it.

\begin{tabular}{|c|c|c|c|c|}
\hline $\begin{array}{l}\text { Not } \\
\text { at } \\
\text { all }\end{array}$ & $\begin{array}{l}\text { A } \\
\text { little } \\
\text { bit }\end{array}$ & $\begin{array}{l}\text { Mod } \\
\text { erate } \\
\text {-ly }\end{array}$ & $\begin{array}{l}\text { Quite } \\
\text { a bit }\end{array}$ & $\begin{array}{l}\text { Ex- } \\
\text { treme } \\
-1 y\end{array}$ \\
\hline 0 & 1 & 2 & 3 & 4 \\
\hline 0 & 1 & 2 & 3 & 4 \\
\hline 0 & 1 & 2 & 3 & 4 \\
\hline 0 & 1 & 2 & 3 & 4 \\
\hline 0 & 1 & 2 & 3 & 4 \\
\hline 0 & 1 & 2 & 3 & 4 \\
\hline 0 & 1 & 2 & 3 & 4 \\
\hline 0 & 1 & 2 & 3 & 4 \\
\hline 0 & 1 & 2 & 3 & 4 \\
\hline 0 & 1 & 2 & 3 & 4 \\
\hline 0 & 1 & 2 & 3 & 4 \\
\hline 0 & 1 & 2 & 3 & 4 \\
\hline 0 & 1 & 2 & 3 & 4 \\
\hline 0 & 1 & 2 & 3 & 4 \\
\hline 0 & 1 & 2 & 3 & 4 \\
\hline 0 & 1 & 2 & 3 & 4 \\
\hline 0 & 1 & 2 & 3 & 4 \\
\hline 0 & 1 & 2 & 3 & 4 \\
\hline 0 & 1 & 2 & 3 & 4 \\
\hline 0 & 1 & 2 & 3 & 4 \\
\hline 0 & 1 & 2 & 3 & 4 \\
\hline 0 & 1 & 2 & 3 & \\
\hline
\end{tabular}




\section{Appendix J \\ IMPACT OF EVENT SCALE - REVISED}

\section{PLEASE RESPOND TO THE ITEMS BELOW BY THINKING ABOUT A DISTRESSING EVENT OR EVENTS THAT YOU EXPERIENCED INDIRECTLY. (HEARD OR LEARNED ABOUT)}

Instructions: The following is a list of difficulties people sometimes experience after stressful life events. Please read each item, and then indicate how distressing each difficulty has been for you during the past month with respect to the event or events. How much were you distressed or bothered by these difficulties?

\section{DISRESSING EVENT(S) EXPERIENCED}

INDIRECTLY (HEARD OR LEARNED ABOUT FROM ANOTHER PERSON OR SOURCE)

1 Any reminder brought back feelings about it.

2 I had trouble staying asleep.

3 Other things kept making me think about it.

4 I felt irritable and angry.

5 I avoided letting myself get upset when I thought about it or was reminded of it.

6 I thought about it when I didn't mean to.

7 I felt as if it hadn't happened or wasn't real.

8 I stayed away from reminders about it.

9 Pictures about it popped into my mind.

10 I was jumpy and easily startled.

11 I tried not to think about it.

12 I was aware that I still had a lot of feelings about it, but I didn't deal with them.

13 My feelings about it were kind of numb.

14 I found myself acting or feeling like I was back at that time.

15 I had trouble falling asleep.

16 I had waves of strong feelings about it.

17 I tried to remove it from my memory.

18 I had trouble concentrating.

19 Reminders of it caused me to have physical reactions, such as sweating, trouble breathing, nausea, or a pounding heart.

20 I had dreams about it.

21 I felt watchful and on guard.

22 I tried not to talk about it.

\begin{tabular}{|c|c|c|c|c|}
\hline $\begin{array}{l}\text { Not } \\
\text { at } \\
\text { all }\end{array}$ & $\begin{array}{l}\text { A } \\
\text { little } \\
\text { bit }\end{array}$ & $\begin{array}{l}\text { Mod } \\
\text { erate } \\
-1 y\end{array}$ & $\begin{array}{l}\text { Quite } \\
\text { a bit }\end{array}$ & $\begin{array}{l}\text { Ex- } \\
\text { treme } \\
-1 y\end{array}$ \\
\hline 0 & 1 & 2 & 3 & 4 \\
\hline 0 & 1 & 2 & 3 & 4 \\
\hline 0 & 1 & 2 & 3 & 4 \\
\hline 0 & 1 & 2 & 3 & 4 \\
\hline 0 & 1 & 2 & 3 & 4 \\
\hline
\end{tabular}

4

4

4

4

4

4

4

4

4

4

4

4

4

4

4

4

4 


\section{Appendix K - ProQOL-CSF-R III \\ PROFESSIONAL QUALITY OF LIFE \\ Compassion Satisfaction and Fatigue Subscales - Revision III}

Helping others puts you in direct contact with other people's lives. As you probably have experienced, your compassion for those you help has both positive and negative aspects. We would like to ask you questions about your experiences, both positive and negative, as a helper. Consider each of the following questions about you and your current situation. Write in the number that honestly shows how often the statement has been true for you in the last 30 days. PLEASE RESPOND FROM YOUR PERSPECTIVE AS AN EDUCATOR.

$0=$ Never $\quad 1=$ Rarely $\quad 2=$ A Few Times $\quad 3=$ Somewhat Often $\quad 4=$ Often $\quad 5=$ Very Often

1. I am happy.

2. I am preoccupied with more than one person I help.

3. I get satisfaction from being able to help people.

4. I feel connected to others.

5. I jump or am startled by unexpected sounds.

6. I have more energy after working with those I help.

7. I find it difficult to separate my private life from my life as a helper.

8. I am losing sleep over a person I help's traumatic experiences.

9. I think that I might have been "infected" by the traumatic stress of those I help.

10. I feel trapped by my work as a helper.

11. Because of my helping, I have feel "on edge" about various things.

12. I like my work as a helper.

13. I feel depressed as a result of my work as a helper.

14. I feel as though I am experiencing the trauma of someone I have helped.

15. I have beliefs that sustain me.

16. I am pleased with how I am able to keep up with helping techniques and protocols.

17. I am the person I always wanted to be.

18. My work makes me feel satisfied.

19. Because of my work as a helper, I feel exhausted.

20. I have happy thoughts and feelings about those I help and how I could help them.

21. I feel overwhelmed by the amount of work or the size of my caseload I have to deal with.

22. I believe I can make a difference through my work.

23. I avoid certain activities or situations because they remind me of frightening experiences of the people I help.

24. I plan to be a helper for a long time.

25. As a result of my helping, I have sudden, unwanted frightening thoughts.

26. I feel "bogged down" by the system.

27. I have thoughts that I am a "success" as a helper.

28. I can't remember important parts of my work with trauma victims.

29. I am an unduly sensitive person.

30. I am happy that I chose to do this work.

(C) B. Hudnall Stamm, Professional Quality of Life: Compassion Satisfaction and Fatigue Subscales-III, $1995-2002$, http://www.isu.edu/ bhstamm. This form may be freely copied as long as (a) author is credited, (b) no changes are made, \& (c) it is not sold. 


\section{Appendix L- Stress Management Strategies Checklist}

Please respond to these stress management statements by circling the response that best describes how you address the stress in your life.

$\mathrm{N}=$ never $\mathrm{S}=$ sometimes $\quad \mathrm{O}=$ often $\quad \mathrm{A}=$ always $\quad \mathrm{F}=$ hope to implement in future

WHEN FEELING STRESSED OR OVERWHELMED:

1) I speak to my family about my stress.

2) I speak to colleagues about my stress.

3) I speak to friends about my stress.

4) I listen to music.

5) I play a musical instrument.

6) I sing or whistle.

7) I write in a journal.

8) I write a letter.

9) I write poetry or a song.

10) I write prose (article, short story, or novel).

11) I take photographs.

12) I engage in a fine arts activity such as drawing, painting, sculpting, or carving.

13) I engage in crafts.

14) I pursue a hobby:

15) I read a magazine or book.

16) I use my computer.

17) I play video games.

18) I watch a television show.

19) I watch a video or go to the movie theatre.

20) I attend a play, ballet, opera, or other cultural activity.

21) I visit a museum or gallery.

22) I attend a sporting activity such as a football, hockey, N or basketball game, swim meet, gymnastics competition, etc.

\begin{tabular}{|c|c|c|c|}
\hline$N$ & $S$ & 0 & $A$ \\
\hline$N$ & $S$ & 0 & $A$ \\
\hline$N$ & $S$ & 0 & $A$ \\
\hline$N$ & $S$ & 0 & $A$ \\
\hline$N$ & $S$ & 0 & $A$ \\
\hline$N$ & $S$ & 0 & $A$ \\
\hline $\mathrm{N}$ & $S$ & 0 & $A$ \\
\hline $\mathrm{N}$ & $S$ & 0 & $A$ \\
\hline$N$ & $S$ & 0 & $A$ \\
\hline $\mathrm{N}$ & $S$ & 0 & $A$ \\
\hline $\mathrm{N}$ & $S$ & 0 & $A$ \\
\hline $\mathrm{N}$ & $S$ & 0 & $A$ \\
\hline $\mathrm{N}$ & $S$ & 0 & $A$ \\
\hline $\mathrm{N}$ & $S$ & 0 & $A$ \\
\hline $\mathrm{N}$ & $S$ & 0 & $A$ \\
\hline $\mathrm{N}$ & $S$ & 0 & $A$ \\
\hline $\mathrm{N}$ & $S$ & 0 & $A$ \\
\hline $\mathrm{N}$ & $S$ & 0 & $A$ \\
\hline $\mathrm{N}$ & $S$ & 0 & $A$ \\
\hline $\mathrm{N}$ & $S$ & 0 & $A$ \\
\hline $\mathrm{N}$ & $S$ & 0 & $A$ \\
\hline$N$ & $S$ & 0 & $A$ \\
\hline
\end{tabular}


23) I engage in an indoor or outdoor housekeeping activity that requires exertion.

24) I take part in an individual fitness activity (sports, exercise).

25) I take part in a group or team fitness activity (sports, exercise).

26) I play with my children or those of friends or relatives. $\quad \begin{array}{llllll}N & S & O & A & F\end{array}$

27) I spend time with pets or other animals. $\quad \mathrm{N} \quad \mathrm{S} \quad \mathrm{O} \quad \mathrm{A} \quad \mathrm{F}$

28) I take a relaxing bath or shower. $\quad \mathrm{N} S \mathrm{~S} \quad \mathrm{O} A \mathrm{~F}$

29) I reflect on happier times (memories, photo albums). $\quad \mathrm{N} S \mathrm{~S} \quad \mathrm{O} A \mathrm{~F}$

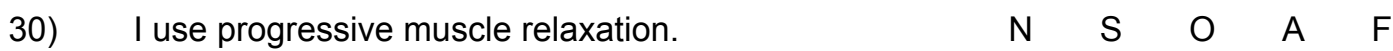

31) I use deep breathing. $\quad \mathrm{N} \quad \mathrm{S} \quad \mathrm{O} \quad \mathrm{A} \quad \mathrm{F}$

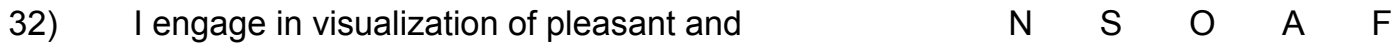
calming images.

33) I engage in meditation.

34) I engage in positive self-talk.

35) I seek connection with nature.

36) I cook a special meal or go out to a favorite restaurant.

37) I socialize with friends.

38) I go for a drive.

39) I try to catch up on my sleep or to get rested.

40) I prioritize my tasks and goals.

41) I explore my options (perhaps ones I had not considered).

42) I set my sights on new personal and/or professional dreams.

43) I implement a problem-solving or decision-making process.

44) I break my goals down into smaller steps and start working toward a goal one step at a time.

45) I make an appointment with my family doctor.

$\begin{array}{lllll}N & S & O & A & F \\ N & S & O & A & F \\ N & S & O & A & F \\ N & S & O & A & F \\ N & S & O & A & F \\ N & S & O & A & F \\ N & S & O & A & F \\ N & S & O & A & F \\ N & S & O & A & F \\ N & S & O & A & F \\ N & S & O & A & F \\ N & S & O & A & F \\ N & S & O & A & F\end{array}$




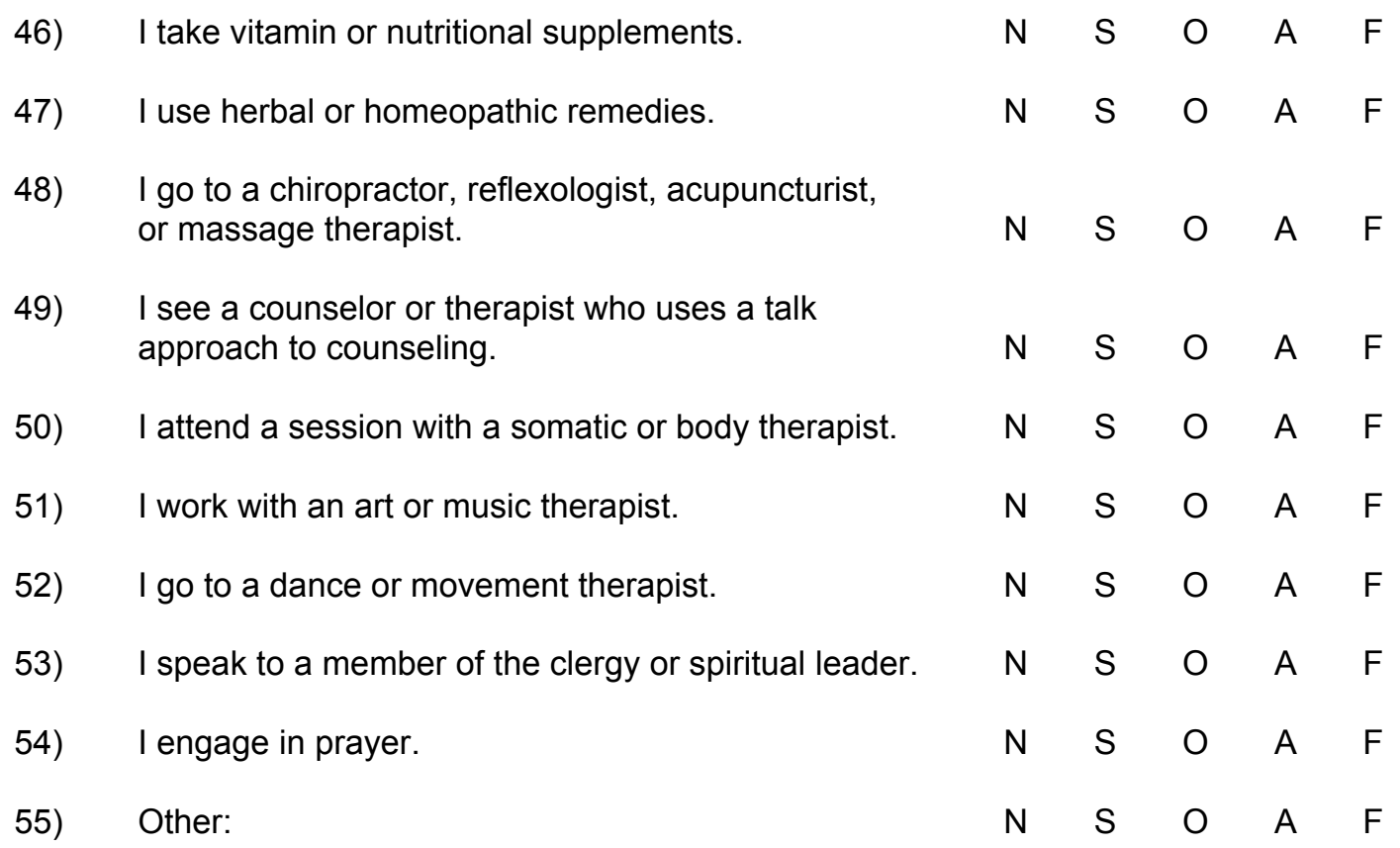

\section{Reflecting on My Repertoire}

A) Scan through your responses, noting any patterns of preferred ways of handling stress. Do you tend to seek the company of others or to spend time alone? Do you lean toward music, art, writing, talking, or physically active pursuits? Which sensory modalities are favored?

B) Underline those strategies that seem to be most effective in helping you deal with stress.

C) Put an asterisk* after those you would like start implementing or to implement more often.

\footnotetext{
**PLEASE NOTE THAT THIS FORM IS NOT TO BE RETURNED WITH THE RESEARCH PACKAGE. IT IS FOR YOUR OWN USE AND CONSIDERATION.
} 
Appendix M

\section{Counseling Referral Resources}

If you experience psychological discomfort or distress after completing the surveys in the participant packet and feel that you might benefit from speaking with a professional counselor, you might wish to contact one of the resources below. Alternatively, you could consult with a physician, member of the clergy or spiritual leader, or check the professional listings in the business pages of the phone directory.

\section{Nova Scotia}

$\begin{array}{ll}\text { Annapolis County Mental Health } & 1-902-825-4825 \\ \text { Kings County Mental Health Clinic } & 1-902-678-7381 \text { or } \\ & 1-902-679-2657 \\ & 1-902-477-5621 \text { or } \\ \text { Nova Scotia Teachers' Union } & 1-800-565-6788\end{array}$

\section{West Virginia}

Chestnut Ridge Outpatient Services 1-304-293-5299

Morgantown Pastoral Counseling 1-304-599-5751

Quin Curtis Center 1-304-293-2001 ext. 31671

Trauma Recovery Institute 1-304-291-2912

Valley Healthcare 1-304-296-1731

1-800-232-0020 (24-hour line)

**PLEASE NOTE THAT THIS FORM IS NOT TO BE RETURNED WITH THE RESEARCH PACKAGE. IT IS FOR YOUR OWN USE AND CONSIDERATION. 


\section{Appendix N}

Date

School Address

\section{Re: Exploring Career Satisfaction, Burnout, and Compassion Fatigue as Indicators of the Quality of Career Engagement of Public School Educators}

Dear Principal:

Approximately two weeks ago I forwarded a package of research materials to your school along with a request for study participants. I am a doctoral student in Counseling Psychology at West Virginia University and my dissertation research is exploring the concepts of career satisfaction, burnout, and compassion fatigue as indicators of the quality of career engagement in public school educators. Would you be so kind as to remind your staff to complete and mail a participant package if they are interested in helping me with my research?

Thank you for your assistance in helping me gather the data necessary to engage in meaningful research. I hope that the research findings will be both relevant and helpful to those in the field of education.

Sincerely,

Beth Robinson

Doctoral Candidate, West Virginia University

206 Timberline

Morgantown, WV 26505

(304)599-5477

peter.beth@worldnet.att.net
After June 4, 2004

P.O. Box 1597

Middleton, Nova Scotia

Canada B0S 1P0 


\section{Curriculum Vitae}

Name: Beth Colleen Robinson

Year of Birth: 1958

Place of Birth: Ottawa, Ontario

Education

West Virginia University, Morgantown, West Virginia

Degree: Ph.D. in Counseling Psychology (APA-accredited) - 2007 (anticipated)

Acadia University, Wolfville, Nova Scotia

Degree: M.Ed. in Counselling - 1991

Mount Saint Vincent University, Halifax, Nova Scotia

Degree: M.Ed. in Educational Psychology and Measurement - 1985

University of Ottawa, Ottawa, Ontario

Degree: B.Ed. in Primary/Junior/Special Education- 1983

Carleton University, Ottawa, Ontario

Degree: B.A. in French - 1980

$\underline{\text { Internship }}$

August 2006 to August 2007 (anticipated) 